
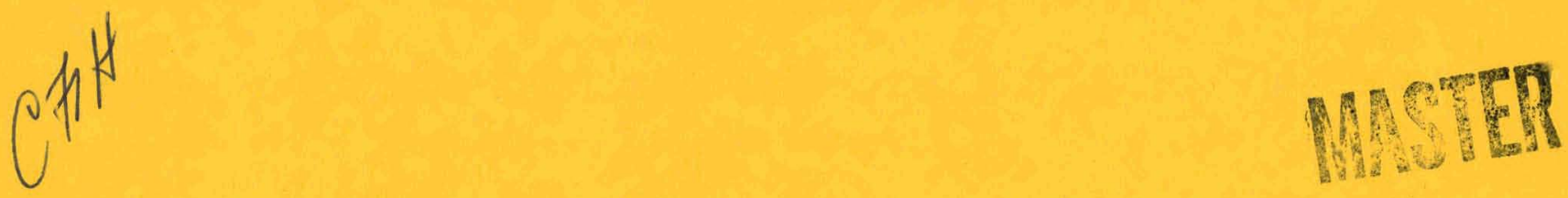

\title{
THERMAL CONDUCTIVITY
}

\section{OF \\ URANIUM-PLUTONIUM OXIDE}

R. A. LASKIEWICZ

G. F. MELDE

S. K. EVANS

P. E. BOHABOY

U. S. ATOMIC ENERGY COMMISSION CONTRACT AT(04-3)-189 PROJECT AGREEMENT 10 


\section{DISCLAIMER}

This report was prepared as an account of work sponsored by an agency of the United States Government. Neither the United States Government nor any agency Thereof, nor any of their employees, makes any warranty, express or implied, or assumes any legal liability or responsibility for the accuracy, completeness, or usefulness of any information, apparatus, product, or process disclosed, or represents that its use would not infringe privately owned rights. Reference herein to any specific commercial product, process, or service by trade name, trademark, manufacturer, or otherwise does not necessarily constitute or imply its endorsement, recommendation, or favoring by the United States Government or any agency thereof. The views and opinions of authors expressed herein do not necessarily state or reflect those of the United States Government or any agency thereof. 


\section{DISCLAIMER}

Portions of this document may be illegible in electronic image products. Images are produced from the best available original document. 


\section{GENERAL (ge ELETRIC}

\section{APPLICABLE TO}

PUBLICATION NO. GEAP-13733

TITLE Thermal Conductivity Of

Uranium-Plutonium Oxide

ISSUE DATE, September 1971

\section{ERRATA And ADDENDA SHEET}

\begin{tabular}{|l} 
NO. $\frac{1}{\text { DATE }} \frac{3-2-72}{}$ \\
\hline NOTE $\begin{array}{l}\text { Correct all copies of tbe applicable } \\
\text { publication as specified below. }\end{array}$
\end{tabular}

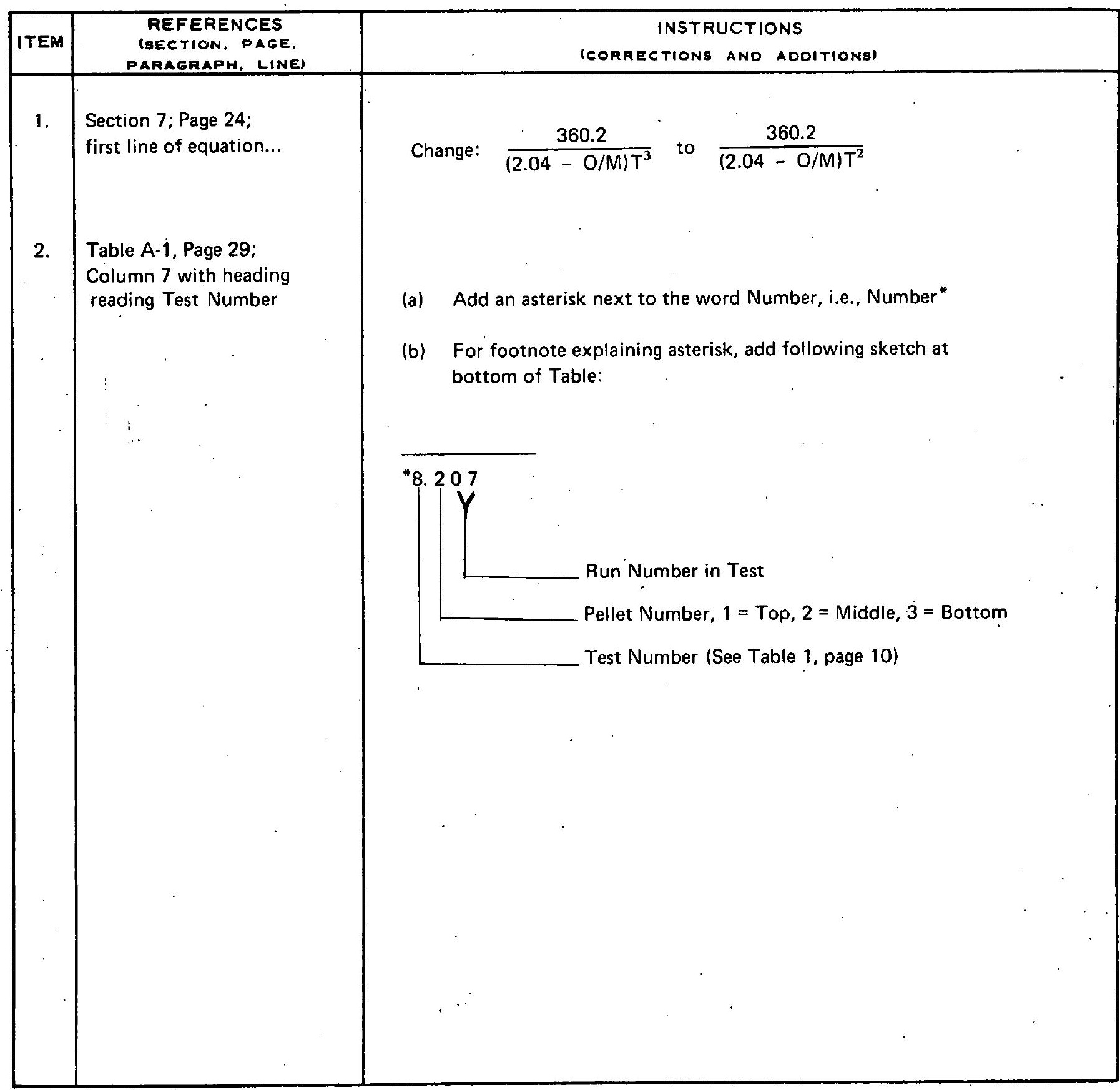


GEAP-13733

AEC Research and

Development Report

NOTICE

September 1971

\section{THERMAL CONDUCTIVITY OF URANIUM - PLUTONIUM OXIDE}

R. A. Laskiewicz

S. K. Evans

G. F. Melde

P. E. Bohaboy
Approved: E. Q Ceite

E. A. Aitken, Manager Plutonium Research

Approved:

Approved:
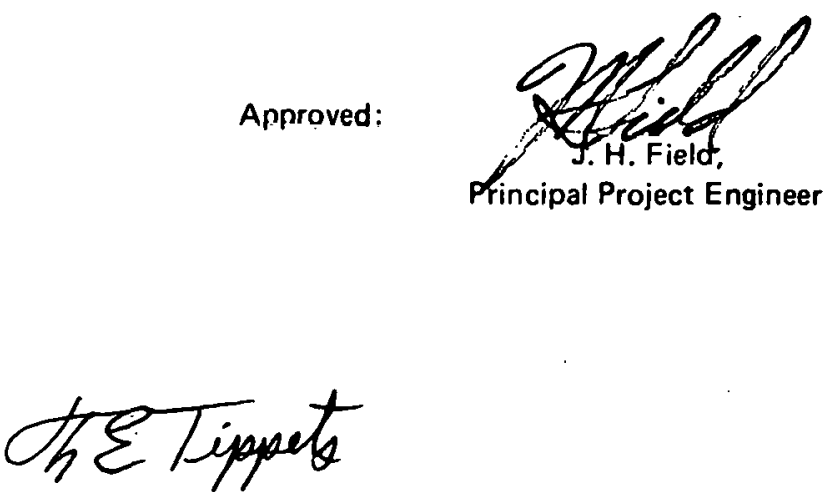

F. E. Tippets, Acting Manager

Development Engineering

U. S. Atomic Energy Commission

Contract No. AT (04-3)-189

Project Agreement No. 10

BREEDER REACTOR DEPARTMENT • GENERAL ELECTRIC COMPANY

SUNNYVALE, CALIFORNIA 94086

85-295-Der. Eng.

EGO-10/71

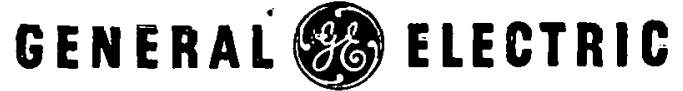




\section{NOTICE}

This report was prepared as an account of work sponsored by the United States Government. Neither the United States nor the United States Atomic Energy Commission, nor any of their employees, nor any of their contractors, subcontractors. or their employees, makes any warranty, express or implied, or assumes any legal liability or responsibility for the accuracy, completeness or usefulness of any information, apparatus, product or process disclosed, or represents that its use would not infringe privately owned rights. 


\section{TABLE OF CONTENTS}

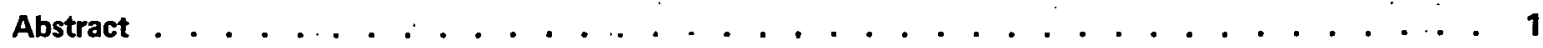

1. Summary .............................. 1

2. Introduction ............................2

3. Prior Work .............................. 2

4. Experimental Design ............................ 4

4.1 Test Furnace . . . . . . . . . . . . . . . . . . . . . . . . . . . . . . . 4

4.2 Specimen Preparation . . . . . . . . . . . . . . . . . . . . . . . . . . 8

4.3 Instrumentation. . . . . . . . . . . . . . . . . . . . . . . . . 9

4.4 Experimental Procedure . . . . . . . . . . . . . . . . . . . . . . . . . . . . . 9

5. Results and Discussion. . . . . . . . . . . . . . . . . . . . . . . 10

5.1 Effect of Stoichiometry and Composition on the Thermal Conductivity of Urania-Plutonia . . . . 10

5.2 Effect of Fabrication Procedure of the Thermal Conductivity of $\left(\mathrm{U}_{0.8} \mathrm{Pu}_{0.2}\right)_{2-\mathrm{O}} \ldots \ldots$

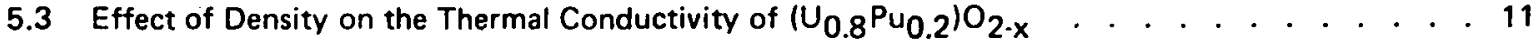

5.4 Electrical Conductivity . . . . . . . . . . . . . . . . . . . . . . . . . . . . 11

5.5 Order-Disorder ........................... . . 14

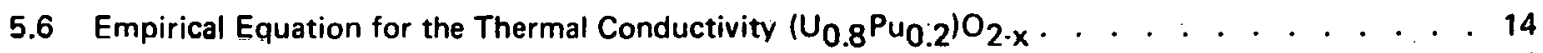

5.7 Microstructures of Tested Specimens . . . . . . . . . . . . . . . . . . . . . . . . . 14

6. Data Analysis . . . . . . . . . . . . . . . . . . . . . . . . . . 20

6.1 Method of Data Analysis . . . . . . . . . . . . . . . . . . . . . . . . . . . . . 20

6.2 Degree of Uncertainty in Results . . . . . . . . . . . . . . . . . . . . . . . . . . 21

7. Conclusions ... . . . . . . . . . . . . . . . . . . . . . . . 24

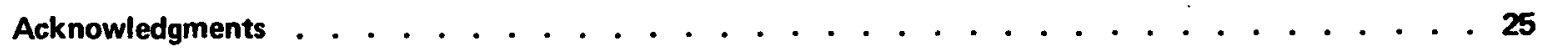

References ............................ 25

\section{APPENDIX}

A. Data............................ . 27

B. Statistical Analygis Rogults . . . . . . . . . . . . . . . . . . . . 53

Distribution. . . . . . . . . . . . . . . . . . . . 73 


\section{LIST OF ILLUSTRATIONS}

Figure

Title

Comparison of Mixed Oxide Thermal Conductivity Data Versus Temperature for

Several Experimenters . . . . . . . . . . . . . . . . . . . . . 3

Schematic of Thermal Conductivity Apparatus . . . . . . . . . . . . . . . . . . . . 4

Vacuum Furnace-Closed. . . . . . . . . . . . . . . . . . . . . . . . . . 5

Vacuum Furnace-Open . . . . . . . . . . . . . . . . . . . 6

Vacuum Furnace Instrumentation . . . . . . . . . . . . . . . . . . . . . 7

Experimental Arrangement . . . . . . . . . . . . . . . . . . . . . . . . 8

Effect of Stoichiometry on Thermal Conductivity of $\left(\mathrm{U}_{0.8} \mathrm{Pu}_{0.2}\right)^{\mathrm{O}_{2-x}}$. . . . . . . . . . 12

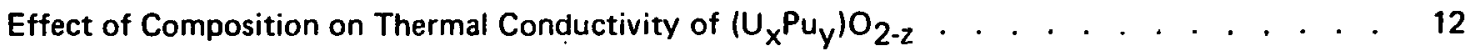

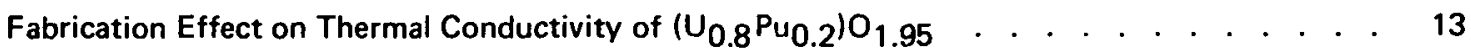

Thermal Conductivity of Coprecipitated and Physically Mixed Pellets. . . . . . . . . . . . 13

Effect of Density on Thermal Conductivity of $\left(\mathrm{U}_{0.8} \mathrm{Pu}_{0.2} \mathrm{O}_{1.95} \ldots \ldots \ldots\right.$

Thermal Conductivity of $91 \%$ Dense $\left(\mathrm{U}_{0.8} \mathrm{Pu}_{0.2}\right)^{\mathrm{O}_{2.00}}$ Showing $90 \%$ Confidence Band and

a Few Selected Data Points with Experimental Uncertainty Bands . . . . . . . . . . . . . 15

Effect of Stoichiometry on the Thermal Conductivity of $91 \%$ Dense $\left(\mathrm{U}_{0.8} \mathrm{Pu}_{0.2}\right)_{2-\mathrm{x}} \ldots \ldots$

Post-Test Microstructure of $84 \%$ Dense $\left(U_{0.8} \mathrm{Pu}_{0.2} \mathrm{JO}_{1.95} \ldots \ldots\right.$. . . . . . . . . . . . . 17

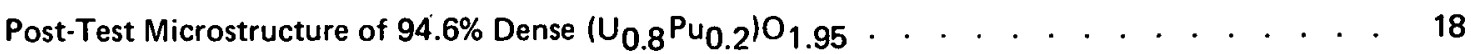

Comparison of the Microstructures of Test Specimens Prepared as

(a) coprecipitated $87 \%$ dense $\left(U_{0.8} \mathrm{Pu}_{0.2}\right)_{1.965}$ and

(b) physically mixed $94.6 \%$ dense $\left(U_{0.8} P_{0.2}\right)^{10} 1.95$

Uncertainties in Heat Flux Measurements as a Function of Temperature . . . . . . . . . . 23

Test 8 (Part I) . . . . . . . . . . . . . . . . . . . . . . . . . 46

Test 8 (Part 1). . . . . . . . . . . . . . . . . . . . . . . . . 46 46

Test 8 (Part II) . . . . . . . . . . . . . . . . . . . . . . . . . . 47

Test 8 (Part II) . . . . . . . . . . . . . . . . . . . . . . . . . . . . . . 47

Test 8 (Part III) . . . . . . . . . . . . . . . . . . . . . . . . . . . . . . . . 48

Test 10 . . . . . . . . . . . . . . . . . . . . . . . . . . . . 48 
GEAP-13733

LIST OF ILLUSTRATIONS (Continued)

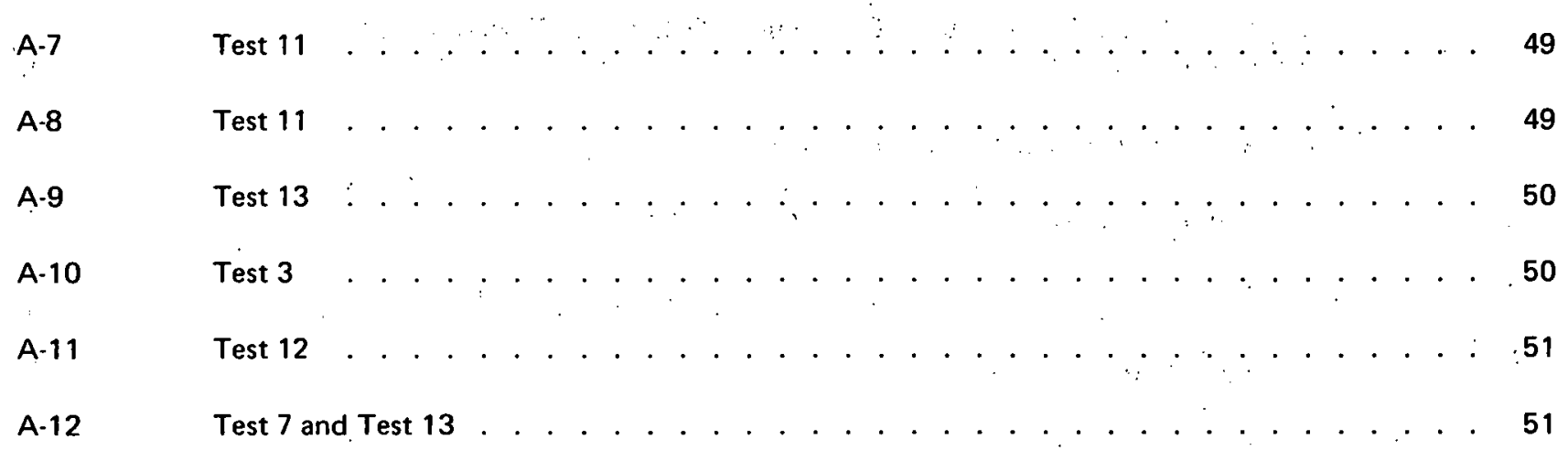

$$
\because
$$

-vi- 


\section{LIST OF TABLES}

\section{Table}

1

A-1

A-2

A-3

A-4

A-5

A. 6

A-7

A.8

A-9

A-10

A-11

A-12
Title

Page

Summary of Test Parameters . . . . . . . . . . . . . . . . . . . . . . 10

Test 8 (Part I) Data . . . . . . . . . . . . . . . . . . . . . . . . . . . 29

Test 8 (Part I) Data . . . . . . . . . . . . . . . . . . . . . . . . . . . . . . . 30

Test 8 (Part II) Data . . . . . . . . . . . . . . . . . . . . . . . . . . . . . . 31

Test 8 (Part II) Data . . . . . . . . . . . . . . . . . . . . . . . . . . 32

Test 8 (Part III) Data . . . . . . . . . . . . . . . . . . . . . . . . . . . . . . 33

Test 10 Data . . . . . . . . . . . . . . . . . . . . 35

Test 11 Data . . . . . . . . . . . . . . . . . . . . . . . . . . 37

Test 11 Data . . . . . . . . . . . . . . . . . . . . . . 38

Test 13 Data . . . . . . . . . . . . . . . . . . . . . . . . . 39

Test 3 Data . . . . . . . . . . . . . . . . . . . . . . . . . . . . . 40

Test 12 Data . . . . . . . . . . . . . . . . . . . . . . . 41

Test 7 and Test 13 Data . . . . . . . . . . . . . . . . . . . . 


\begin{abstract}
Out-of-pile thermal conductivity measurements were made on urania-plutonia fuel mixtures for varying fuel temperature, density, stoichiometry, composition and fabrication method. The measurements were made in a helium-6\% hydrogen atmosphere using a radial heat flow technique. The empirical equation developed for the thermal conductivity of $\left(\mathrm{U}_{0.8} \mathrm{Pu}_{0.2}\right)_{2-\mathrm{x}}$ is:

where

$$
k=0.01624+\frac{1}{(0.9702-0.4465 \mathrm{D}) \mathrm{T}}+0.5841 \times 10^{-12} \mathrm{~T}^{3}+\frac{360.2}{(2.04-0 / \mathrm{M}) \mathrm{T}^{2}}
$$

$$
\begin{aligned}
& \left.k=\text { thermal conductivity (watts } / \mathrm{cm}-{ }^{\circ} \mathrm{C}\right) \\
& T=\text { temperature }\left(800-2300^{\circ} \mathrm{C}\right) \\
& D=\text { fractional density }(0.84-0.91)
\end{aligned}
$$$$
\mathrm{O} / \mathrm{M} \text { = stoichiometry }(1.94-2.00)
$$

Typical values for $k$ on this curve (for $D=0.91, P u /(U+P u)=0.2$ and $O / M=2.00$ ) are:

$\begin{array}{rc}\left.T l^{\circ} \mathrm{C}\right) & k\left(W / \mathrm{cm}-{ }^{\circ} \mathrm{C}\right) \\ 800 & 0.0318 \\ 1000 & 0.0266 \\ 1500 & 0.0224 \\ 2000 & 0.0231 \\ 2300 & 0.0248\end{array}$

The equation was obtained using a weighted non-linear regression analysis. Data above $\sim 1800^{\circ} \mathrm{C}$ indicated that the thermal conductivity increased slightly above this temperature. The results are in good agreement with previously published data. Error analyses inherent in the regression technique used showed that the equation has $90 \%$ confidence limits of $\pm 11 \%$ which reflect the experimental and curve fitting errors involved in its development.
\end{abstract}

\title{
1. SUMMARY
}

Qut-of-pile thermal conductivity measurements were made on urania-plutonia fuel mixtures as a function of fuel temperature, density, stoichiometry, compusition and fabrication method. An empirical equation was developed for the thermal conductivity of $\mathrm{UO}_{2}-20 \% \mathrm{PuO}_{2}$.

Using weighted, non-linear regression analyses, an empirical equation for the thermal conductivity of $\left(U_{0.8} P_{0.2}\right)_{2-x}$ was determined as a function of several variables. The equation is:

$$
k=0.01524+\frac{1}{(0.9702-0.4465 \mathrm{D}) \mathrm{T}}+0.5841 \times 10^{-12} \mathrm{~T}^{3}+\frac{360.2}{(2.04-0 / \mathrm{M}) \mathrm{T}^{2}}
$$

where

$$
\begin{aligned}
\mathrm{K} & \left.=\text { thermal conductivity (watts } / \mathrm{cm}-{ }^{\circ} \mathrm{C}\right) \\
\mathrm{T} & =\text { temperature }\left(800 \text { to } 2300^{\circ} \mathrm{C}\right) \\
\mathrm{D} & =\text { fractional density }(0.84 \text { to } 0.91) \\
\mathrm{O} / \mathrm{M} & =\text { oxygen/metal ratio }(1.94 \text { to } 2.00)
\end{aligned}
$$

Statictical analyses showed that this empirical equation had $90 \%$ confidence limits of $\pm 11 \%$. Measurements showed that the thermal conductivity increased slightly at temporatures greater than about $1800^{\circ} \mathrm{C}$. This result was included in the empirical equation and is largely accounted for by the $\mathrm{T}^{3}$ term of the equation. 
The effect of density change on the thermal conductivity of mixed oxide fuel was found to be much less than in previous studies using stoichiometric uranium dioxide. The effects of varying density and plutonium composition were overshadowed by the effects of varying stoichiometry. The thermal conductivity was found to increase as the stoichiometry increased.

Fuel fabrication methods were found to have a negligible effect on the thermal conductivity. It was presumed, but not investigated here, that this would indeed be the case as long as the plutonia in the mixed oxide fuel remained well-distributed throughout the fuel lattice.

The application of the out-of-pile thermal conductivity data from this experiment to in-pile usage requires additional input from integral to melt thermal conductivity data to ensure that the required boundary conditions are fully met.

\section{INTRODUCTION}

One important parameter in determining the limiting power level for an oxide nuclear fuel element is the thermal conductivity of the fuel. In addition, the shape of the conductivity versus temperature curve is of importance in calculating the Doppler coefficient and transient behavior of fast flux, oxide-fueled reactors. Although several in-pile and out-of-pile investigations of thermal conductivity of stoichiometric and hyperstoichiometric uranium dioxide have been reported, relatively little work has been done with mixed uranium-plutonium oxide fuels.

In-pile conductivity data are complicated by the compound effect of fission product generation, fuel restructuring, and power cycling, as well as time and temperature. Some of these variables can be interpreted by outt-of-pile measurements which provide the basis for a systematic evaluation of any existing trends.

The use of plutonium-uranium oxides as fast ceramic reactor fuels requires a thorough understanding of the thermal behavior of the material. Due to the large temperature gradients that occur in the fuel during irradiation, a variety of structures and compositions develops in the fuel matrix which. affect both the physical and mechanical properties. Preferential migration of oxygen to the colder regions of the mixed oxide fuel has been observed out-of-pile. In a similar manner the plutonium in mixed oxide fuels irradiated in a fast flux tend to migrate to the center of the fuel. The occurrence of equiaxed and columnar grain growth also result in a variety of density and grain size regions. All of the above conditions produce a complex fuel matrix which can appreciably alter the heat transfer across the fuel pin.

The thermal conductivity data now available in the literature is not adequate to cover the various conditions and temperature ranges of concern found in irradiated fuel. Much of the current data available is in the form of thermal diffusivity measurements which require somewhat uncertain heat capacity data for conversion to actual thermal conductivity (watts $/ \mathrm{cm}^{\circ} \mathrm{C}$ ) measurements.

The out-of-pile thermal conductivity study reported here was designed to yield data which will be directly applicable to realistic conditions.

This work was undertaken to obtain an equation for the thermal conductivity of $20 \%$ plutonium concentration $\left(\mathrm{Pu}-\mathrm{U}^{-\mathrm{O}_{2}}\right.$ as a function of temperatures, fuel densities and composition which will be encountered in fast ceramic reactor fuels. Other fuel parameters such as oxygen/metal $(\mathrm{O} / \mathrm{M})$ ratio and fuel powder preparation methods were also studied to investigate their effects on thermal conductivity. The thermal conductivity of stoichiometric $\mathrm{UO}_{2}$ was also measured.

It is the purpose of this report to present these experimental results in graphical and tabular form, as well as obtaining a mathematical expression for the thermal conductivity of mixed oxide fuel based on out-of-pile measurements.

\section{PRIOR WORK}

The thermal conductivity characteristics of uranium dioxide have been extensively investigated both in- and out-of-pile, and the results summarized by Asamoto. ${ }^{1}$ However, relatively few investigations have studied the $(\mathrm{Pu}-\mathrm{U}) \mathrm{O}_{2}$ system. Some of the early work has been summarized by Hetzler, ${ }^{2}$ and more recent contributions have been made by him along with Schmidt, ${ }^{3}$ Gibby, ${ }^{4}$ Van Craeynest $^{5}$ and Baily. ${ }^{6}$ While these experimenters used three different experimental techniques to measure the thermal conductivity of mixed oxide fuel, their results are in reasonable agreement. As an example of comparison, the curves of thermal conductivity versus temperature for these recent experiments (for $96 \%$ T.D. and $O / M=2.00$ ) are plotted in Figure 1 along with the results of the measurements reported here for the same experimental conditions. 


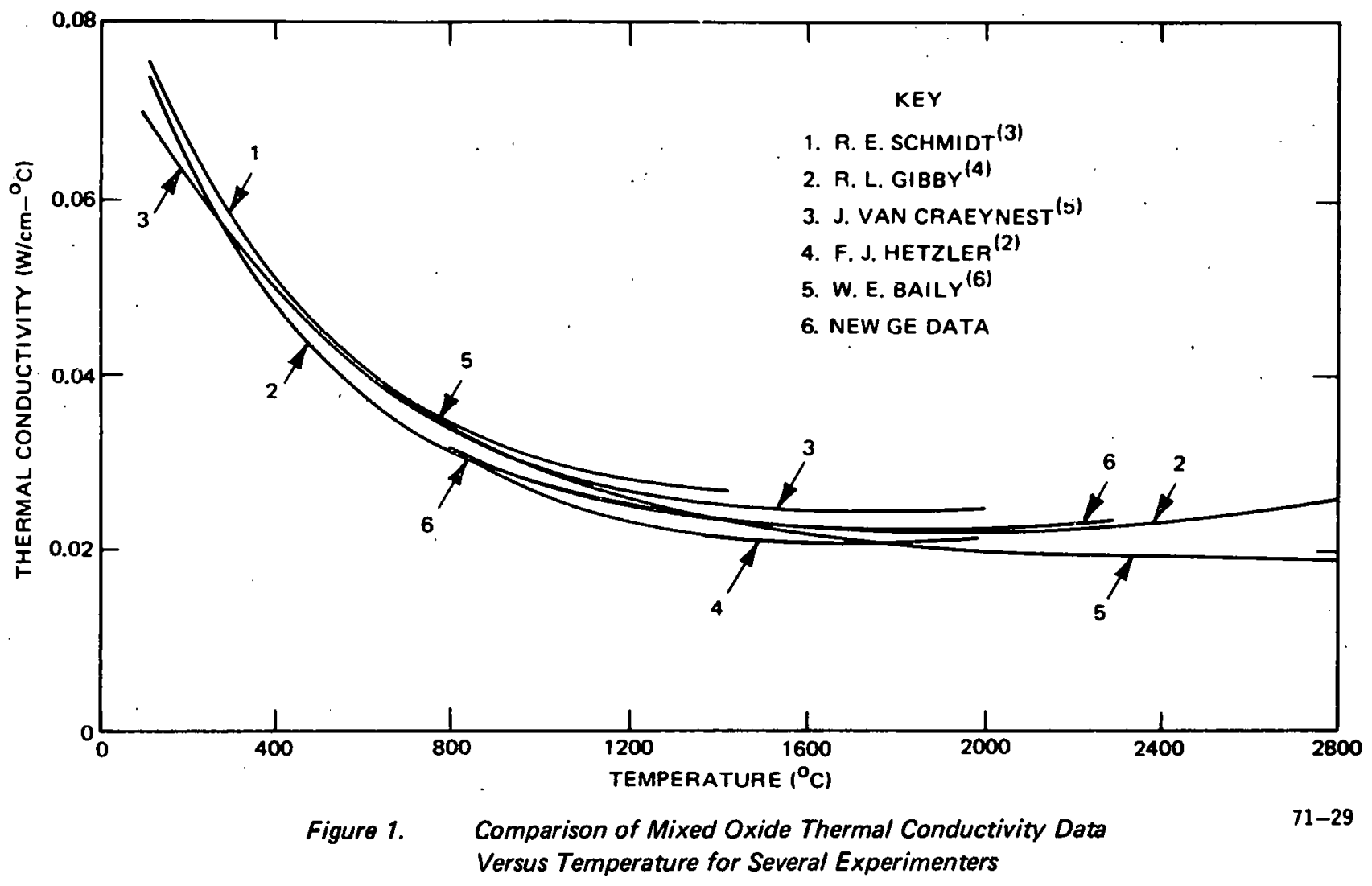

Additional thermal conductivity values were needed to supplement the information already available on mixed plutonium-uranium oxide fuels because of the following conditions:

1) A large portion of the data was developed from thermal diffusivity measurements. Since thermal conductivity values are calculated using estimated numbers for the specific heat of the material, there is some uncertainty in the conductivity values obtained.

2) Little data have teen reported for temperatures greater than $1900^{\circ} \mathrm{C}$.

3) The data on the effects of plutonium content and density are sparse and inconclusive.

4) While the role of stoichiometry in the thermal conductivity has been investigated by several authors, ${ }^{2}, 3,7$ inadequate control of the test atmospheres may well have resulted in $\mathrm{O} / \mathrm{M}$ shifts during high temperature tests. In general these possible stoichiometry changes were not taken into account in the analysis of the earlier data.

The present out-of-pile thermal conductivity study fills in the oroas where data are needed and also serves as a check on the data already present in the literature.

It is worthwhile to note that Baily ${ }^{6}$ retained the same density correlation factor that was developed by Asamuto ${ }^{1}$ for $\mathrm{UO}_{2}$; however, the thermal conductivity was presumed to be constant above $2000^{\circ} \mathrm{C}$. Also, all data at high temperatures $\left(>2000^{\circ} \mathrm{C}\right)$ is subject to some speculation. The high temperature electrical conductivity of the fuel may be sufficiently large enough at high temperatures so that some joule heating occurs in the specimen itself rather than bcing confiner to a tungsten rod which is used as a heat source by several experimenters. Ainscough ${ }^{8}$ has shown that such power generation in the specimens will lend to artifically high valuos for the measured thermal conductivity. Gibby ${ }^{4}$ has eliminated this problem using his laser pulse technique; however, his results using the calculation of thermal diffusivity required knowing the fuel heat capacity $\left(C_{p}\right)$ accurately. Calculations nf this latter quantity are subject to error. Gibby's studies used $95.5 \%$ dense, $25 \% \mathrm{PuO}_{2}$ coprecipitated fuel.

Schmidt ${ }^{9}$, in a recent paper, asserts that the mechanisms of electronic and radiative heat transfer have only minor effects, if any, on the thermal conductivity of uranium dioxide. His analysis demonstrated that the specific heat of the fuel material was the predominant factor in determining the temperature dependence of the thermal conductivity of UQ, above $1200^{\circ} \mathrm{C}$. He also determined that $2050^{\circ} \mathrm{C}$ is the limiting temperature above which the thermal conductivity of $\mathrm{UO}_{2}$ begins to increase because the specilic heat incroases with temperature in this region. Several authors ${ }^{10,11,12}$ have shown this trend of specific heat versus temperature for $\mathrm{UO}_{2}, \mathrm{PuO}_{2}$ and mixed oxide fuels. 


\section{EXPERIMENTAL DESIGN}

\subsection{TEST FURNACE}

Thermal conductivity measurements were carried out in a vacuum furnace modified to accommodate a radial heat flow power generation apparatus.

A schematic diagram of the furnace used for these experiments is shown in Figure 2. Several modifications were made to the standard frame in order to provide a viable experimental arrangement in an alpha enclosure. Electrodes were fitted through the top and bottom of 'the furnace casing so that the annular test pellets could be placed on a tungsten rod heated by means of the electrodes. Electrical contact between the tungsten rod and the bottom electrode was provided through a Ga-24.5\% In eutetic liquid' metal pool. This eliminated any tungsten rod expansion problems. Legs were fastened to the bottom of the furnace to provide clearance and access under the furnace case. The furnace door was modified so that it could be swung to the side of the furnace, providing improved access to the furnace interior through the alpha enclosure glove ports. Figures 3 through 5 show the furnace and its instrumentation.

General furnace heating was provided by tungsten mesh elements in the furnace case and on the furnace door. The purpose of the tungsten mesh heaters was to control the outer surface temperature of the test specimens so that the $\Delta T$ could be adjusted to desired values. Large interlocking copper blades completed the electrical circuits when the door was closed.

Separate SCR linear power control supplies provided power to the tungsten mesh and rod heaters. The two heat sources could be controlled separately but operated simultaneously if desired.

The furnace door was supplied with a 2 -inch by $1 / 4$-inch slit (covered by a vycor window) for viewing the pellet column with minimum heat loss from the furnace.

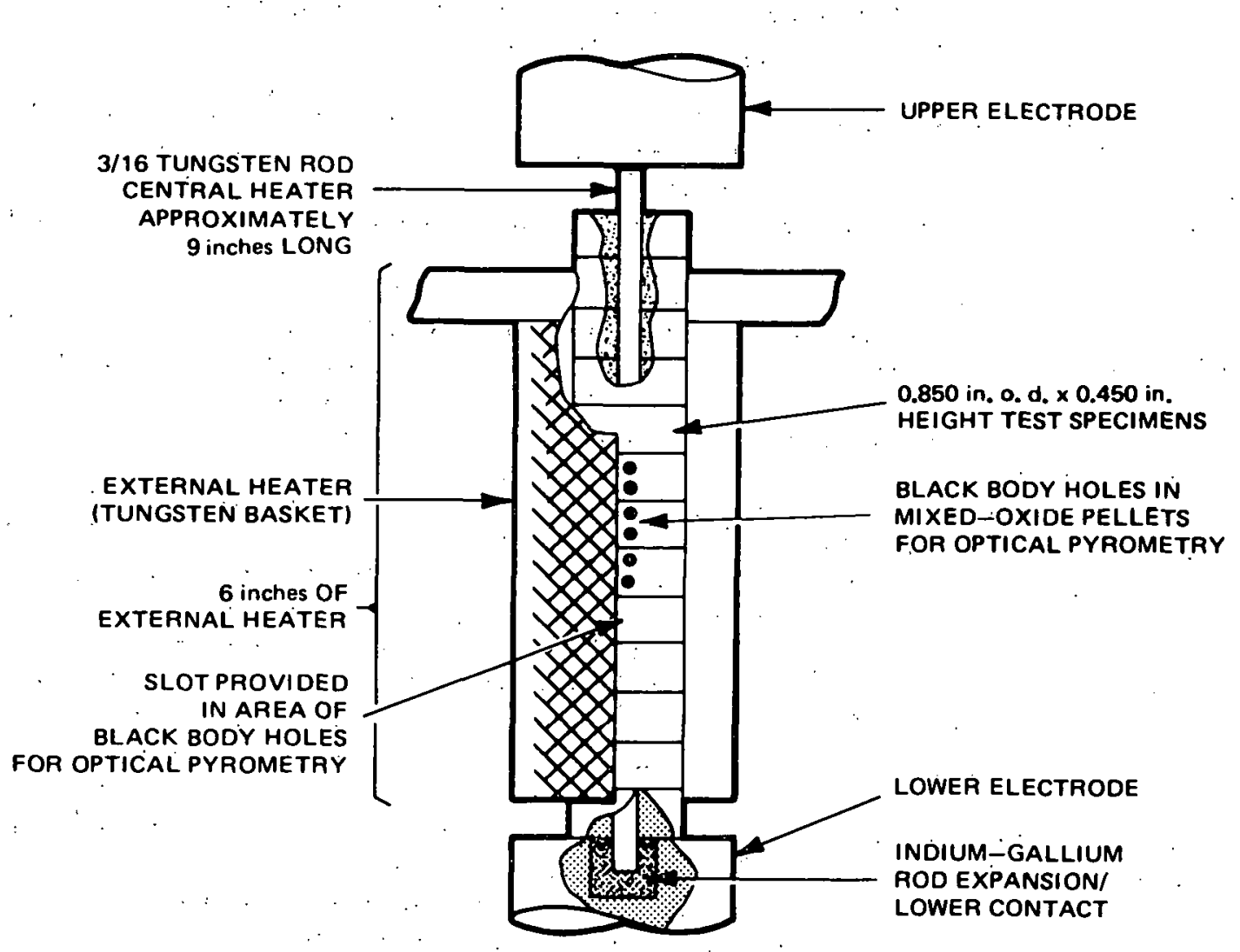

Figure 2. Schematic of Thermal Conductivity Apparatus 
GEAP-13733

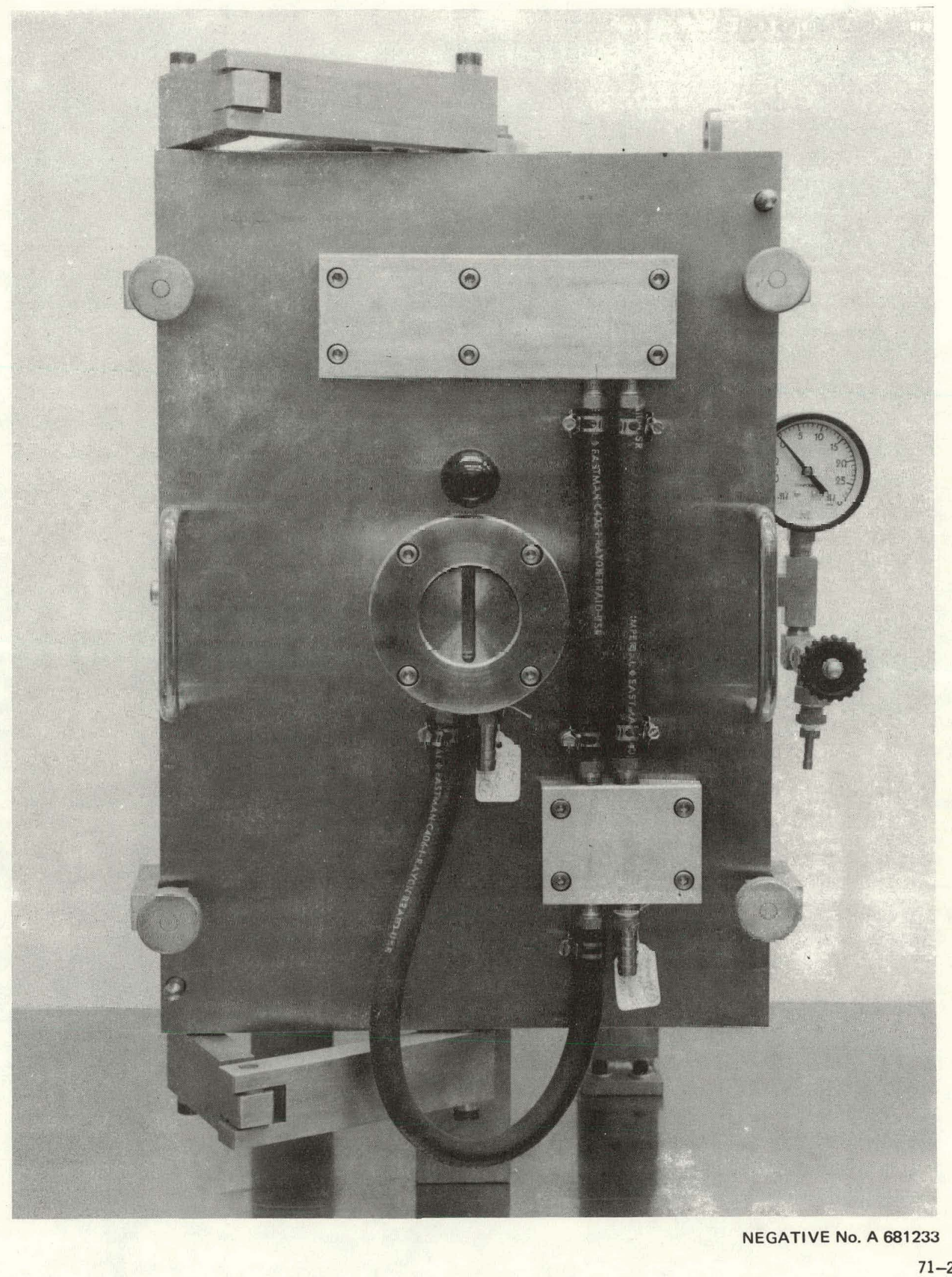

Figure 3. Vacuum Furnace-Closed 


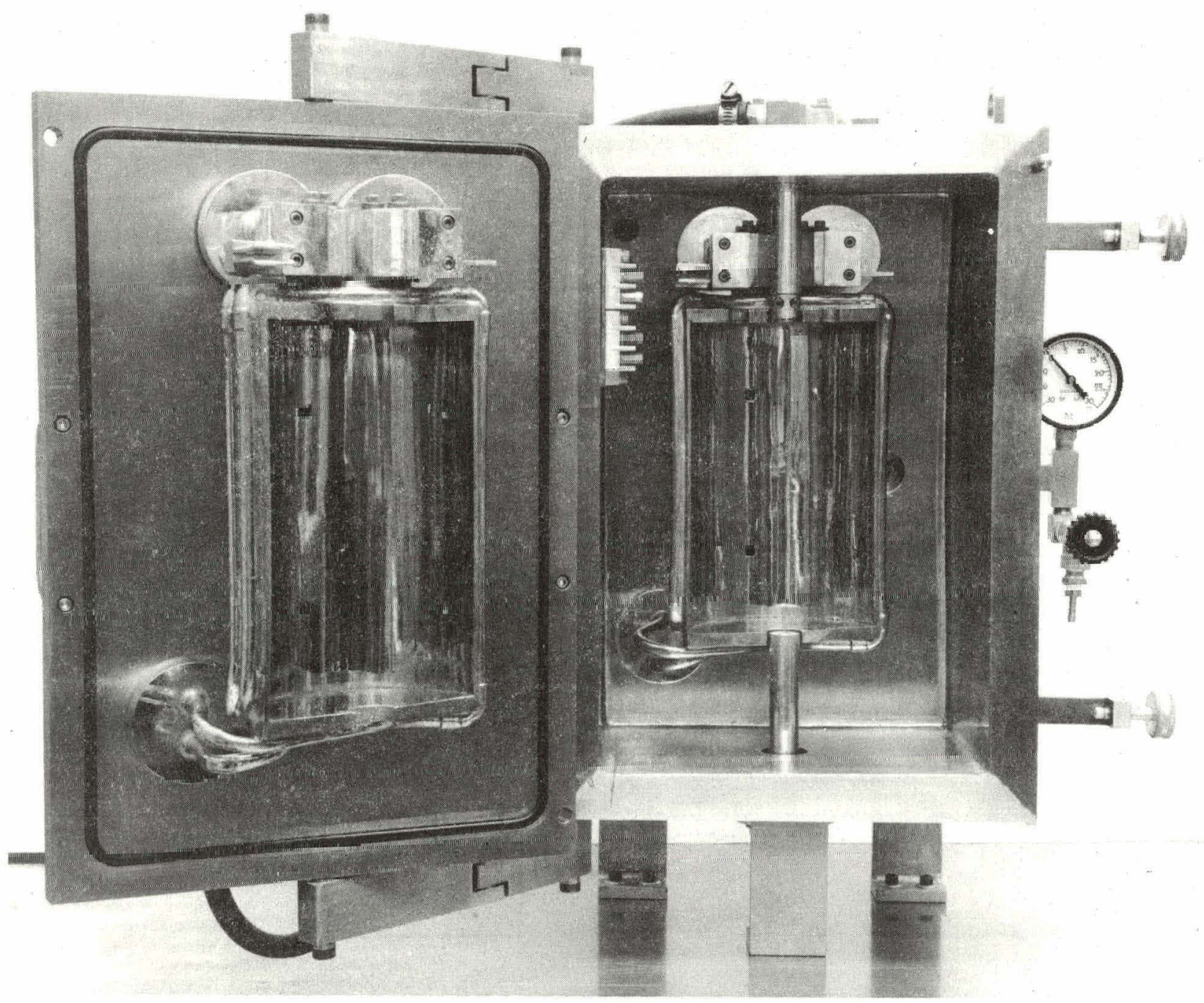

NEGATIVE No. A 681234

71-3

Figure 4. Vacuum Furnace-Open 


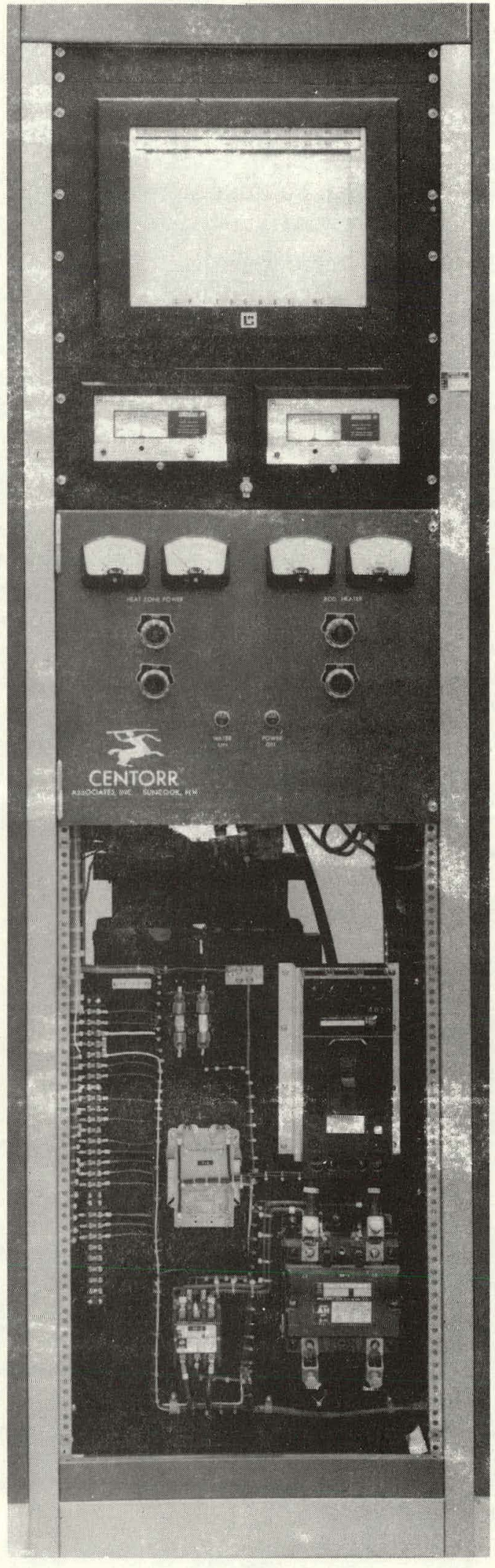




\subsection{SPECIMEN PREPARATION}

Test pellets were fabricated to various stoichiometry, plutonium content, and density specifications. The majority of the pellets were prepared from physically mixed $\mathrm{PuO}_{2}$ and $\mathrm{UO}_{2}$ but a few were prepared from coprecipitated powder. Physically mixed $\mathrm{UO}_{2}-20 \% \mathrm{PuO}_{2}$ was prepared by blending the proper amounts of $\mathrm{UO}_{2}$ and $\mathrm{PuO}_{2}$ powders in a twin shell blender followed by hammermilling. $\mathrm{UO}_{2}-10 \%$ was prepared from $\mathrm{UO}_{2}-20 \% \mathrm{PuO}_{2}$ by blending in additional $\cup_{2}$. Coprecipitated $\cup_{2}-20 \% \mathrm{PuO}_{2}$ and $\cup_{2}-30 \% \mathrm{PuO}_{2}$ were prepared by precipitating the proper mixtures of uranyl nitrate and plutonium nitrate using the reverse strike method. The precipitates were washed and then calcined at $700^{\circ} \mathrm{C}$ in dry $\mathrm{N}_{2}-6 \% \mathrm{H}_{2}$ followed by ball-milling to obtain a sinterable powder.

Fabrication procedures and quality control checks were used to promote a single-phase solid solution and protect against large inhomogeneities in the fuel matrix.

The experimental arrangement is illustrated in Figure 6. The stack of three pellets in each test usually contained two mixed oxide pellets and one uranium oxide pellet. Each pellet contained four black-body holes, and beginning with Test 8 (see Table 1), the $\mathrm{UO}_{2}$ pellet was the top pellet of the three test pellets in all but one test (Test 13). $\mathrm{UO}_{2}$ insulator pellets were placed on both sides of the test pellets to complete the pellet stack.

Pellets $0.850 \pm 0.05$ inch o.d. and $0.450 \pm 0.05$ inch in height were made by granulating the compacted powders through a coarse screen followed by cold pressing and sintering in dry $\mathrm{N}_{2}-6 \% \mathrm{H}_{2}$ at $1650^{\circ} \mathrm{C}$ to produce annular pellets with 84 to $97.6 \%$ T.D. and $\mathrm{O} / \mathrm{M}=1.95$. The pellets were centerless ground to ensure that a right circular cylindrical shape was maintained. The central annuli were 0.200 inches in diameter so that the pellets could be stacked in a column on the 0.1875 inch diameter tungsten heater rod. ${ }^{*}$ The pellets were slotted along a radius to prevent breakage from differential thermal expansion. Black-body holes 0.030 to 0.050 inches in diameter were drilled at $0.120,0.180,0.240$, and 0.300 inch depths in each pellet. The holes had length to diameter (L/D) ratios from 4 to 6.

* No provision was made to maintain concentricity of the annular pellets with respect to the tungsten heater rod. Electrical contact was possible and is considered in Section 5.4.

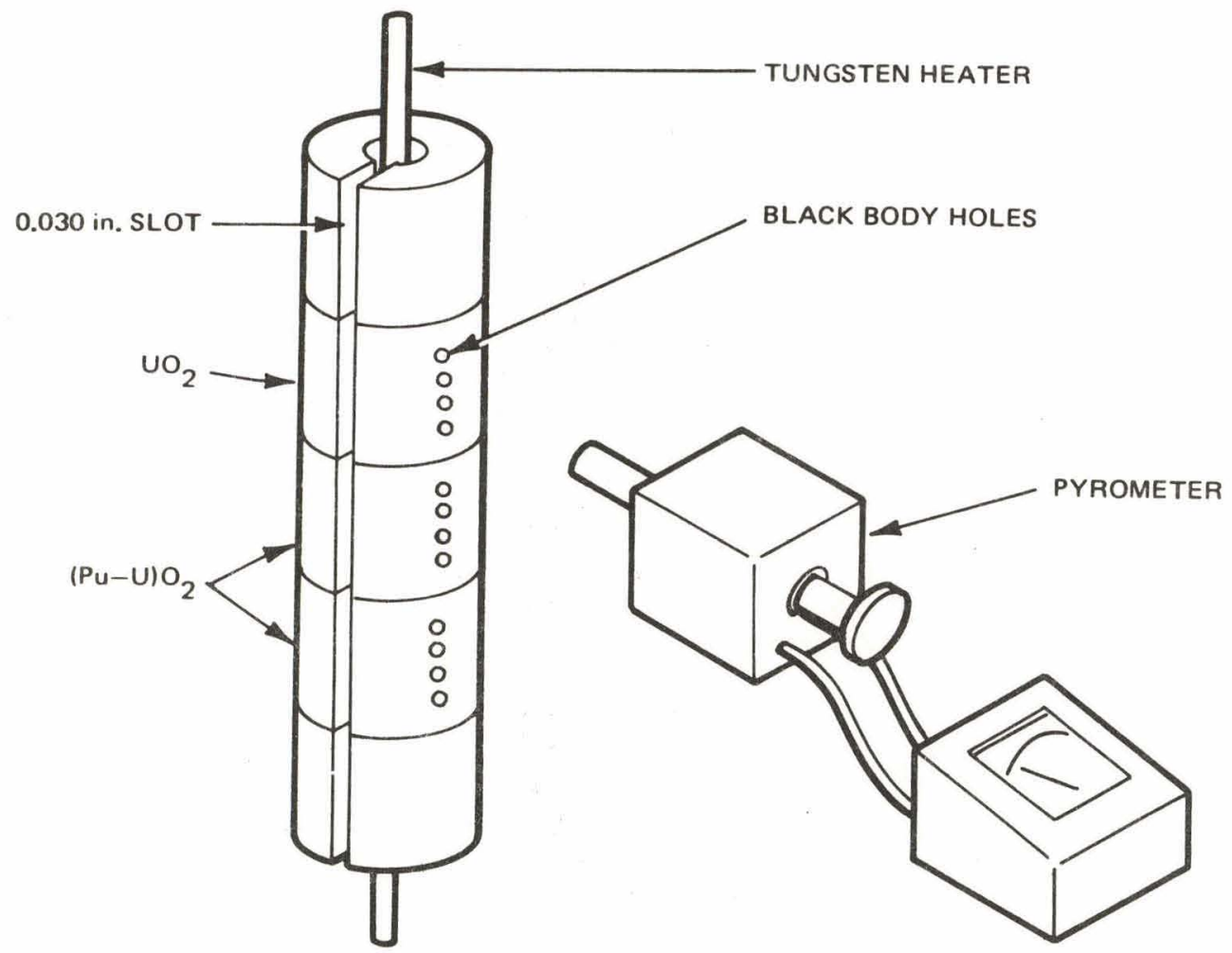

Figure 6. Experimental Arrangement 


\subsection{INSTRUMENTATION}

A Pyro disappearing filament optical pyrometer was used to measure the black-body hole temperatures. Pyrometer readings were standardized against tungsten/tungsten-26\% rhenium thermocouples inserted into a cavity in the test pellet. Standardization measurements were carried out under isothermal conditions. Optical pyrometer measurements were limited to maximum temperatures of approximately $2200^{\circ}$ to $2400^{\circ} \mathrm{C}$ because of fuel vaporization and the corresponding distortion of the black-body holes.

Total current through the tungsten rod heater was measured with a Weston multirange Ammeter 0 to 1 up to 0 to 50 amperes, $\pm 1 / 4 \%$ accuracy) in series with a $240 / 1$ stepdown transformer.

\subsection{EXPERIMENTAL PROCEDURE}

Three test pellets were positioned on the.tungsten heater rod with $7 \mathrm{UO}_{2}$ insulator pellets below and $6 \mathrm{UO}_{2}$ insulator pellets above them to minimize axial heat losses. The loaded rod was inserted into the furnace so that the bottom of the rod was suspended freely in the indium-gallium pool. The bottom insulator pellet rested on the ledge of the liquid metal pool. The three test pellets were positioned so that the black-body holes could be observed through the slit in the furnace door.

The furnace was evacuated to $\sim 10^{-1} \mathrm{~mm} \mathrm{Hg}$ and back filled with dry $\mathrm{He}-6 \% \mathrm{H}_{2}$ a minimum of three times to provide a low enough oxygen pressure so that it would be easily gettered by the hydrogen in the furnace atmosphere without significantly affecting the $\mathrm{H}_{2} \mathrm{O} / \mathrm{H}_{2}$ ratio.

Thermal conductivity measurements were conducter by energizing the tungsten mesh and rod heaters simultaneously at zero power and slowly increasing both simultaneously until a temperature of approximately $800^{\circ} \mathrm{C}$ was observed at the pellet surface and the temperature difference between the deepest and most shallow black-body holes was about $200^{\circ} \mathrm{C}$. The radial temperature difference in the test pellets was held to a maximum of $200^{\circ} \mathrm{C}$ and to a maximum of $50^{\circ} \mathrm{C}$ between adjacent black body holes. This should have minimized any oxygen migration from the hotter to the cooler regions of the pellets. Further temperature increases were carried out using the mesh heater alone, so that the power input to the center of the pellet stack remained relatively constant. Steady-state was reached quite rapidly (within 10 minutes). Temperatures were measured with a disappearing filament micro-optical pyrometer focused on the bottoms of the four radial holes, drilled to different depths in the specimen. The entire set of black-body holes was measured in sequence; then the sequence was repeated at least four times. When five consecutive measurements of each black-body hole were within \pm 5 degrees, those five measurements were concluded to be at steady state. The next series of measurements was then made after increasing the furnace temperature. Current measurements are taken after each furnace temperature increase (see Section 6.1).

Measurements for the urania-plutonia system encompassed the following conditions: densities of 84 to $97.6 \%$ T.D., O/M ratios of 1.94 to 2.00 , plutonium contents of 0 to $100 \%$, temperatures of 800 to $\sim 2300^{\circ} \mathrm{C}$, and two fuel preparation methods-coprecipitation and physically-mixed. Only the $20 \%$ plutonium content data were ultimately used to develop the empirical equation.

Measurements at various stoichiometries were made by annealing the test pellets to obtain a stoichiometry of 1.940. The precise weight of each pellet was mcasurod at this time. Thermal conductivity measurements were made from 800 to $2300^{\circ} \mathrm{C}$ while the test pellets were surrounded by a tantalum sleeve to retain the low stoichiometry. The pellets were then cooled and removed from the furnace for weighing. The pellets were then placed ayain in the furnace and annealed in dry $\mathrm{He}-6 \% \mathrm{H}_{2}$ for two hours at $1600^{\circ} \mathrm{C}$ after which thermal conductivity measurements were again carried out from 800 to $2300^{\circ} \mathrm{C}$. The weighing procedure was repeated and the pellets were annealed for two hours in $\mathrm{He}-6 \% \mathrm{H}_{2}$ to which a small amount of $\mathrm{H}_{2} \mathrm{O}$ was added. Thermal conductivity measurements from 800 to $2300^{\circ} \mathrm{C}$ were repeated in this atmosphere.

The weighing procedure was again repeated and the pellets were annealed in $\mathrm{He}-6 \% \mathrm{H}_{2}$ saturated with room temperature $\mathrm{H}_{2} \mathrm{O}$ for 2 hours at $1600^{\circ} \mathrm{C}$. Thermal conductivity measurements were then carried out in this atmosphere from 800 to $2300^{\circ} \mathrm{C}$. In this manner thermal conductivity measurements were made at stoichiometries of $1.940,1.948$, 1.980 , and 2.00 .

The test parameters are summarized in Table 1. 
Table 1

SUMMARY OF TEST PARAMETERS

\begin{tabular}{|c|c|c|c|c|c|c|c|}
\hline $\begin{array}{l}\text { Test } \\
\text { Number }\end{array}$ & $\begin{array}{c}\text { Number of } \\
\text { Pellets }\end{array}$ & $\begin{array}{l}\text { Starting }^{\mathrm{a}} \\
\text { Material }\end{array}$ & Wt \% Pu & $\mathrm{O} / \mathrm{M}$ & $\begin{array}{c}\text { Density } \\
\text { Range } \\
\text { (\% T.D.) }\end{array}$ & $\begin{array}{c}\text { Temperature } \\
\text { Range }\left({ }^{\circ} \mathrm{C}\right)\end{array}$ & Comments \\
\hline 1 & 7 & C. & 20 & 1.95 & $92.78-93.1$ & $1200-2300$ & Results Not Used \\
\hline 2 & 11 & C & 20 & 2.00 & $92.78-93.1$ & $800-2300$ & Results Not Used \\
\hline 3 & 12 & PM & 30 & 2.00 & $93.28-93.41$ & $800-2300$ & \\
\hline 4 & 31 & PM & 20 & $\begin{array}{l}1.95 \\
2.00\end{array}$ & $92.12-92.7$ & $800-2300$ & Results Not Used \\
\hline 5 & 27 & PM & 20 & $\begin{array}{l}1.95 \\
2.00\end{array}$ & $94.58-95.03$ & $800-2300$ & Results Not Used \\
\hline 6 & 5 & PM & 20 & & $91.26-97.6$ & $800-1200$ & Column Too Short \\
\hline 7 & 6 & - & $\mathbf{0}$ & 2.00 & 97.63 & $800-1800$ & $100 \% \cup_{2}$ \\
\hline $8(1)$ & 8. & PM & 20 & $\begin{array}{l}1.94 \\
1.95\end{array}$ & 91.0 & $800-1400$ & One Pellet Was $\mathrm{UO}_{2}{ }^{b}$ \\
\hline $8(11)$ & 9 & PM & 20 & $\begin{array}{l}1.98 \\
2.00\end{array}$ & 91.0 & $800-1450$ & One Pellet Was $\mathrm{UO}_{2}{ }^{b}$ \\
\hline $8(I I I)$ & 8 & PM & 20 & 1.95 & 91.0 & $800-2300$ & One Pellet Was $\mathrm{UO}_{2}{ }^{b}$ \\
\hline 10 & 8 & PM & 20 & 1.96 & 84.0 & $800-2300$ & One Pellet Was $\mathrm{UO}_{2} b$ \\
\hline 11 & 8 & $\mathrm{C}$ & 20 & 1.965 & $85.5 \cdot 86.9$ & $800-2300$ & One Pellet Was $\mathrm{UO}_{2} \mathrm{~b}$ \\
\hline 12 & 6 & PM & 100 & 1.86 & 97.6 & $800-2000$ & One Pellet Was $\mathrm{UO}_{2} \mathrm{~b}$ \\
\hline 13 & 8 & PM & $0 / 10$ & 1.986 & $91.0-97.6$ & $800-2300$ & One Pellet Was $\mathrm{UO}_{2} \mathrm{~b}$ \\
\hline
\end{tabular}

(a) $\mathrm{C}=$ Coprecipitated powder, $\mathrm{PM}=$ physically-mixed powder

(b) The $\mathrm{UO}_{2}$ pellet was $97.6 \%$ T.D. and $\mathrm{O} / \mathrm{M}=2.00$

\section{RESULTS AND DISCUSSION}

Thermal conductivity measurements were carried out on specimens of urania-plutonia mixtures as functions of temperature, stoichiometry, density, composition and fabrication procedure. The results are discussed in terms of current theories on phonon transfer in solids. An empirical equation given in Section 7 was generated which described that part of the data which involved changes in microstructure, temperature and stoichiometry.

\subsection{EFFECT OF STOICHIOMETRY AND COMPOSITION ON THE THERMAL CONDUCTIVITY OF URANIA-PLUTONIA}

The effects of stoichiometry on the thermal conductivity of physically blended $\mathrm{UO}_{2}-20 \% \mathrm{PuO}_{2}$ are shown in Figure 7. This experiment was conducted from $800^{\circ} \mathrm{C}$ to $2300^{\circ} \mathrm{C}$ on a single set of pellets by varying the oxygen activity in the furnace atmosphere in accordance with the experimental procedure discussed in Subsection 4.4 . Measurements were made at stoichiometries varying from 1.94 to 2.00 . The results exhibited the expected increase in thermal conductivity as the stoichiometry increases at low temperatures. This is in accordance with the thermal diffusivity measurements of Gibby, ${ }^{4}$ and Van Craeynest and Weilbacher ${ }^{5}$ who found a monotonic increase in thermal diffusivity as the stoichiometric composition is approached.

The strong effect of stoichiometry on the thermal conductivity of the mixed oxide material is worthy of further comment. At temperatures much greater than the Debye temperature, the thermal conductivity is largely dependent upon the phonon mean free path length. As this path length is reduced, phonon scattering becomes more pronounced with a resulting decrease in thermal conductivity, following roughly a $\mathrm{T}^{-1}$ dependence on the temperature. When the mean free path is reduced to interatomic distances, further reduction of path length has no effect and the thermal conductivity becomes temperature independent. This condition apparently exists in $(\mathrm{U}, \mathrm{Pu}) \mathrm{O}_{2-x}$ at temperatures above about $1400^{\circ} \mathrm{C}$ as indicated by the data discussed here. Below this temperature, the thermal conductivity increases with decreasing temperature $i$ and is also highly dependent upon impurity scattering centers such as oxygen vacancies. The stoichiometry and composition dependences in the thermal conductivity data indicate that the phonon mean free path is reduced to interatomic distances with only about $3 \%$ of the oxygen sub-lattice replaced by vacancies. 
As additional vacancies are introduced, either by lowering the oxygen activity or by increasing the plutonium content, the thermal conductivity does not continue to decrease. The constancy of the thermal conductivity for large oxygen vacancy concentrations also strongly supports the hypothesis that the substitution of plutonium for uranium does not alter the lattice vibrational spectrum significantly. That this is the case is illustrated in Figure 8 which exhibits the thermal conductivity as a function of composition for hypo-stoichiometric urania-plutonia of a constant oxygen-to-plutonium ratio. Experiments were performed on specimens of urania-plutonia with plutonium compositions of $10,20,30$ and $100 \%$. In each case the experiments were carried out in dry $\mathrm{He}-6 \% \mathrm{H}_{2}$ so that conditions of constant oxygen-to-plutonium ratio prevailed at each test temperature. The oxygen-to-plutonium ratios varied from approximately 1.82 at $800^{\circ} \mathrm{C}$ to 1.65 at $2300^{\circ} \mathrm{C}$, assuming that equilibrium with the furnace gas took place at each temperature during the test.

Corresponding $\mathrm{O} / \mathrm{M}$ 's varied (e.g., for constant $20 \%$ plutonium composition) from 1.96 at $800^{\circ} \mathrm{C}$ to 1.93 at $2300^{\circ} \mathrm{C}$. Gibby ${ }^{4}$ has indicated that the addition of plutonium to the $\mathrm{UO}_{2}$ lattice had virtually no effect on the thermal conductivity except where it altered the defect concentration in the oxygen sub-lattice. He has reported data on thermal diffusivity in urania-plutonia solutions as a function of plutonium content, and the relatively small effects reported would be completely over-shadowed by the larger number of impurity scattering centers due to the anion defect structure in the hypostoichiometric mixed oxide material.

\subsection{EFFECT OF FABRICATION PROCEDURE OF THE THERMAL CONDUCTIVITY OF $\left(\mathrm{U}_{0.8} \mathrm{Pu}_{0.2}\right)^{\mathrm{O}_{2-x}}$}

While most of the materials studied in this work were prepared by physically blending the urania and plutonia powders in the proper proportions, some tests were carried out on material which was derived from a coprecipitation process, as described in the section on "experimental design." Figures 9 and 10 show comparisons of thermal conductivity measurements in urania-plutonia fabricated using physically blended and coprecipitated powders. Any differences observed here were generally within experimental error, and are contained within the confidence band on the empirical equation. The thermal conductivities of these materials might be expected to be different if the plutonia agglomerates were of sufficient size to rcsult in the material being basically a matrix of $\mathrm{UO}_{2}$ with large islands of hypostoichiometric plutonia. This situation would probably result in somewhat higher conductivity observed for the physically blended material. Since this is not the case, it can be assumed that the plutonia was sufficiently well distributed so that these inhomogeneous effects were generally not present.

\subsection{EFFECT OF DENSITY ON THE THERMAL CONDUCTIVITY OF $\left(\mathrm{U}_{0.8} \mathrm{Pu}_{0.2}\right)_{2-x}$}

The effect of density on the thermal conductivity of urania-20\% plutonia is illustrated in Figure 11 . Contrary to the normal models of porosity effects on thermal conductivity, no significant density effect on the thermal conductivity was observed in these measurements. Since all of the available theoretical models concerning porosity in thermal conductivity measurements are based on the assumption of closed porosity, the presence of open pores and fissures in this material would preclude an analysis based on these theoretical models. It is likely that the ratios of open to closed porosity in the various materials tested are such that any large density variation, such as would be predicted by any of the theoretical models, are not apparent. The low stoichiometry $(1.95 \mathrm{o} / \mathrm{m})$ overshadowed the density effect in this case (Subsection 5.5).

\subsection{ELECTRICAL CONDUCTIVITY}

The electrical conductivity of mixed oxide fuels varies with stoichiometry and plutonium content such that it increases with increasing stoichiometry and with increasing plutonium contents. The samples were tested in dry hydrogen, which fixed the $\mathrm{O} / \mathrm{Pu}$ ratio at each temperature while electrical conductivity increased with increasing temperature. Increasing plutonium content would result in greater electrical conductivity although offset to some extent by any decrease in stoichiometry. An increase in electrical conductivity would have caused some amounts of joule heating if the pellets had come in contact with the central tungsten heating rod. Although the electrical conductivity of tungsten is much larger than that of a urania-plutonia ceramic, this might explain to some extent the wide variations in thermal conductivity observed at high temperatures for the 30 to $100 \% \mathrm{PuO}_{2}$ samples, shown in Figure 8. 


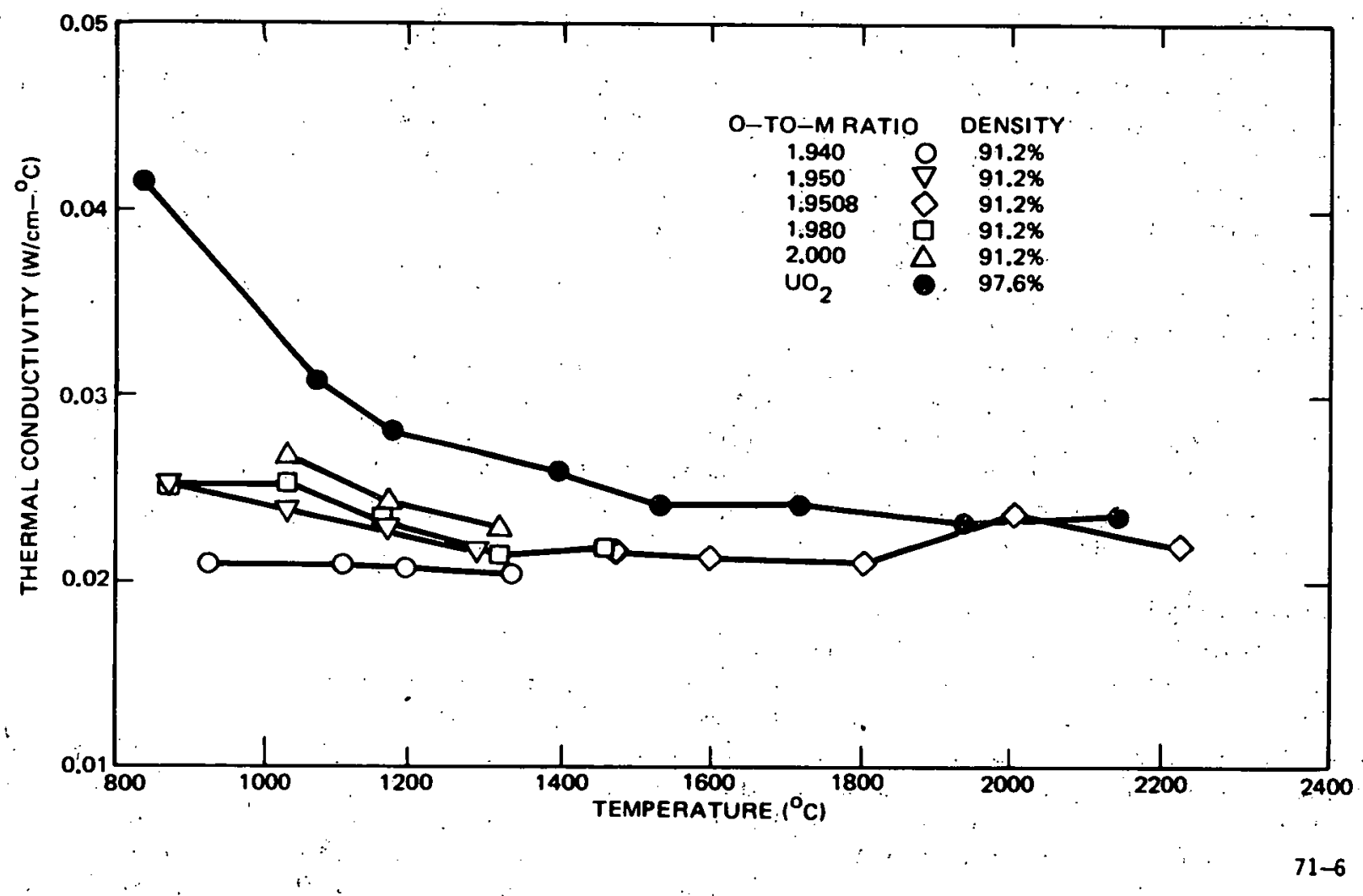

Figure 7. Effect of Stoichiometry on Thermal Conductivity of $\left(U_{0.8} \mathrm{Pu}_{0.2} \mathrm{O}_{2-x}\right.$

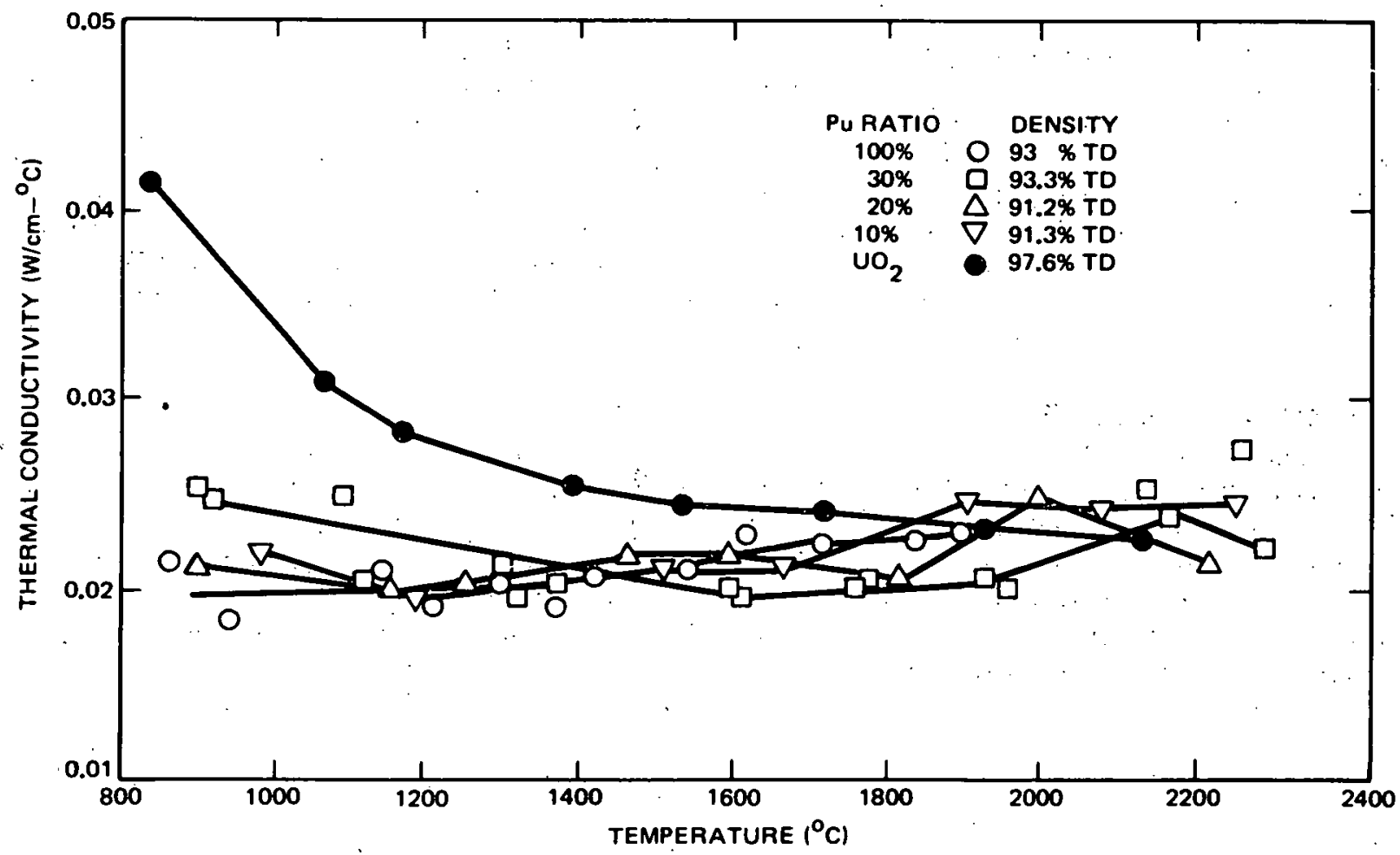

Figure 8. Effect of Composition on Thermal Conductivity of $\left(U_{x} P u_{y}\right) O_{2-2}$ 


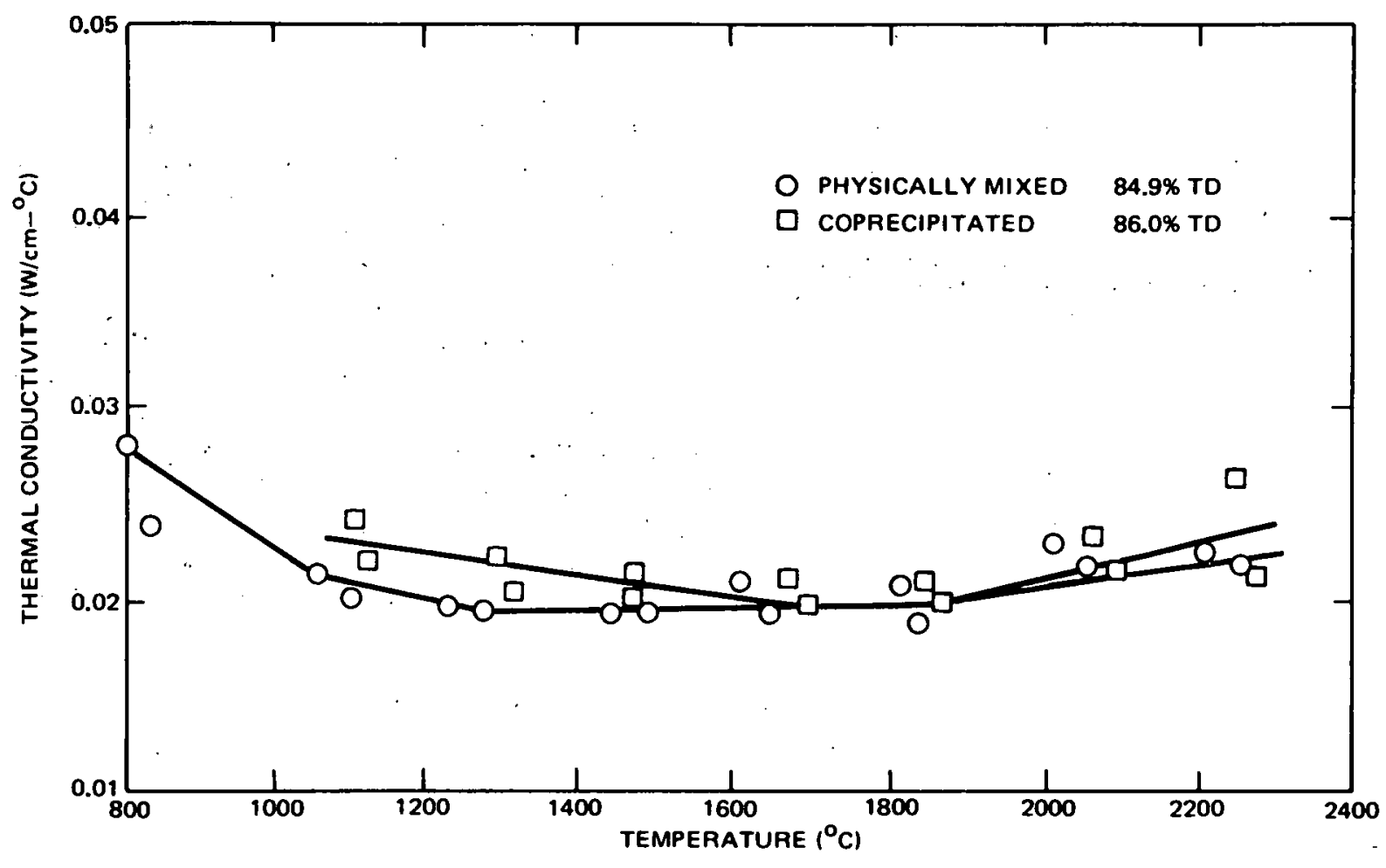

Figure 9. Fabrication Effect on Thermal Conductivity of $\left(U_{0.8} P u_{0.2}\right)_{1.95}$

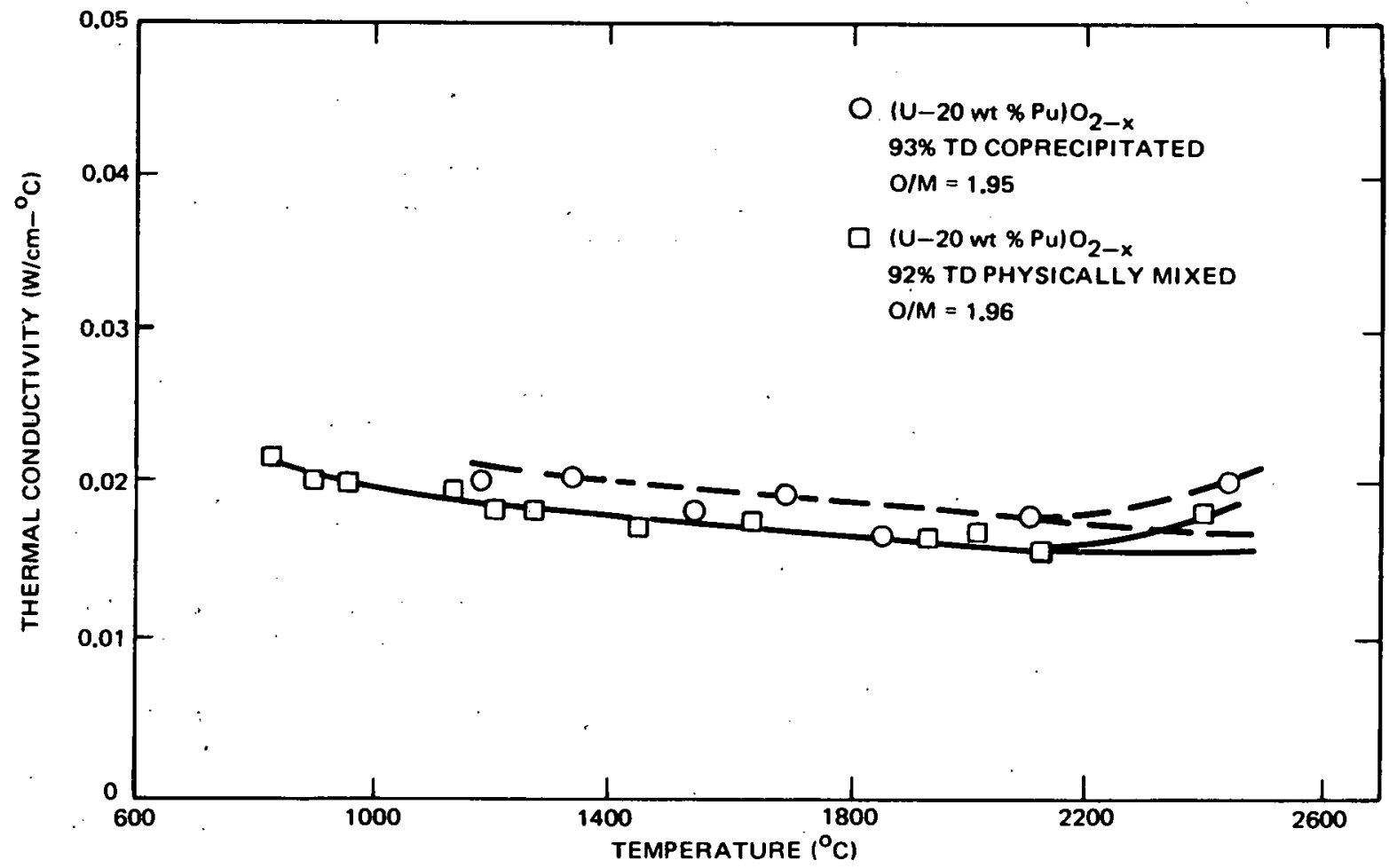

Figure 10. Thermal Conductivity of Coprecipitated and Physically Mixed Pellers 


\subsection{ORDER-DISORDER}

The thermal conductivity of a solid decreases with decreasing density and increasing molecular disorder. The disorder effect increases with temperature up to the temperature at which radiative heat transfer effects dominate and cause the observed increase in thermal conductivity at high temperatures. In mixed oxide fuels, increasing disorder can be caused by the formation of a non-ideal solid solution, such as one containing scattering centers formed due to oxygen vacancies. The number of oxygen vacancies depends on the stoichiometry $(O / M$ ratio) of the fuel and not the $\mathrm{O} / \mathrm{Pu}$ ratio. Test 8 of this work demonstrated the effect of this increase in thermal conductivity due to increases in $\mathrm{O} / \mathrm{M}$. The magnitude of the effect decreased as the deviation from stoichiometry $(\mathrm{O} / \mathrm{M}=2.00)$ increased and as the temperature increased. With increasing plutonium content, disorder also increased but the effect was overshadowed by disorder resulting from an increased number of oxygen vacancies since the measurements were made at low $O / M$ values for plutonium content greater than $20 \%$. Also overshadowed by the effect of stoichiometry was the effect of density on thermal conductivity. Thus the results presented indicate the strong effect of stoichiometry and a lesser effect of plutonium content and density. For this reason, plutonium content was not included as a parameter in the empirical equation and the density correlation factor of 0.4465 developed.by Asamoto ${ }^{1}$ was retained. The second term of the empirical equation given in Section 7 reflects a much lesser effect of density on thermal conductivity than was observed in the $\mathrm{UO}_{2}$ study by Asamoto.

\subsection{EMPIRICAL EQUATION FOR THE THERMAL CONDUCTIVITY $\left(U_{0.8} \mathrm{Pu}_{0.2}\right)_{2-\mathrm{O}}$}

Figure 12 shows the plot of the empirical equation developed for the thermal conductivity of $91 \%$ dense $\left(\mathrm{U}_{0.8} \mathrm{Pu}_{0.2}\right)_{2-\mathrm{O}}$ which is given in Section 7 , as a function of temperature over the range of 800 to $2300^{\circ} \mathrm{C}$. The increase in the thermal conductivity' observed above $\sim 1800^{\circ} \mathrm{C}$. was predicted by the equation. The $90 \%$ confidence band has been shown in Figure 12 to indicate the statistical accuracy of the equation. A few selected data points have been added to Figure 12 to illustrate the curve-fitting technique. The experimental uncertainty associated with each of these data points has been indicated in the figure by a vertical bar. These uncertainties were used as the weighting factors in the statistical analyses discussed in Section 6.1.

Figure 13 shows the empirical equation plotted for $91 \%$ dense $\left(U_{0.8} \mathrm{Pu}_{0.2}\right)_{2-x}$ and varying stoichiometry as a function of temperature. The effect of changing stoichiometry discussed in the preceding sections is evident here.

\subsection{MICROSTRUCTURES OF TESTED SPECIMENS}

Metallographic examinations were conducted on selected thermal conductivity test specimens to determine the extent of fuel restructuring during the high temperature portions of the thermal conductivity measurements. Two examples are presented where varying degrees of restructuring occurred. Figure 14 illustrates the microstructure of $84 \%$ dense $\left(U_{0.8} \mathrm{Pu}_{0.2}\right)_{1.95}$ subjected to a radial temperature gradient with a central temperature $>2400^{\circ} \mathrm{C}$ for 40 minutes. Extensive pore migration was evident in the center which extended to about $2200^{\circ} \mathrm{C}$. Had the test continued for a longer period, a mature columnar grain growth region would have formed.

Figure 15 shows the microstructure of $94.6 \%$ dense $\left(U_{0.8} P u_{0.2}\right)_{1.95}$ subjected to a radial temperature gradient with a center temperature $>2378^{\circ} \mathrm{C}$ for 20 minutes.

Barely perceptible evidence for pore migration above $2200^{\circ} \mathrm{C}$ was visible. The shorter test time combined with the higher density and smaller pore size served to inhibit pore movement to the extent that only negligible amounts were seen.

The minimum temperature observed for pore migration was somewhat higher than that observed for $\mathrm{UO}_{2}$ specimens subjected to similar treatments. Asamoto ${ }^{1}$ and Lawson ${ }^{13}$ have reported pore sweeping in $\mathrm{UO}_{2}$ at temperatures greater than $1950^{\circ} \mathrm{C}$. Possibly with longer heat treatments the mixed oxide would have exhibited pore migration at lower temperatures. However, the lower heavy metal-bearing vapor pressures in the hypostoichiometric mixed oxide tended to delay the kinetics of pore'migration to the extent that the onset of observable pore movement was permanently shifted to higher temperatures.

Figure 16 (a) and (b) compare the microstructures of test specimens prepared by different powder preparation methods. Figure $16(a)$ shows coprecipitated $87 \%$ dense $\left(U_{0.8} P_{0.2}\right)_{1.95}$ and Figure 16 (b) shows physically-mixed 94.6\% dense $\left(U_{0.8} P_{0.2}\right)_{1.95} \mathrm{O}$. Both figures indicated that, as a result of the small temperature gradient, little grain growth occurred. Grains of comparable characteristics were observed in the two figures, which represent regions of comparable temperature.

The microstructures shown in Figures 14, 15, and 16 can be considered typical of all the tests done in this study. 


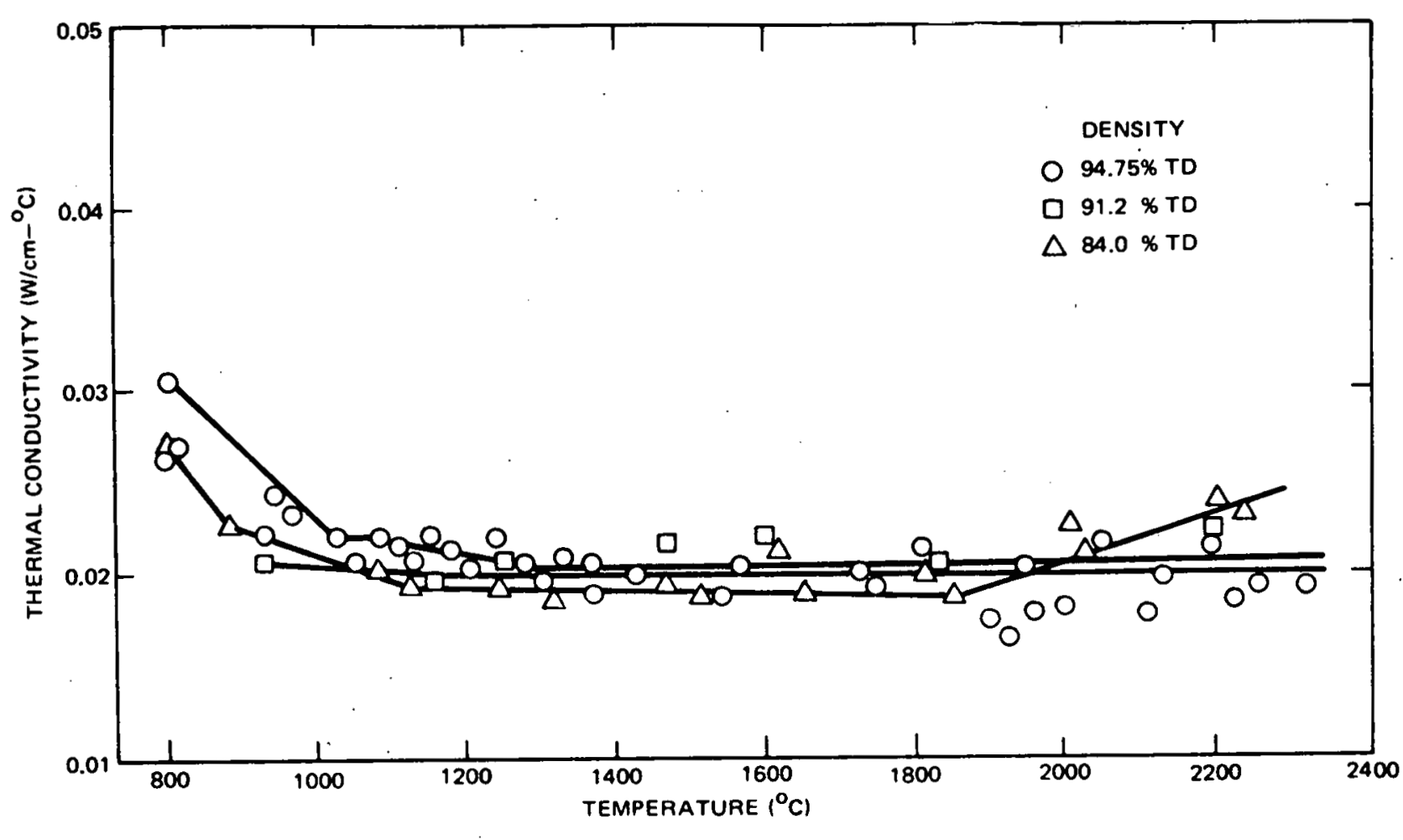

Figure 11. Effect of Density on Thermal Conductivity of $\left(U_{0.8^{P}} \mathrm{u}_{0.2}\right)_{1.95}$

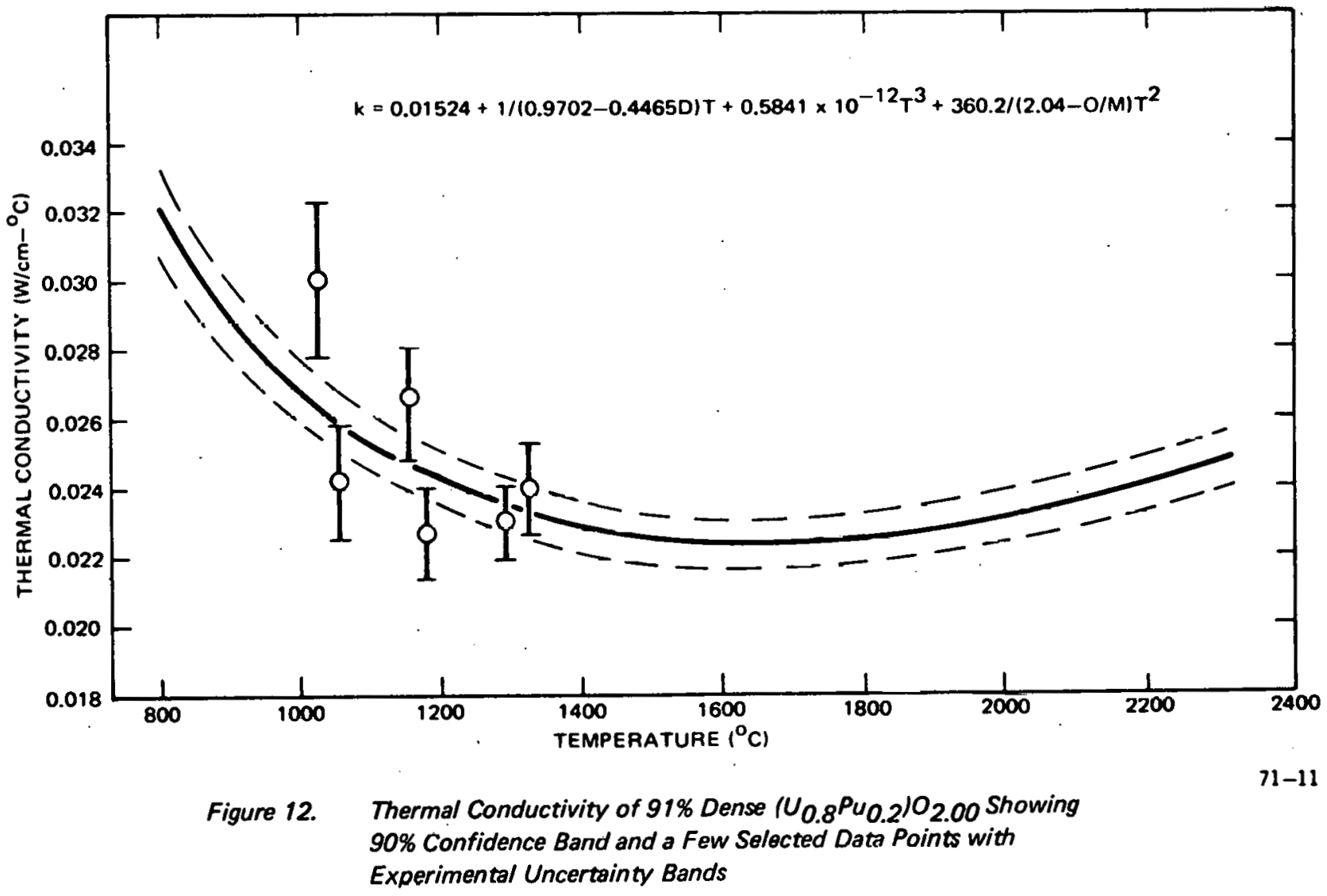




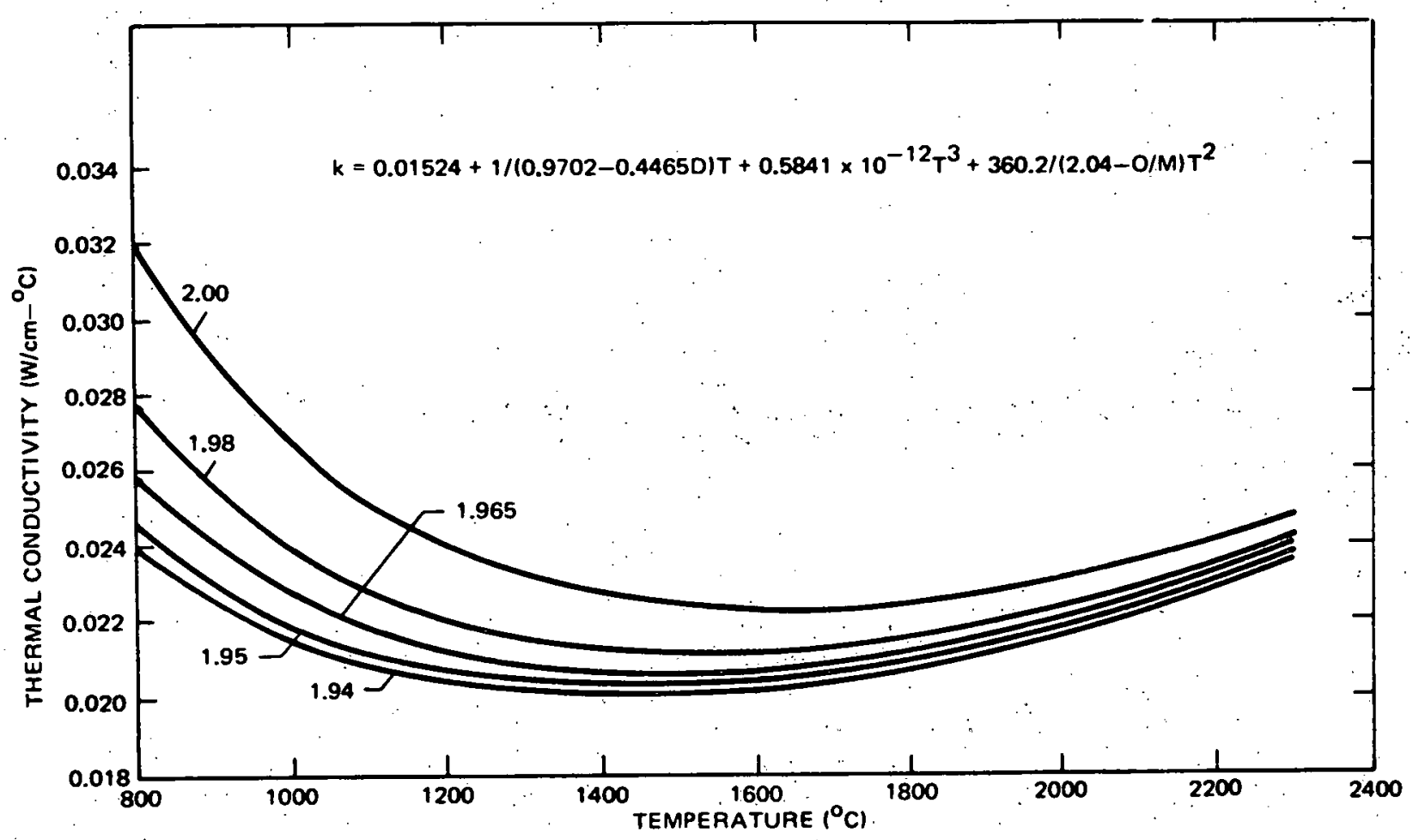

71-12

Figure 13. Effect of Stoichiometry on the Thermal Conductivity of 91\% Dense $\left(U_{0.8}{ }^{P} u_{0.2}\right) O_{2-x}$ 


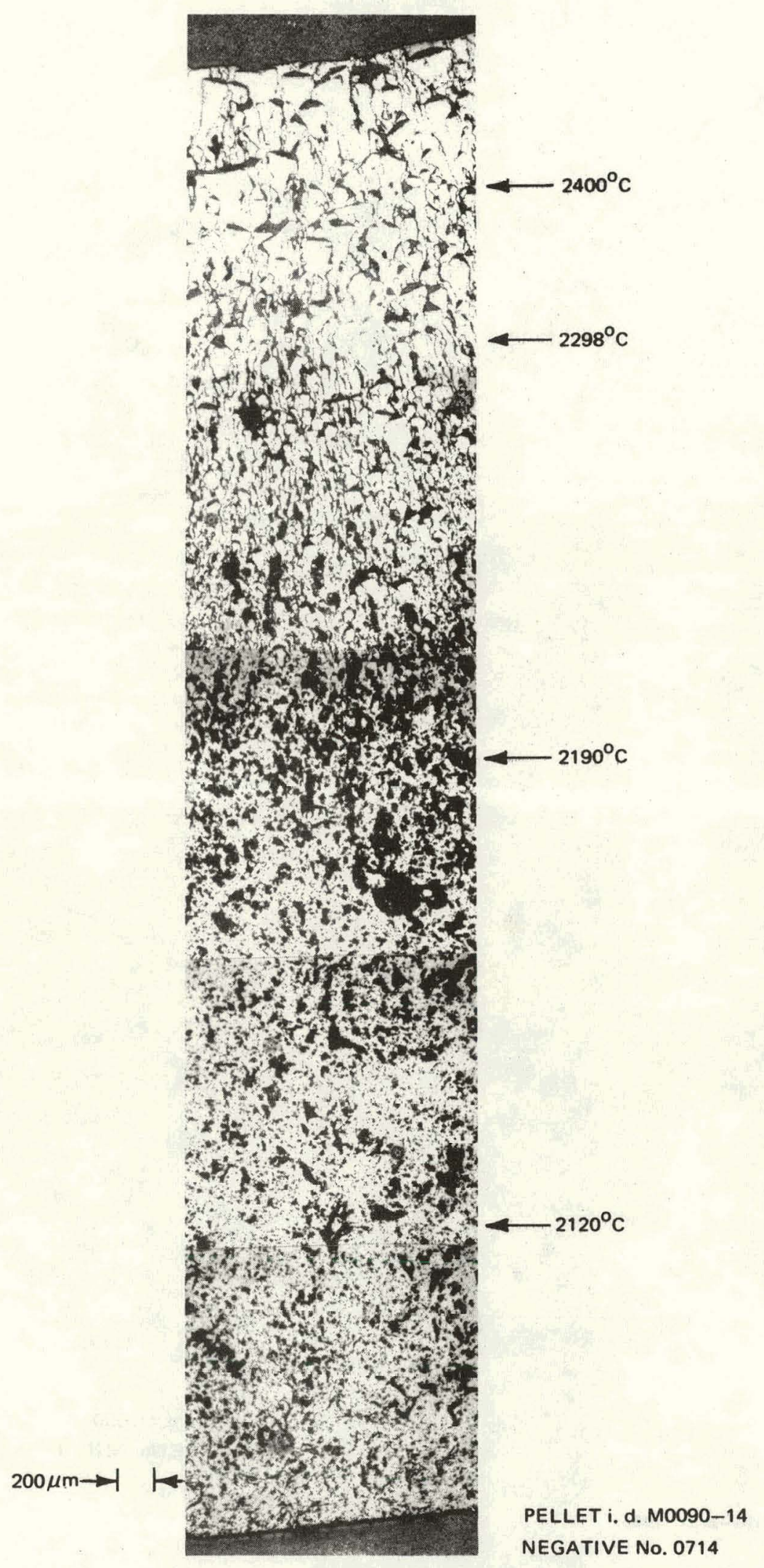

Figure 14. Post-Test Microstructure of $84 \%$ Dense $\left(U_{0.8} P_{0.2}\right)_{1.95}$ 
GEAP-13733

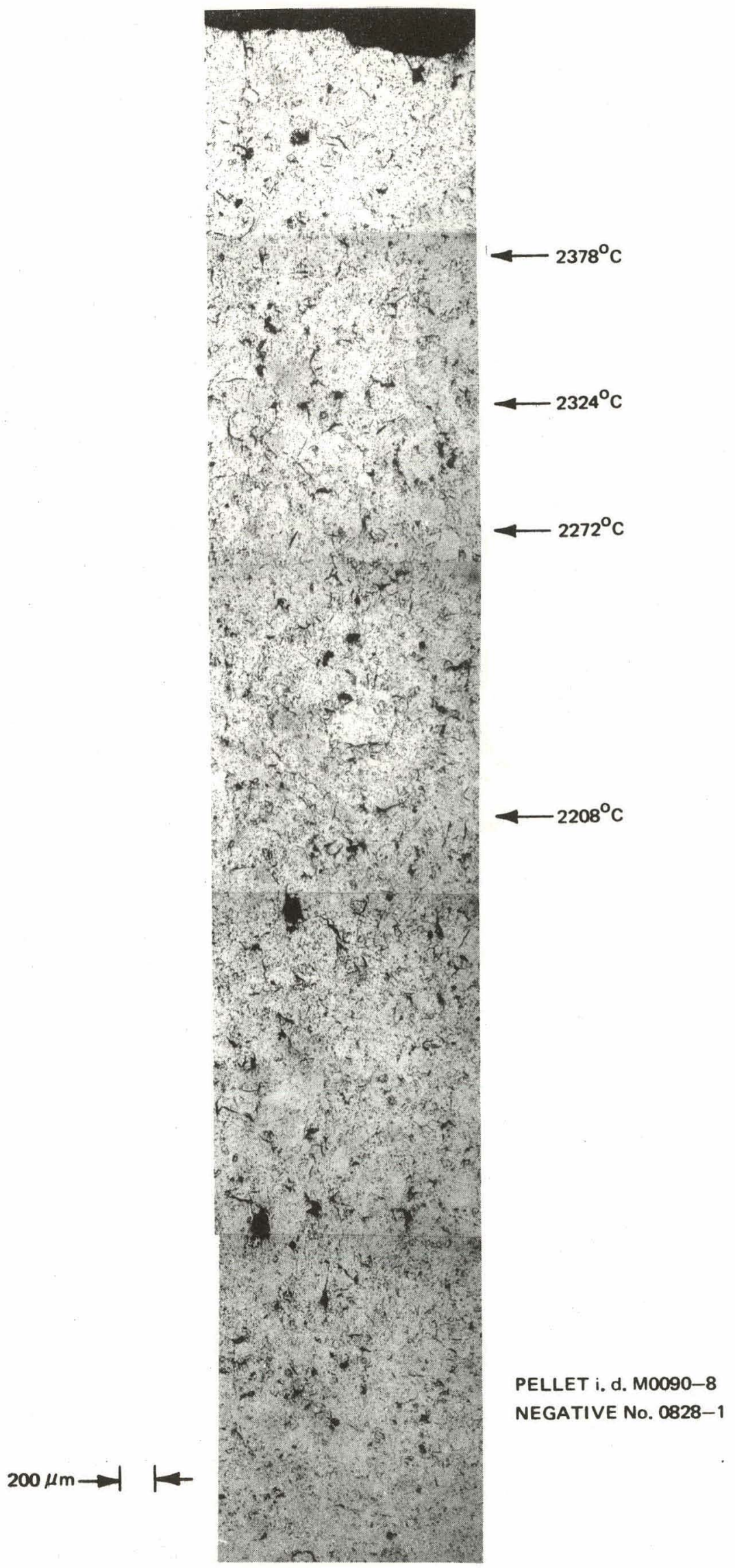

Figure 15. Post-Test Microstructure of $94.6 \%$ Dense $\left(U_{0.8} P_{0.2}\right)^{O} O_{1.95}$ 


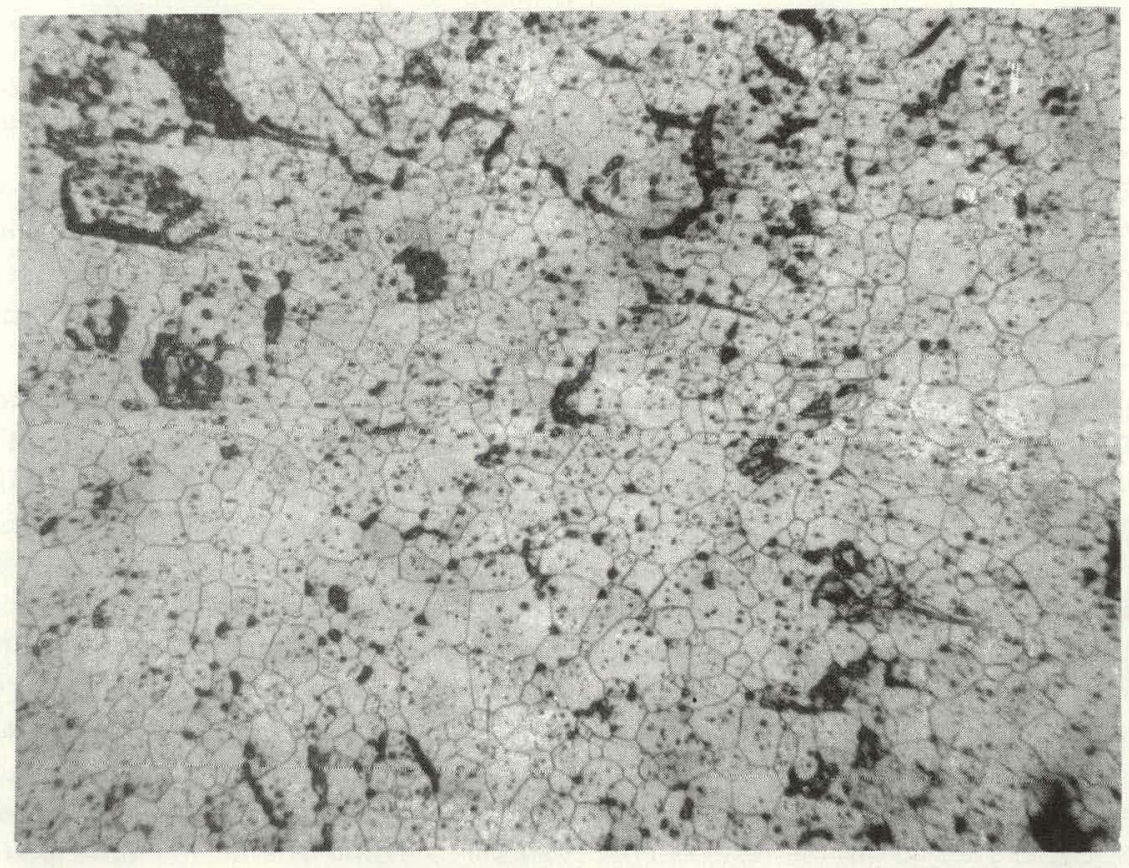

$250 x$

NEGATIVE No. 0827

(a) PREPARED AS COPRECIPITATED $87 \%$ T.D. $\left(U_{0.8} \mathrm{Pu}_{0.2}\right)^{\prime} \mathrm{O}_{1,965}$ PELLET i. d. B486-2

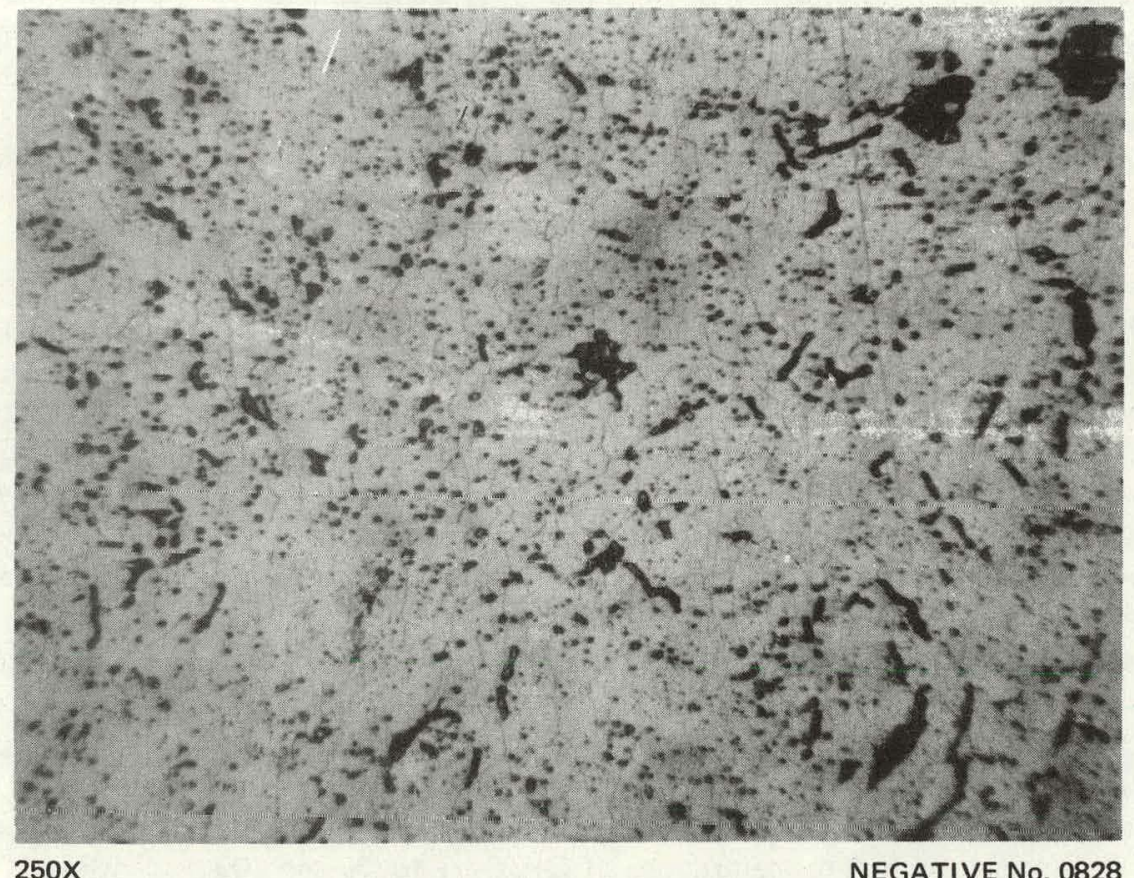

(b) PREPARED AS PHYSICALLY-MIXED 94.6\% T.D. $\left(U_{0.8} \mathrm{Pu}_{0.2}\right)_{1.95}$

PELLET i. d. M0090-8

Figure 16. Comparison of the Microstructures of Test Specimens 


\section{DATA ANALYSIS}

\subsection{METHOD OF DATA ANALYSIS}

Each test pellet had four black-body holes, and a maximum of five temperature measurements were taken at each of the holes. The current (I) through the tungsten rod was measured once for each run of sixty (maximum) temperature measurements. Attempts to measure the voltage through the tungsten rod were futile since the temperature (which thus determined the rod power by multiplying $E X$ I) was not uniform over the entire length of the rod. Rod temperature however was assumed to be uniform throughout the test pellet stack. Also, voltage tap connections to the tungsten rod were difficult to attain due to the high temperatures involved. A single test thus consisted of up to twenty temperature measurements for each pellet and up to three pellets per test. Black-body hole depth measurements $(r)$ were recorded before and after testing to an accuracy of \pm 1 mil. If a significant deviation in hole depth was found in a particular hole, the temperature data for that hole were deleted. The time of each temperature measurement was recorded at the beginning of each sequence of measurements (i.e., after twelve consecutive measurements).

The data taken from each set of up to four black-body holes was plotted as temperature versus log radius. This yielded up to twenty points in an approximate straight line, assuming a constant thermal conductivity yield a parabolic temperature profile in a cylindrical pellet. Inconsistencies in black-body hole depths (pellet radii) were recognized if points in these plots deviated from the best fit line. General consistency of the data was also judged from these plots, which formed a basis for deleting several tests (see Table 1). Since there were different fuel materials in each test column $\left(\mathrm{UO}_{2}\right.$ and $\mathrm{PuO}_{2}$ have different thermal conductivities) and because of general furnace heating variations, an axial temperature gradient existed across the test column. However, the only axial temperature gradient of importance was the one which existed across the length of each individual pellet. Measurements showed that this gradient could be a maximum of $10^{\circ} \mathrm{C}$, but usually only about $5^{\circ} \mathrm{C}$ over the entire length of a pellet. The resultant actual temperature gradient between black-body holes at equal depths was negligible. A least-squares line was fit through the data remaining using computer code technique. The code extrapolated the best-fit line through the origin $(r=0)$ or pellet inside diameter which determined the center temperature as well as the various $\Delta T$ 's and $\Delta r^{\prime}$ s for each pellet. This was done by next calculating the gap conductivity of the helium gas filling the space between the pellet's inside diameter and tungsten rod. ${ }^{14}$ Using this, the temperature drop between the pellet's inside diameter and tungsten rod were determined and the rod temperature, assumed to be uniform, was calculated. An empirical equation ${ }^{15}$ of resistance of unalloyed tungsten as a function of temperature was used to calculate the resistance of the tungsten rod which then yielded the power (Q) in the rod by means of the $Q=I^{2} R$ relation. The same value of $Q$ was used for all five observations at each black-body hole.

A least-squares line was fit through each set of up to four consecutive temperature measurements, one for each of the four black-body holes per pellet. Thirty seconds elapsed between consecutive temperature measurements, but about six minutes elapsed between measurements at the same hole. For up to five measurements per hole, up to five least-squares lines were obtained for each pellet. These least-squares plots consisted of lines of temperature versus log $r$ as before. Temperature differences were calculated from the equations of these least-squares lines, and using the slopes of the lines, up to five values of thermal conductivity $(k)$ were determined in a manner outlined in detail by Asamoto. ${ }^{1}$ The validity of such a procedure depended upon provisions which were made to hold the radial temperature differences between adjacent black-body holes to a maximum of about $50^{\circ} \mathrm{C}$ (see Section 4.4 ) so that a mean value of the thermal conductivity could be assumed within such a temperature region.

In such a manner, values for $\mathrm{k}$ were calculated for the various tests under varying conditions of temperature (as controlled by varying the power in the tungsten heater rod), $\mathrm{O} / \mathrm{M}$ ratio, and density. Only the results of tests $8(\mathrm{I}), 8(\mathrm{II})$, $8(I I I), 10$ and 11 (396 data points) were used to determine an empirical equation and comprise only $20 \% \mathrm{Pu}$ concentration fuel. Except for test numbers 3 and 7, test data prior to test number 8 (see Table 1) were not reported due to inconsistencies and/or uncertainties in the black-body holes measurements. Although the data of test numbers 3 , 7, 12 and 13 (which were for plutonium concentrations of $\mathrm{O}\left[\mathrm{UO}_{2}\right], 10,30$ and 100 percent) were not used to fit the empirical equation, they were, however, discussed in the results. These tests were not used for determining the equation because a consistent relationship between thermal conductivity and plutonium content for hypo-stoichiometric fuel could not be established.

In order to fit an equation to the $\mathbf{3 9 6}$ data points (see Appendix A for data listing) which were valid, a computer code was developed to perform a weighted regression analysis for a non-linear equation form. 
From experiments such as this, thermal conductivity of mixed oxide fuel has been found to be a function of several variables. These variables include: temperature, fuel density, plutonium content, and oxygen/metal (O/M) ratio. Theoretical models along with prior work set the guidelines for the general form of the equation:

where

$$
k=C_{1}+\frac{1}{\left(C_{2}-0.4465 D\right) T}+C_{3} T^{3}+\frac{C_{4}}{(2.04-O / M) T^{2}}
$$

$$
\begin{aligned}
k & =\text { thermal conductivity }\left(\text { watts } / \mathrm{cm} \cdot{ }^{\circ} \mathrm{C}\right) \\
T & =\text { temperature }\left({ }^{\circ} \mathrm{C}\right) \\
D & =\text { fractional density } \\
O / M & =\text { oxygen/metal ratio } \\
C_{i} & =\text { constants determined by data analysis }(i=1-4)
\end{aligned}
$$

The factor (0.4465) multiplying the density (D) in the second term of the equation was derived from prior work by Asamoto ${ }^{1}$ on $\mathrm{UO}_{2}$. Insufficient data prohibited the determination of such a factor for mixed oxide fuel here. The factor (2.04) in the denominator of the last term was determined empirically.

The $T^{3}$ term was required to produce the observed increase in thermal conductivity at high temperatures. Linear $(T)$ and $T^{2}$ relationships were tried first, but it was found that the $T^{3}$ relationship was the most satisfactory. Caution is noted regarding any extrapolation of the equation above $2300^{\circ} \mathrm{C}$ (i.e., above the upper limit of experimental data) which might result in an overprediction of the thermal conductivity as a result of this $T^{3}$ term.

A weighted regression analysis was required since not all data points were known with equal precision. Those at lower temperatures were less precise than at higher temperatures. This was due to experimental errors which are explained in Section 6.3.1. The computer code which was developed fit an equation of the form discussed here to the entire set of data by determining the constants $C_{i}$ such that the equation described the data to within acceptable limits (see Section 6.3). It is not the purpose of this report to give a detailed description of the mathematics which were involved. However, initial estimates for the constants $C_{i}$ were required for the curve-fitting analysis. These estimates were determined using both hand calculations and a generalized (non-weighted) curve fitting computer code. Only "ball-park" estimates were required and were easily obtained. These initial guesses were:

$$
C_{1}=0.01, C_{2}=0.5, C_{3}=1 \times 10^{-13} \text {, and } C_{4}=1.0 \times 10^{3}
$$

The variation of $k$ with various powers of $T$ was determined by noting trends on plots of $k$ versus $T$ as a function of $D, O / M$, etc. Intuition entered also, as in the case of the $C_{3} T^{3}$ term which was required to fit the curve to the high temperature data which showed a slight increase in $k$ as a function of $T$. The factor 2.04 in the last term was determined by hand calculations at first, but later it was allowed to float as a fifth constant in the computer calculatiuris and the value of 2.04 was confirmed.

The detailed weighted non-linear regression analysis yielded final values for the four constants of: $C_{1}=1.524 X$ $10^{-2}, C_{2}=0.9702, C_{3}=0.6841 \times 10^{-12}$ and $C_{4}=360.2$ to form the final equation reported here. The computer code also yielded statistical parameters which are discussed in Section 6.3, and a plotting routine was also included.

\subsection{DEGREE OF UNCERTAINTY IN RESULTS}

\subsubsection{Mixed Oxide Thermal Conductivity Experimental Error Analysis}

This analysis of errors in thermal conductivity measurements was based on the general probable error equatiun.

$$
P^{2}=\left(P_{x} \frac{\partial z}{\partial x}\right)^{2}+\left(P_{y} \frac{\partial z}{\partial y}\right)^{2}+\cdots
$$

when $z=f(x, y, \ldots)$ is the function for which the probable error is to be determined and $P_{x}, P_{y}, \ldots$ are the probable errors attached to the given variables.

The equation for thermal conductivity of a cylindrical material with radial heat flow is:

$$
K=\frac{Q}{2 \pi} \frac{\left(\operatorname{lnr_{2}}-\operatorname{lnr_{1})}\right.}{\left(T_{1}-T_{2}\right)}=\frac{Q}{2 \pi} \frac{\ln \left(r_{2} / r_{1}\right)}{\Delta T}
$$


The variables of interest are $Q, r_{1}, r_{2}$, and $\Delta T$.

The partial derivatives are:

$$
\begin{aligned}
& \frac{\partial K}{\partial Q}=\frac{\ln \left(r_{2} / r_{1}\right)}{2 \pi(\Delta T)} \\
& \frac{\partial K}{\partial r_{2}}=\frac{Q}{2 \pi \Delta T}\left(\frac{1}{r_{2}}\right) \\
& \frac{\partial K}{\partial r_{1}}=\frac{Q}{2 \pi \Delta T}\left(\frac{1}{r_{1}}\right) \\
& \frac{\partial K}{\partial(\Delta T)}=-\frac{Q}{2 \pi} \ln \left(r_{2} / r_{1}\right)\left[\frac{1}{(\Delta T)^{2}}\right]
\end{aligned}
$$

and the error equation becomes:

$$
P^{2}=P_{Q}^{2}\left[\frac{\ln \left(r_{2} / r_{1}\right)}{2 \pi \Delta T}\right]^{2}+P_{r_{2}}^{2}\left(\frac{Q}{2 \pi(\Delta T) r_{2}}\right)^{2}+P_{i_{1}}^{2}\left(\frac{Q}{2 \pi(\Delta T) r_{1}}\right)^{2}+P_{\Delta T}^{2}\left(\frac{Q \ln \left(r_{2} / r_{1}\right)^{2}}{2 \pi(\Delta T)^{2}}\right)^{2}
$$

Consider first the probable error in power (Q) determined by errors in assignment of the tungsten rod temperature (the actual voltage and current measurements were known to a higher order of precision).'

The temperature drop between the tungsten rod and the fuel inside diameter was largely determined by the $\mathrm{He}$ gas conduction in the gap. The thermal conductivity of $\mathrm{He}$ at various temperatures was calculated from equations given by Hirschfelder. ${ }^{14}$

The results of these calculations are shown below:

$\begin{array}{cc}\mathrm{T}^{\circ} \mathrm{K} & \mathrm{K}_{\mathrm{He}}\left(\text { watts } / \mathrm{cm}^{\circ} \mathrm{K}\right) \\ 1000 & 3.41 \times 10^{-3} \\ 1500 & 4.60 \times 10^{-3} \\ 2000 & 5.33 \times 10^{-3} \\ 2500 & 6.19 \times 10^{-3}\end{array}$

The error in power $(Q)$ was calculated as follows: The $\mathrm{UO}_{2}$ data from tests 8 and 13 were compared with Asamoto's $\mathrm{s}^{2}$. data, finding that difference between data was no more than 0.00125 at $800^{\circ} \mathrm{C}$. Since $\mathrm{K}_{\mathrm{UO}_{2}} \approx 0.04$, then for this data $\mathrm{KUO}_{2} \approx 0.04 \pm 0.00125$ which represents a $3.1 \%$ error at $800^{\circ} \mathrm{C}$. This corresponded to a temperature error at the tungsten rod of $\pm 25^{\circ} \mathrm{C}$. The gap width between the rod and the pellets was calculated for a total temperature drop of $50^{\circ} \mathrm{C}$ as follows:

$$
\ln r_{2}=\ln r_{1}+\left(\frac{2 \pi K}{Q_{L}}\right) \Delta T_{g a p}
$$

where $K$ is conductivity of $H e$, using a hypothetical $Q_{L}$ which remained constant for this gap analysis.

$$
\begin{aligned}
& \ln r_{2}=\ln (0.0938 \times 2.59)+\frac{2 \pi \times 3 \times 10^{-3} \times 50}{50} \\
& \ln r_{2}=\ln (0.238)+1.88 \times 10^{-2} \\
& \ln \left(\frac{r_{2}}{r_{1}}\right)=1.88 \times 10^{-2} \\
& \frac{r_{2}}{r_{1}}=e^{1.88 \times 10^{-2}}=1.01005 \times 1.0088=1.019 \\
& r_{2}=1.019 \times 0.0938=0.0956
\end{aligned}
$$

or a gap of 1.8 mils on the average. Using this gap and a $Q_{L}$ of 50 watts $/ \mathrm{cm}:{ }^{\circ} \mathrm{C}, \Delta T$ 's were calculated for higher tem. peratures using adjusted $\mathrm{K}_{\mathrm{He}}$ values as well. 
Once the temperature drops across the gap were known for each rod temperature, the error in rod temperature was calculated as

$$
\pm \frac{\Delta T_{\text {gap }}}{2 T_{\text {rod }}}
$$

Since the resistivity of tungsten varied linearly with temperature, this error was also the error in linear power, which is plotted in Figure 17 as $\mathrm{PQ}$.

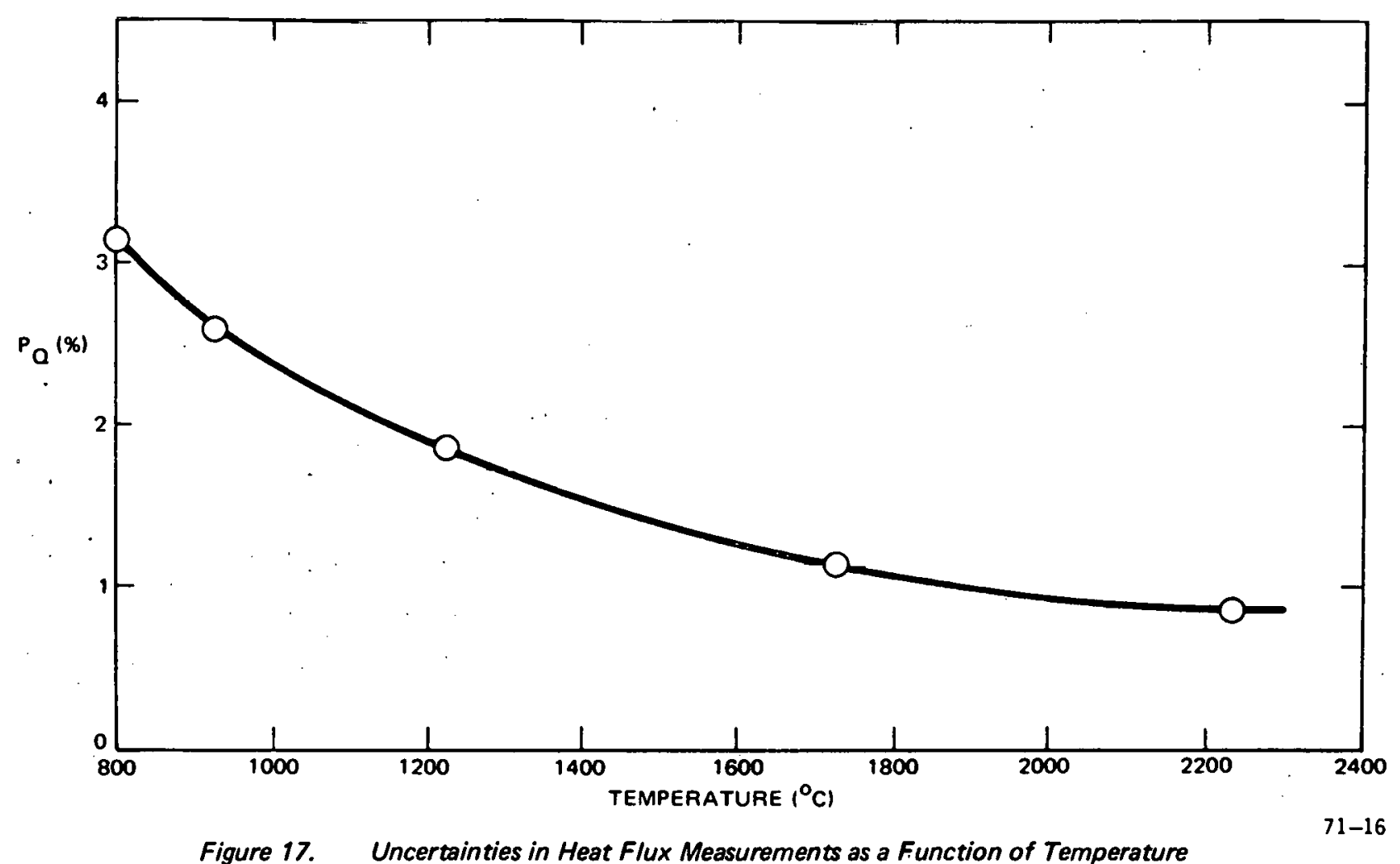

Errors due to the uncertainty in $\Delta T$ between measured points were also present and comparable to the error in $Q$, but to be conservative, the entire error was attributed to uncertainties in $Q$. This yielded a value for the $\Delta T$ across the gap at $800^{\circ} \mathrm{C}$ of $50^{\circ} \mathrm{C}$. Using this $\Delta \mathrm{T}$ and the conductivity values for He as a function of temperature, an effective gap width was calculated. Then new $\Delta T$ and error values were calculated. The results of these calculations are shown in Figure 17.

The probable errors in the radii of black-body holes were calculated on the basis of $\operatorname{Pr}_{1}=\operatorname{Pr}_{2}= \pm 1 \mathrm{mil}$.

The probable errors in $\Delta T$ were found based upon the reproduribility of individual temperature measurements using optical pyrometry. It has been shown that measurements such as these are reproducible (i.e., the variation among a series of temperature measurements at the same point compared with the one most often obtained) to within $\pm 3^{\circ} \mathrm{C}$. $^{2}$ There may well have been a systematic error in the temperature measurements. If a black-body cavity (hole) started out with a temperature not constant over its surface, it could be postulated that radiative transfer would have brought the walls close to a uniform temperature. If such a mechanism existed, then the temperature measured would have been lower than the maximum temperature without radiative transfer. Such a systematic error would not affect $\Delta T$ however. The variation in the absolute values of individual optical pyrometer measurements has been shown to be $\pm 2 \%$ up to $2000^{\circ} \mathrm{C}$ and $\pm 3 \%$ between $2000^{\circ} \mathrm{C}$ and $2400^{\circ} \mathrm{C}$. ${ }^{1}$ The probable error in $\Delta T$, called $P_{\Delta T}$, was then just the square root of the sum of the squares of the error in reproducibility for two temperature measurements, $\pm\left(3^{2}+3^{2}\right)^{1 / 2{ }^{\circ} \mathrm{C}, \text { or }}$ about $\pm 4^{\circ} \mathrm{C}$. 
Then the squares of all the error terms were summed and the resulting probable error in $K$ was the square root of that sum. It can be noted here however, with respect to the relative importance of the sources of experimental error, that the error due to uncertainties in $Q$ was more than one order of magnitude greater than the errors due to uncertainties in either black-body hole depth or $\Delta T$.

\subsubsection{Confidence Limits}

The weighted regression analysis which was used to fit an equation to the data reported here was designed to also calculate a $90 \%$ confidence band on the equation. The computer code combined the experimental error associated with each data point (which were used as "veighting factors") with the error involved the deviations of each data point from the regression line. Results are tabulated in. Appendix B, and it was apparent that the width of the confidence band at each data point was not the same since the experimental conditions varied.

The "independent variable" listed is temperature and the "dependent variable" is thermal conductivity. Percent error width for each data point is listed in the final column. The $90 \%$ confidence limits were placed on the equation determined using one-half the mean value of the percent error widths of all 396 data points.. This in effect gave a reasonably conservative $90 \%$ confidence band of uniform width for the entire equation. It must be remembered that not all data points need to fall within a $90 \%$ confidence band. This is especially true in a weighted regression analysis like the one which was done here, since some points were known more precisely than others.

\section{CONCLUSIONS}

1. The thermal conductivity of $(0.2 \mathrm{Pu}-0.8 \mathrm{U}) \mathrm{O}_{2-\mathrm{x}}$ was found to be a function of several variables. The equation is

where

$$
k=0.01524+\frac{1}{(0.9702-0.4465 \mathrm{D}) \mathrm{T}}+\left(0.5841 \times 10^{-12}\right) \mathrm{T}^{3}+\frac{360.2}{(2.04-\mathrm{O} / \mathrm{M}) \mathrm{T}^{3}}
$$

$$
\begin{aligned}
K & \left.=\text { thermal conductivity (watts } / \mathrm{cm}-{ }^{\circ} \mathrm{C}\right) \\
T & =\text { temperature }\left(800 \text { to } 2300^{\circ} \mathrm{C}\right) \\
\mathrm{D} & =\text { fractional density }(0.84 \text { to } 0.91) \\
\mathrm{O} / \mathrm{M} & =\text { oxygen/metal ratio }(1.940 \text { to } 2.000)
\end{aligned}
$$

2. The thermal conductivity of mixed oxide fuel was found to increase slightly at temperatures greater than about $1800^{\circ} \mathrm{C}$.

3. For design purposes, $90 \%$ confidence limits of $\pm 11 \%$ may be applied to the above equation as determined by a weighted regression analysis.

4. The application of the out-of-pile thermal conductivity data from this experiment to in-pile usage requires additional input from integral to melt thermal conductivity data to ensure that the required boundary conditions are fully met. ${ }^{16,17}$ 


\section{ACKNOWLEDGMENTS}

The authors wish to thank W. E. Baily, R. N. Duncan and C. N. Spalaris for their direction and encouragement during the course of this investigation; T. F: Green, G. E. Valley Forge Space Center, Philadelphia, Pa. for his development of the weighted non-linear regression analysis code; C. R. Mijares and N. R. McBurney for their assistance in the computer analysis of the data; M. L. Thompson for his supervision of the test fuel fabrication; and D. C. Common and R. H. Cummings, who performed the laboratory measurements.

\section{REFERENCES}

1. Asamoto, R. R., Anselin, F. L., and Conti, A. E., The Effect of Density on the Thermal Conductivity of Uranium Dioxide, April 1968 (GEAP-5493).

2. Hetzler, F. J., Lannin, T. E., Perry, K. J., and Zebroski, E. L., The Thermal Conductivity of Uranium and Uranium-Plutonium Oxides, August 1967 (GEAP-4879).

3. Schmidt, H. E., and Richter, J., The Influence of Stoichiometry on the Thermal Conductivity of $\left(U_{0.8} P u_{0.2}\right)^{\prime} O_{2 \pm x}$ Oxide Fuel Thermal Conductivity Symposium, Stockholm, Sweden, June 1, 1967.

4. Gibby, R. L., "The Effect of Plutonium Content on the Thermal Conductivity of $(U, P u) \mathrm{O}_{2}$ Solid Solutions," J. Nucl. Mat. 38: 163-177 (1971).

5. Van Craeynest, J. C., and Weilbacher, J. C., Etude De La Conductibilite Thermique Des Oxydess Mixtes D'Uranium Et De Plutonium, J. Nucl. Mat. 26: 132-136 (1968).

6. Baily, W. E., et al., Thermal Conductivity of Uranium-Plutonium Oxide Fuels, Nuclear Metallurgy, Volume 13, International Symposium on Plutonium Fuels Technology. Proceedings of the 1967 Nuclear Metallurgy Symposium, Scottsdale, Arizona, October 4-6, 1967, AlME.

7. Gibby, R. L., The Effect of Oxygen Stoichiometry on the Thermal Diffusivity and Conductivity of

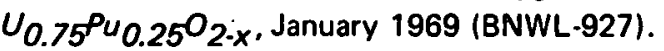

8. Ainscough, J. B., "The Effect of Electrical Conduction in $\mathrm{UO}_{2}$ on the Measurements of its High Temperature Thermal Conductivity as Determined by Radial Flow Techniques," J. Nucl. Mat. 20, pp. 184-192 (1966).

9. Schmidt, H. E., "Some Considerations on the Thermal Conductivity of Stoichiometric Uranium Dioxide at High Temperatures," J. Nucl. Mat. 39:pp. 234-237 (1971).

10. Kruger, O. L., Savage, H., "Heat Capacity and Thermodynamic Properties of Plutonium Dioxide," J. of Chemical Physics (49) 4540 (1968).

11. Hein, R. A., and Flagella, P. N., Enthalpy Measurements of $U O_{2}$ and Tungsten to $3260^{\circ}$ K, February 16,1968 , (GEMP-578).

12. Ogard, A. E., and Leary, J. A., High Temperature Heat Content and Heat Capacity of Uranium Dioxide and Uranium Dloxide-Plutonium Dioxide Solid Solutions, LA-DC-8620 (1967).

13. Lawson, V. B., and MacEwan, J. R., Thermal Simulation Experiments with a $\mathrm{UO}_{2}$ Fuel Rod Assembly, March 1960 (CRFD-915).

14. Hirschfelder, J. O., et al., Molecular Theory of Gases and Liquids, John Wiley \& Sons, Inc., New York, New York, (1954), p. 534.

15. Feith, A. D., The Thermal Conductivity and Electrical Resistivity of Tungsten-26 Weight Percent Rhenium, 1967 (GEMP-562).

16. Craig, C. N., and Baily, W. E., In-Pile Comparison of Effective Thermal Conductivity of $\left(\mathrm{PuO}_{2}-\mathrm{UO}_{2}\right)$ Mixed Oxides, January 1988 (GEAP-5556).

17. Cantley, D. A., Rubin, B. F., and Craig, C. N., Stoichiometric Effects on the Integrated Thermal Conductivity of Mixed Oxide Fuels, to be published (GEAP-13734). 


\section{APPENDIX A. DATA}

The tables, found in Appendix $A$ contain the following information: thermal conductivity $\left(K, W / \mathrm{cm}-{ }^{\circ} \mathrm{C}\right)$, temperature $\left({ }^{\circ} \mathrm{C}\right)$. fractional density, fractional plutonium content, test number, and a data point reference number. For the $20 \%$ Pu data, the weighting factors used for the weighted non-linear regression analysis have been included.

Each table of data has been plotted with a figure number corresponding to the data tables. In the figures with $20 \%$ Pu data a smooth curve of the empirical equation has been plotted. 
Table A-1

TEST 8 (PART I) DATA

\begin{tabular}{|c|c|c|c|c|c|c|c|}
\hline K & $\begin{array}{c}\text { Temperature } \\
\left({ }^{\circ} \mathrm{C}\right)\end{array}$ & Density & $\mathrm{O} / \mathrm{M}$ & Pu & Weight & $\begin{array}{c}\text { Test } \\
\text { Number }\end{array}$ & Number \\
\hline 0.0202 & 954 & 0.91 & 1.940 & 0.20 & 0.001892 & 8.201 & 0001 \\
\hline 0.0199 & 953 & 0.91 & 1.940 & 0.20 & 0.001863 & 8.201 & 0002 \\
\hline 0.0200 & 951 & 0.91 & 1.940 & 0.20 & 0.001873 & 8.201 & 0003 \\
\hline 0.0200 & 948 & 0.91 & 1.940 & 0.20 & 0.001873 & 8.201 & 0004 \\
\hline 0.0199 & 946 & 0.91 & 1.940 & 0.20 & 0.001863 & 8.201 & 0005 \\
\hline 0.0193 & 1125 & 0.91 & 1.940 & 0.20 & 0.001195 & 8.202 & 0006 \\
\hline 0.0192 & 1126 & 0.91 & 1.940 & 0.20 & 0.001189 & 8.202 & 0007 \\
\hline 0.0193 & 1126 & 0.91 & 1.940 & 0.20 & 0.001195 & 8.202 & 0008 \\
\hline 0.0195 & 1126 & 0.91 & 1.940 & 0.20 & 0.001207 & 8.202 & 0009 \\
\hline 0.0197 & 1125 & 0.91 & 1.940 & 0.20 & 0.001220 & 8.202 & 0010 \\
\hline 0.0195 & 1202 & 0.91 & 1.940 & 0.20 & 0.001045 & 8.203 & 0011 \\
\hline 0.0196 & 1203 & 0.91 & 1.940 & 0.20 & 0.001051 & 8.203 & 0012 \\
\hline 0.0192 & 1205 & 0.91 & 1.940 & 0.20 & 0.001029 & 8.203 & 0013 \\
\hline 0.0193 & 1203 & 0.91 & 1.940 & 0.20 & 0.001035 & 8.203 & 0014 \\
\hline 0.0194 & 1204 & 0.91 & 1.940 & 0.20 & 0.001040 & 8.203 & 0015 \\
\hline 0.0200 & 1347 & 0.91 & 1.940 & 0.20 & 0.000892 & 8.204 & 0016 \\
\hline 0.0197 & 1348 & 0.91 & 1.940 & 0.20 & 0.000878 & 8.204 & 0017 \\
\hline 0.0196 & 1346 & 0.91 & 1.940 & 0.20 & 0.000874 & 8.204 & 0018 \\
\hline 0.0199 & 1347 & 0.91 & 1.940 & 0.20 & 0.000887 & 8.204 & 0019 \\
\hline 0.0195 & 1347 & 0.91 & 1.940 & 0.20 & 0.000870 & 8.204 & 0020 \\
\hline 0.0210 & 895 & 0.91 & 1.940 & 0.20 & 0.001974 & 8.301 & 0021 \\
\hline 0.0213 & 893 & 0.91 & 1.940 & 0.20 & 0.002002 & 8.301 & 0022 \\
\hline 0.0207 & 893 & 0.91 & 1.940 & 0.20 & 0.001946 & 8.301 & 0023 \\
\hline 0.0213 & 892 & 0.91 & 1.940 & 0.20 & 0.002002 & 8.301 & 0024 \\
\hline 0.0216 & 890 & 0.91 & 1.940 & 0.20 & 0.002030 & 8.301 & 0025 \\
\hline 0.0236 & 1076 & 0.91 & 1.940 & 0.20 & 0.001476 & 8.302 & 0026 \\
\hline 0.0236 & 1076 & 0.91 & 1.940 & 0.20 & 0.001476 & 8.302 & 0027 \\
\hline 0.0233 & 1077 & 0.91 & 1.940 & 0.20 & 0.001457 & 8.302 & 0028 \\
\hline 0.0236 & 1077 & 0.91 & 1.940 & 0.20 & 0.001476 & 8.302 & 0029 \\
\hline 0.0239 & 1077 & 0.91 & 1.940 & 0.20 & 0.001494 & 8.302 & 0030 \\
\hline 0.0229 & 1155 & 0.81 & 1.940 & 0.20 & 0.001276 & 8.303 & 0031 \\
\hline 0.0226 & 1157 & 0.91 & 1.940 & 0.20 & 0.001259 & 8.303 & 0032 \\
\hline 0.0223 & 1156 & 0.91 & 1.940 & 0.20 & 0.001243 & 8.303 & 0033 \\
\hline 0.0223 & 1157 & 0.91 & 1.940 & 0.20 & 0.001243 & 8.303 & 0034 \\
\hline 0.0223 & 1157 & 0.91 & 1.940 & 0.20 & 0.001243 & 8.303 & 0035 \\
\hline 0.0207 & 1296 & 0.91 & 1.940 & 0.20 & 0.000911 & 8.304 & 0036 \\
\hline 0.0207 & 1297 & 0.91 & 1.940 & 0.20 & 0.000911 & 8.304 & 0037 \\
\hline 0.0211 & 1297 & 0.91 & 1.940 & 0.20 & 0.000929 & 8.304 & 0038 \\
\hline 0.0211 & 1296 & 0.91 & 1.940 & 0.20 & 0.000929 & 8.304 & 0039 \\
\hline 0.0211 & 1297 & 0.911 & 1.940 & 0.20 & 0.000929 & 8.304 & 0040 \\
\hline
\end{tabular}


GEAP-13733

Table A-2

TEST 8 (PART I):DATA

\begin{tabular}{|c|c|c|c|c|c|c|c|}
\hline K & $\begin{array}{c}\text { Temperature } \\
\left({ }^{\circ} \mathrm{C}\right)\end{array}$ & Density & $\mathrm{O} / \mathrm{M}$ & $\mathbf{P u}$ & Weight & $\begin{array}{c}\text { Test } \\
\text { Number }\end{array}$ & Number \\
\hline 0.0224 & 1295 & 0.91 & 1.950 & 0.20 & 0.001312 & 8.205 & 0001 \\
\hline 0.0215 & 1283 & 0.91 & 1.950 & 0.20 & 0.001259 & 8.205 & 0002 \\
\hline 0.0209 & 1284 & 0.91 & 1.950 & 0.20 & 0.001224 & 8.205 & 0003 \\
\hline 0.021 .1 & 1282 & 0.91 . & 1.950 & 0.20 & 0.001236 & $8: 205$ & 0004 \\
\hline 0.0209 & 1284 & 0.91. & 1.950 & 0.20 & 0.001224 & 8.205 & 0005 \\
\hline 0.0217 & 1175 & 0.91 & 1.950 & 0.20 & 0.001151 & 8.206 & 0006 \\
\hline 0.0213 & 1172 & 0.91 & 1.950 & 0.20 & 0.001130 & 8.206 & 0007 \\
\hline 0.0214 & 1171. & 0.91 & 1.950 & 0.20 & 0.001135 & 8.206 & 0008 \\
\hline 0.0214 & 1172 & 0.91 & 1.950 & 0.20 & 0.001135 & 8.206 & 0009 \\
\hline 0.0210 & 1172 & 0.91 & 1.950 & 0.20 & 0.001114 & 8.206 & 0010 \\
\hline 0.0216 & 1046 & 0.91 & 1.950 & 0.20 & 0.001513 & 8.207 & 0011 \\
\hline 0.0210 & 1044 & 0.91 & 1.950 & 0.20 & 0.001471 & 8.207 & 0012 \\
\hline 0.0215 & 1044 & 0.91 & 1.950 & 0.20 & 0.001506 & 8.207 & 0013 \\
\hline 0.0213 & 1042 & 0.91 & 1.950 & 0.20 & 0.001492 & 8.207 & 0014 \\
\hline 0.0212 & 1042 & 0.91 & 1.950 & 0.20 & 0.001485 & 8.207 & 0015 \\
\hline 0.0220 & 891 & 0.91 & 1.950 & 0.20 & 0.002110 & 8.208 & 0016 \\
\hline 0.0224 & 891. & 0.91 & 1.950 & 0.20 & 0.002148 & 8.208 & 0017 \\
\hline 0.0223 & 890 & 0.91 & 1.950 & 0.20 & 0.002138 & 8.208 & 0018. \\
\hline 0.0222 & 890 & 0.91 & 1.950 & 0.20 & 0.002129 & 8.208 & 0019 \\
\hline 0.0215 & 890 & 0.91 & 1.950 & 0.20 & 0.002062 & 8.208 & 0020 \\
\hline 0.0246 & 1147 & 0.91 & 1.950 & 0.20 & 0.001361 & 8.306 & 0021 \\
\hline 0.0246 & 1145 & 0.91 & 1.950 & 0.20 & 0.001361 & 8.306 & 0022 \\
\hline 0.0253 & 1145 & 0.91 & 1.950 & 0.20 & 0.001399 & 8.306 & 0023 \\
\hline 0.0249 & 1146 & 0.91 & 1.950 & 0.20 & 0.001377 & 8.306 & 0024 \\
\hline 0.0249 & 1146 & 0.9 .1 & 1.950 & 0.20 & 0.001377 & 8.306 & 0025 \\
\hline 0.0253 & 1021. & 0.91 & 1.950 & 0.20 & 0.002104 & 8.307 & 0026 \\
\hline 0.0274 & 1016 . & 0.91 & 1.950 & 0.20 & 0.002279 & 8.307 & 0027 \\
\hline 0.0274 & 1017 & 0.91 & 1.950 & 0.20 & 0.002279 & 8.307 & 0028 \\
\hline 0.0270 & 1016 & 0.91 & 1.950 & 0.20 & 0.002245 & 8.307 & 0029 \\
\hline 0.0274 & 1017 & 0.91 & 1.950 & 0.20 & 0.002279 & 8.307 & 0030 \\
\hline 0.0296 & 868 & 0.91 & 1.950 & $0: 20$ & 0.003033 & 8.308 & 0031 \\
\hline 0.0280 & 866 & 0.91 & 1.950 & 0.20 & 0.002869 & 8.308 & 0032 \\
\hline 0.0285 & 865 & 0.91 & 1.950 & 0.20 & 0.002920 & 8.308 & 0033 \\
\hline 0.0291 & 866 . & 0.91 & 1.950 & 0.20 & 0.002892 & 8.308 & 0034 \\
\hline 0.0285 & 864 & 0.91 & 1.950 & 0.20 & 0.002920 & 8.308 & 0035 \\
\hline
\end{tabular}


Table A-3

TEST 8 (PART II) DATA

\begin{tabular}{|c|c|c|c|c|c|c|c|}
\hline K & $\begin{array}{c}\text { Temperature } \\
{ }^{\circ} \mathrm{C} \text { Cl }\end{array}$ & Density & $O / M$ & $\mathbf{P u}$ & Weight & $\begin{array}{c}\text { Test } \\
\text { Number }\end{array}$ & Number \\
\hline 0.0229 & 1446 & 0.91 & 1.980 & 0.20 & 0.000856 & 8.209 & 0001 \\
\hline 0.0227 & 1445 & 0.91 & 1.980 & 0.20 & 0.000849 & 8.209 & 0002 \\
\hline 0.0227 & 1445 & 0.91 & 1.980 & 0.20 & 0.000849 & 8.209 & 0003 \\
\hline 0.0224 & 1445 & 0.91 & 1.980 & 0.20 & 0.000838 & 8.209 & 0004 \\
\hline 0.0227 & 1445 & 0.91 & 1.980 & 0.20 & 0.000849 & 8.209 & 0005 \\
\hline 0.0220 & 1309 & 0.91 & 1.980 & 0.20 & 0.001001 & 8.210 & 0006 \\
\hline 0.0219 & 1309 & 0.91 & 1.980 & 0.20 & 0.000996 & 8.210 & 0007 \\
\hline 0.0222 & 1307 & 0.91 & 1.980 & 0.20 & 0.001010 & 8.210 & 0008 \\
\hline 0.0222 & 1308 & 0.91 & 1.980 & 0.20 & 0.001010 & 8.210 & 0009 \\
\hline 0.0218 & 1308 & 0.91 & 1.980 & 0.20 & 0.000992 & 8.210 & 0010 \\
\hline 0.0236 & 1160 & 0.91 & 1.980 & 0.20 & 0.001380 & 8.211 & 0011 \\
\hline 0.0242 & 1159 & 0.91 & 1.980 & 0.20 & 0.001415 & 8.211 & 0012 \\
\hline 0.0240 . & 1158 & 0.91 & 1.980 & 0.20 & 0.001404 & 8.211 & 0013 \\
\hline 0.0239 & 1158 & 0.91 & 1.980 & 0.20 & 0.001398 & 8.211 & 0014 \\
\hline 0.0242 & 1157 & 0.91 & 1.980 & 0.20 & 0.001415 & 8.211 & 0015 \\
\hline 0.0259 & 1027 & 0.91 & 1.980 & 0.20 & 0.001953 & 8.212 & 0016 \\
\hline 0.0259 & 1026 & 0.91 & 1.980 & 0.20 & 0.001953 & 8.212 & 0017 \\
\hline 0.0261 & 1027 & 0.91 & 1.980 & 0.20 & 0.001968 & 8.212 & 0018 \\
\hline 0.0259 & 1027 & 0.91 & 1.980 & 0.20 & 0.001953 & 8.212 & 0019 \\
\hline 0.0259 & 1025 & 0.91 & 1.980 & 0.20 & 0.001953 & 8.212 & 0020 \\
\hline 0.0260 & 875 & 0.91 & 1.980 & 0.20 & 0.002744 & $8.2,13$ & 0021 \\
\hline 0.0267 & 873 & 0.91 & 1.980 & 0.20 & 0.002818 & 8.213 & 0022 \\
\hline 0.0266 & 872 & 0.91 & 1.980 & 0.20 & 0.002807 & 8.213 & 0023 \\
\hline 0.0267 & 872 & 0.91 & 1.980 & 0.20 & 0.002818 & 8.213 & 0024 \\
\hline 0.0267 & 872 & 0.91 & 1.980 & 0.20 & 0.002818 & 8.213 & 0025 \\
\hline 0.0210 & 1440 & 0.91 & 1.970 & 0.20 & 0.000796 & 8.309 & 0026 \\
\hline 0.0210 & 1440 & 0.91 & 1.980 & 0.20 & 0.000796 & 8.309 & 0027 \\
\hline 0.0208 & 1439 & 0.91 & 1.980 & 0.20 & 0.000789 & 8.309 & 0028 \\
\hline 0.0210 & 1439 & 0.91 & 1.980 & 0.20 & 0.000796 & 8.309 & 0029 \\
\hline 0.0208 & 1439 & 0.91 & 1.980 & 0.20 & 0.000789 & 8.309 & 0030 \\
\hline 0.0203 & 1301 & 0.91 & 1.980 & 0.20 & 0.000969 & 8.310 & 0031 \\
\hline 0.0201 & 1303 & 0.91 & 1.980 & 0.20 & 0.000959 & 8.310 & 0032 \\
\hline 0.0205 & 1301 & 0.91 & 1.980 & 0.20 & 0.000978 & 8.310 & 0033 \\
\hline 0.0203 & 1300 & 0.91 & 1.980 & 0.20 & 0.000969 & 8.310 & 0034 \\
\hline 0.0216 & 1158 & 0.91 & 1.980 & 0.20 & 0.001269 & 8.311 & 0035 \\
\hline 0.0218 & 1158 & 0.91 & 1.980 & 0.20 & 0.001281 & 8.311 & 0036 \\
\hline 0.0216 & 1158 & 0.91 & 1.980 & 0.20 & 0.001269 & 8.311 & 0037 \\
\hline 0.0216 & 1157 & 0.91 & 1.980 & 0.20 & 0.001269 & 8.311 & 0038 \\
\hline 0.0218 & 1158 & 0.91 & 1.980 & 0.20 & 0.001281 & 8.311 & 0039 \\
\hline 0.0241 & 1030 & 0.91 & 1.980 & 0.20 & 0.001832 & 8.312 & 0040 \\
\hline 0.0248 & 1029 & 0.91 & 1.980 & 0.20 & 0.001885 & 8.312 & 0041 \\
\hline 0.0248 & 1030 & 0.91 & 1.980 & 0.20 & 0.001885 & 8.312 & 0042 \\
\hline 0.0245 & 1029 & 0.91 & 1.980 & 0.20 & 0.001863 & 8.312 & 0043 \\
\hline 0.0248 & 1029 & 0.91 & 1.980 & 0.20 & 0.001885 & 8.312 & 0044 \\
\hline 0.0242 & 876 & 0.91 & 1.980 & 0.20 & 0.002583 & 8.313 & 0045 \\
\hline 0.0234 & 874 & 0.91 & 1.980 & 0.20 & 0.002498 & 8.313 & 0046 \\
\hline 0.0251 & 876 & 0.91 & 1.980 & 0.20 & 0.002679 & 8.313 & 0047 \\
\hline 0.0246 & 876 & 0.91 & 1.980 & 0.20 & 0.002626 & 8.313 & 0048 \\
\hline 0.0251 & 876 & 0.91 & 1.980 & 0.20 & 0.002679 & 8.313 & 0049 \\
\hline
\end{tabular}


Table A-4

TEST 8 (PART II) DATA

\begin{tabular}{|c|c|c|c|c|c|c|c|}
\hline K & $\begin{array}{c}\text { Temperature } \\
\left({ }^{\circ} \mathrm{C}\right)\end{array}$ & Density & $\mathrm{O} / \mathrm{M}$ & $\mathbf{P u}$. & Weight & $\begin{array}{l}\text { Test } \\
\text { Number }\end{array}$ & Numbér \\
\hline 0.0239 & 13.18 & 0.91 & 2.000 & 0.20 & 0.001332 & 8.214 & 0001 \\
\hline 0.0230 & 1320 & 0.91 & 2.000 & 0.20 & 0.001282 & 8.214 & 0002 \\
\hline 0.0230 & 1319 & 0.91 & 2.000 & 0.20 & 0.001282 & 8.214 & 0003 \\
\hline 0.0230 & 1318 & 0.91 & 2.000 & 0.20 & 0.001282 & 8.214 & 0004 \\
\hline 0.0231 & 1319 & 0.91 & 2.000 & 0.20 & 0.001288 & 8.214 & 0005 \\
\hline 0.0223 & 1175 & 0.91 & 2.000 & 0.20 & 0.001325 & 8.215 & 0006 \\
\hline 0.0225 & 1174 & 0.91 & 2.000 & 0.20 & 0.001337 & 8.215 & 0007 \\
\hline 0.0227 & 1173 & 0.91 & 2.000 & 0.20 & 0.001349 & 8.215 & 0008 \\
\hline 0.0226 & 1173 & 0.91 & 2.000 & 0.20 & 0.001343 & 8.215 & 0009 \\
\hline 0.0231 & 1173 & 0.91 & 2.000 & 0.20 & 0.001373 & 8.215 & 0010 \\
\hline 0.0242 & 1044 & 0.91 & 2.000 & 0.20 & 0.001741 & 8.216 & 0011 \\
\hline 0.0242 & 1044 & 0.91 & 2.000 & 0.20 & 0.001741 & 8.216 & 0012 \\
\hline 0.0241 & 1045 & 0.91 & 2.000 & 0.20 & 0.001734 & 8.216 & 0013 \\
\hline 0.0240 & 1045 & 0.91 & 2.000 & 0.20 & 0.001727 & 8.216 & .0014 \\
\hline 0.0239 & 1046 & 0.91 & 2.000 & 0.20 & 0.001720 & 8.216 & 0015 \\
\hline 0.0229 & 1290 & 0.91 & 2.000 & 0.20 & 0.001056 & 8.314 & 0016 \\
\hline 0.0229 & 1291 & 0.91 & 2.000 & 0.20 & 0.001056 & 8.314 & 0017 \\
\hline 0.0229 & 1290 & 0.91 & 2.000 & 0.20 & 0.001056 & $8.3 \cdot 14$ & 0018 \\
\hline 0.0224 & 1289 & 0.9 .1 & 2.000 & 0.20 & 0.001033 & 8.314 & 0019 \\
\hline 0.0226 & 1291. & $0: 91$ & 2.000 & 0.20 & 0.001042 & 8.314 & 0020 \\
\hline 0.0249 & 1148 & 0.91 & 2.000 & $0: 20$ & 0.00147 .1 & 8.315 & 0021 \\
\hline 0.0260 & 1147 & 0.91 & 2.000 & 0.20 & 0.001536 & 8.315 . & 0022 \\
\hline 0.0264 & 1147. & 0.91 & 2.000 & 0.20 & 0.001559 & 8.315 & 0023 \\
\hline 0.0256 & 1147 & 0.91 & 2.000 & 0.20 & 0.001512 & 8.3 .15 & 0024. \\
\hline 0.0260 & .1146 & $0.91^{\prime}$ & 2.000 & 0.20 & 0.001536 & $8.315^{\circ}$ & 0025 \\
\hline 0.0284 & 1018 & 0.91 & 2.000 & 0.20 & 0.002 .106 & 8.316 & 0026 \\
\hline 0.0294 & 1019 & $0: 91$ & 2.000 & 0.20 & 0.002180 & 8.316 & 0027 \\
\hline 0.0300 & 1020 & 0.91 & 2.000 & 0.20 & 0.002225 & 8.316 & 0028 \\
\hline 0.0284 & 1019 & 0.91 & 2.000 & 0.20 & 0.002106 & 8.316 & 0029 \\
\hline 0.0294 & 1019 & 0.91 & 2.000 & 0.20 & 0.002180 & 8.316 & 0030 \\
\hline
\end{tabular}


Table A-5

TEST 8 (PART III) DATA

\begin{tabular}{|c|c|c|c|c|c|c|c|}
\hline K & $\begin{array}{c}\text { Temperature } \\
\left({ }^{\circ} \mathrm{C}\right)\end{array}$ & Density & $\mathrm{O} / \mathrm{M}$ & Pu & Weight & $\begin{array}{c}\text { Test } \\
\text { Number }\end{array}$ & Number \\
\hline 0.0199 & 880 & 0.91 & 1.950 & 0.20 & 0.000947 & 8.218 & 0001 \\
\hline 0.0193 & 885 & 0.91 & 1.950 & 0.20 & 0.000919 & 8.218 & 0002 \\
\hline 0.0196 & 884 & 0.91 & 1.950 & 0.20 & 0.000933 & 8.218 & 0003 \\
\hline 0.0199 & 884 & 0.91 & 1.950 & 0.20 & 0.000947 & 8.218 & 0004 \\
\hline 0.0196 & 880 & 0.91 & 1.950 & 0.20 & 0.000933 & 8.218 & 0005 \\
\hline 0.0200 & 1119 & 0.91 & 1.950 & 0.20 & 0.000670 & 8.219 & 0006 \\
\hline 0.0195 & 1.122 & 0.91 & 1.950 & 0.20 & 0.000653 & 8.219 & 0007 \\
\hline 0.0197 & 1117 & 0.91 & 1.950 & 0.20 & 0.000660 & 8.219 & 0008 \\
\hline 0.0198 & 1118 & 0.91 & 1.950 & 0.20 & 0.000663 & 8.219 & 0009 \\
\hline 0.0201 & 1119 & 0.91 & 1.950 & 0.20 & 0.000673 & 8.219 & 0010 \\
\hline 0.0205 & 1240 & 0.91 & 1.950 & 0.20 & 0.000694 & 8.220 & 0011 \\
\hline 0.0193 & 1242 & 0.91 & 1.950 & 0.20 & 0.000654 & 8.220 & 0012 \\
\hline 0.0193 & 1241 & 0.91 & 1.950 & 0.20 & 0.000654 & 8.220 & 0013 \\
\hline 0.0197 & 1241 & 0.91 & 1.950 & 0.20 & 0.000667 & 8.220 & 0014 \\
\hline 0.0196 & 1240 & 0.91 & 1.950 & 0.20 & 0.000664 & 8.220 & 00.15 \\
\hline 0.0217 & 1446 & 0.91 & 1.950 & 0.20 & 0.000510 & 8.221 & 0016 \\
\hline 0.0217 & 1448 & 0.91 & 1.950 & 0.20 & 0.000510 & 8.221 & 0017. \\
\hline 0.0217 & 1451 & 0.91 & 1.950 & 0.20 & 0.000510 & 8.221 & 0018 \\
\hline 0.0219 & 1449 & 0.91 & 1.950 & 0.20 & 0.000515 & 8.221 & 0019 \\
\hline 0.02 .15 & 1148 & 0.91 & 1.950 & 0.20 & 0.000506 & 8.221 & 0020 \\
\hline 0.0211 & 1582 & 0.91 & 1.950 & 0.20 & 0.000432 & 8.222 & 0021 \\
\hline 0.0213 & 1581 & 0.91 & $1: 950$ & 0.20 & 0.000436 & 8.222 & 0022 \\
\hline 0.0212 & 1584 & 0.91 & 1.950 & 0.20 & 0.000434 & 8.222 & 0023 \\
\hline 0.0210 & 1582 & 0.91 & 1.950 & 0.20 & 0.000430 & 8.222 & 0024 \\
\hline 0.0212 & 1582 & 0.91 & 1.950 & 0.20 & 0.000434 & 8.222 & 0025 \\
\hline 0.0209 & 1795 & 0.91 & 1.950 & 0.20 & 0.000403 & 8.223 & 0026 \\
\hline 0.0209 & 1797 & 0.91 & 1.950 & 0.20 & 0.000403 & 8.223 & 0027 \\
\hline 0.0210 & 1795 & 0.91 & 1.950 & 0.20 & 0.000405 & 8.223 & 0028 \\
\hline 0.0211 & 1795 & 0.91 & 1.950 & 0.20 & 0.000407 & 8.223 & 0029 \\
\hline 0.0209 & 1797 & 0.91 & 1.950 & 0.20 & 0.000403 & 8.223 & 0030 \\
\hline 0.0232 & 1984 & 0.91 & 1.950 & 0.20 & n nกn444 & 8.224 & 0031 \\
\hline 0.0239 & 1986 & 0.91 & 1.950 & 0.20 & 0.000458 & 8.224 & 0032 \\
\hline 0.0243 & 1984 & 0.91 & 1.950 & 0.20 & 0.000465 & 8.224 & 0033 \\
\hline 0.0235 & 1986 & 0.91 & 1.950 & 0.20 & 0.000450 & 8.224 & 0034 \\
\hline 0.0237 & 1986 & 0.91 & 1.950 & 0.20 & 0.000454 & 8.224 & 0035 \\
\hline 0.0247 & 2195 & 0.91 & 1.950 & 0.20 & 0.000567 & 8.225 & 0036 \\
\hline 0.0220 & 2198 & 0.91 & 1.950 & 0.20 & 0.000505 & 8.225 & 0037 \\
\hline 0.0209 & 2196 & 0.91 & 1.950 & 0.20 & 0.000480 & 8.225 & 0038 \\
\hline 0.0212 & 2199 & 0.91 & 1.950 & 0.20 & 0.000487 & 8.225 & 0039 \\
\hline 0.0211 & 2198 & 0.91 & 1,950 & 0.20 & 0.000485 & 8.225 & 0040 \\
\hline 0.0211 & 2198 & 0.91 & 1.950 & 0.20 & 0.000485 & 8.225 & 0041 \\
\hline 0.0228 & 826 & 0.91 & 1.950 & 0.20 & 0.001159 & 8.318 & 0042 \\
\hline 0.0226 & 827 & 0.91 & 1.950 & 0.20 & 0.001149 & 8.318 & 0043 \\
\hline 0.0217 & 829 & 0.91 & 1.950 & 0.20 & 0.001103 & 8.318 & 0044 \\
\hline 0.0219 & 827 & 0.91 & 1.950 & $0: 20$ & 0.001113 & 8.318 & 0045 \\
\hline 0.0219 & 827 & 0.91 & 1.950 & 0.20 & 0.001113 & 8.318 & 0046 \\
\hline 0.0191 & 1065 & 0.911 & 1.950 & 0.20 & 0.000628 & 8.319 & 0047 \\
\hline
\end{tabular}


Table A-5 (continued)

\begin{tabular}{|c|c|c|c|c|c|c|c|}
\hline$\dot{K}$ & $\begin{array}{c}\text { Temperature } \\
{ }^{\circ} \mathrm{C} \text { C) }\end{array}$ & Density & $\mathrm{O} / \mathrm{M}$ & $\mathbf{P u}$ & Weight & $\begin{array}{c}\text { Test } \\
\text { Number }\end{array}$ & Number \\
\hline 0.0195 & 1065 & 0.91 & 1.950 & 0.20 & 0.000641 & 8.319 & 0048 \\
\hline 0.0196 & 1063 & 0.91 & 1.950 & 0.20 & 0.000641 & 8.319 & 0049 \\
\hline 0.0196 & 1065 & 0.91 & 1.950 & 0.20 & 0.000645 & 8.319 & 0050 \\
\hline 0.0197 & 1065 & 0.91 & 1.950 & 0.20 & 0.000648 & 8.319 & 0051 \\
\hline 0.0186 & 1187 & 0.91 & 1.950 & 0.20 & 0.000594 & 8.320 & 0052 \\
\hline 0.0190 & 1188 & 0.91 & 1.950 & 0.20 & 0.000607 & 8.320 & 0053 \\
\hline 0.0193 & 1185. & 0.91 & 1.950 & 0.20 & 0.000617 & $8.320^{\circ}$ & 0054 \\
\hline 0.0190 & 1183 & 0.91 & 1.950 & 0.20 & 0.000607 & 8.320 & 0055 \\
\hline 0.0192 & 1.187 & 0.91 & 1.950 & 0.20 & 0.000613 & 8.320 & 0056 \\
\hline 0.0201 & 1402 & 0.91 & 1.950 & $0: 20$ & 0.000557 & 8.321 & 0057 \\
\hline 0.0202 & 1397 & 0.91 & 1.950 & 0.20 & 0.000560 & 8.321 & 0058 \\
\hline $0.0198^{\prime}$ & 1399 & 0.91 & 1.950 & 0.20 & 0.000549 & 8.321 & 0059 \\
\hline 0.0202 & 1397 & 0.91 & 1.950 & 0.20 & 0.000560 & 8.321 & 0060 \\
\hline 0.0206 & 1399 & 0.91 & 1.950 & 0.20 & 0.000571 & 8.321 & 0061 \\
\hline 0.0215 & 1529 & 0.91 & 1.950 & 0.20 & 0.000499 & 8.322 & 0062 \\
\hline 0.0208 & 1531 & 0.91 & 1.950 & $0: 20$ & 0.000483 & 8.322 & 0063 \\
\hline 0.0209 & 1532 & 0.91 & 1.950 & 0.20 & 0.000485 & 8.322 & 0064 \\
\hline 0.0209 & 1532 & 0.91 & 1.950 & 0.20 & 0.000485 & 8.322 & 0065 \\
\hline 0.0211 & 1531. & 0.91 & 1.950 & 0.20 & 0.000490 & 8.322 & 0066 \\
\hline 0.0191 & 1743 & 0.91 & 1.950 & 0.20 & 0.000497 & 8.323 & 0067 \\
\hline 0.0197 & 1739 & 0.91 & 1.950 & 0.20 & 0.000513 & 8.323 & 0068 \\
\hline 0.0192 & 1738 & 0.91 & 1.950 & 0.20 & 0.000500 & 8.323 & 0069 \\
\hline 0.0191 & 1738 & 0.91 & 1.950 & 0.20 & 0.000497 & 8.323 & 0070 \\
\hline 0.0193 & 1742 & 0.91 & 1.950 & 0.20 & 0.000502 & 8.323 & 0071 \\
\hline 0.0231 & 1940 & 0.91 & 1.950 & 0.20 & 0.000519 & 8.324 & 0072 \\
\hline 0.0238 & 1937 & 0.91 & 1.950 & 0.20 & 0.000535 & 8.324 & 0073 \\
\hline 0.0238 & 1937. & 0.91 & 1.950 & 0.20 & 0.000535 & 8.324 & 0074 \\
\hline 0.0234 & 1939 & 0.91 & 1.950 & 0.20 & 0.000526 & 8.324 & 0075 \\
\hline 0.0238 & 1940 & 0.91 & 1.950 & 0.20 & 0.000535 & 8.324 & 0076 \\
\hline 0.0245 & 2127 & 0.91 & 1.950 & 0.20 & 0.000928 & 8.325 & 0077 \\
\hline 0.0203 & 2141 & 0.91 & 1.950 & 0.20 & 0.000769 & 8.325 & 0078 \\
\hline 0.0222 & 2139 & 0.91 & 1.950 & 0.20 & 0.000841 & 8.325 & 0079 . \\
\hline 0.0216 & 2146 : & 0.91 & 1,950 & 0.20 & 0.000818 & 8.325 & 0080 \\
\hline 0.0220 & 2143 & 0.91 & 1.950 & 0.20 & 0.000833 & 8.325 & 0081 \\
\hline 0.0213 & 2145 & 0.91 & 1.950 & 0.20 & 0.000807 & 8.325 & 0082 \\
\hline
\end{tabular}


Table A-6

TEST 10 DATA

\begin{tabular}{|c|c|c|c|c|c|c|c|}
\hline $\mathbf{K}$ & $\begin{array}{l}\text { Temperature } \\
\left.{ }^{\circ} \mathrm{C}\right)\end{array}$ & Density & $\mathrm{O} / \mathrm{M}$ & $\mathbf{P u}$ & Weight & $\begin{array}{c}\text { Test } \\
\text { Number }\end{array}$ & Number \\
\hline 0.0238 & 838 & 0.84 & 1.960 & 0.20 & 0.001592 & 10.201 & 0001. \\
\hline 0.0226 & 842 & 0.84 & 1.960 & 0.20 & 0.001505 & 10.201 & 0002 \\
\hline 0.0227 & 839 & 0.84 & 1.960 & 0.20 & 0.001518 & 10.201 & 0003 \\
\hline 0.0226 & 839 & 0.84 & 1.960 & 0.20 & $0.001511^{\circ}$ & 10.201 & 0004 \\
\hline 0.0223 & 841 & 0.84 & 1.960 & 0.20 & 0.001491 & 10.201 & 0005 \\
\hline 0.0207 & 1096 & 0.84 & 1.960 & 0.20 & 0.000870 & 10.202 & 0006 \\
\hline 0.0206 & 1096 & 0.84 & 1.960 & 0.20 & 0.000866 & 10.202 & 0007 \\
\hline 0.0206 & 1094 & 0.84 & 1.960 & 0.20 & 0.000866 & 10.202 & 0008 \\
\hline 0.0205 & 1095 & 0.84 & 1.960 & 0.20 & 0.000862 & 10.202 & 0009 \\
\hline 0.0205 & 1095 & 0.84 & 1.960 & 0.20 & 0.000862 & 10.202 & 0010 \\
\hline 0.0199 & 1285 & 0.84 & 1.960 & 0.20 & 0.000560 & 10.203 & 0011 \\
\hline 0.0194 & 1288 & 0.84 & 1.960 & 0.20 & 0.000546 & 10.203 & 0012 \\
\hline 0.0200 & 1287 & 0.84 & 1.960 & 0.20 & 0.000563 & 10.203 & 0013 \\
\hline 0.0199 & 1286 & 0.84 & 1.960 & 0.20 & 0.000560 & 10.203 & 0014 \\
\hline 0.0198 & 1288 & 0.84 & 1.960 & 0.20 & 0.000557 & 10.203 & 0015 \\
\hline 0.0202 & 1484 & 0.84 & 1.960 & 0.20 & 0.000432 & 10.204 & 0016 \\
\hline 0.0204 & 1483 & 0.84 & 1.960 & 0.20 & 0.000437 & 10.204 & 0017 \\
\hline 0.0201 & 1485 & 0.84 & 1.960 & 0.20 & 0.000430 & 10.204 & 0018 \\
\hline 0.0201 & 1484 & 0.84 & 1.960 & 0.20 & 0.000430 & 10.204 & 0019 \\
\hline 0.0202 & 1485 & 0.84 & 1.960 & 0.20 & 0.000432 & 10.204 & 0020 \\
\hline 0.0197 & 1659 & 0.84 & 1.960 & 0.20 & 0.000926 & 10.205 & 0021 \\
\hline 0.0196 & 1653 & 0.84 & 1.960 & 0.20 & 0.000921 & 10.205 & 0022 \\
\hline 0.0200 & 1641 & 0.84 & 1.960 & 0.20 & 0.000940 & 10.205 & 0023 \\
\hline 0.0211 & 1638 & 0.84 & 1.960 & 0.20 & 0.000991 & 10.205 & 0024 \\
\hline 0.0204 & 1653 & 0.84 & 1.960 & 0.20 & 0.000958 & 10.205 & 0025 \\
\hline 0.0197 & 1832 & 0.84 & 1.960 & 0.20 & 0.000343 & 10.206 & 0026 \\
\hline 0.0198 & 1833 & 0.84 & 1.960 & 0.20 & 0.000345 & 10.206 & 0027 \\
\hline 0.0203 & 1832 & 0.84 & 1.960 & 0.20 & 0.000353 & 10.206 & 0028 \\
\hline 0.0199 & 1832 & 0.84 & 1.960 & 0.20 & 0.000347 & 10.206 & 0029 \\
\hline 0.0198 & 1832 & 0.84 & 1.960 & 0.20 & 0.000345 & 10.206 & 0030 \\
\hline 0.0228 & 2044 & 0.84 & 1.960 & 0.20 & $0.00 n 423$ & $10.2 n 7$ & กก.31 \\
\hline 0.0226 & 2048 & 0.84 & 1.960 & 0.20 & 0.000419 & 10.207 & 0032 \\
\hline 0.0225 & 2047 & 0.84 & 1.960 & 0.20 & 0.000418 & 10.207 & 0033 \\
\hline 0.0225 & 2047 & 0.84 & 1.960 & 0.20 & 0.000418 & 10.207 & 0034 \\
\hline 0.0228 & 2049 & 0.84 & 1.960 & 0.20 & 0.000423 & 10.207 & 0035 \\
\hline 0.0234 & 2238 & 0.84 & 1.960 & 0.20 & 0.000404 & 10.208 & 0036 \\
\hline 0.0236 & 2239 & 0.84 & 1.960 & 0.20 & 0.000408 & 10.208 & 0037 \\
\hline 0.0231 & 2242 & 0.84 & 1.960 & 0.20 & 0.000399 & 10.208 & 0038 \\
\hline 0.0236 & 2239 & 0.84 & 1.960 & 0.20 & 0.000408 & 10.208 & 0039 \\
\hline 0.0231 & 2242 & 0.84 & 1.960 & 0.20 & 0.000399 & 10.208 & 0040 \\
\hline 0.0277 & 803 & 0.84 & 1.960 & 0.20 & 0.002004 & 10.301 & 0041 \\
\hline 0.0244 & 804 & 0.84 & 1.960 & 0.20 & 0.001765 & 10.301 & 0042 \\
\hline 0.0257 & 804 & 0.84 & 1.960 & 0.20 & 0.001859 & 10.301 & 0043 \\
\hline 0.0266 & 803 & 0.84 & 1.960 & 0.20 & 0.001925 & 10.301 & 0044 \\
\hline 0.0255 & 803 & 0.84 & 1.960 & 0.20 & 0.001845 & 10.301 & 0045 \\
\hline 0.0214 & 1049 & 0.84 & 1.960 & 0.20 & 0.000877 & 10.302 & 0046 \\
\hline 0.0217 & 1048 & 0.84 & 1.960 & 0.20 & 0.000889 & 10.302 & 0047 \\
\hline
\end{tabular}


Table A.6 (continued)

\begin{tabular}{|c|c|c|c|c|c|c|c|c|}
\hline$K$ & & $\begin{array}{c}\text { Temperature } \\
\left({ }^{\circ} \mathrm{C}\right)\end{array}$ & Density & O/M & $\mathbf{P u}$ & Weight & $\begin{array}{c}\text { Test } \\
\text { Number }\end{array}$ & Number \\
\hline 0.0217 & & 1046 & 0.84 & 1.960 & 0.20 & 0.000889 & 10.302 & 0048 \\
\hline 0.0214 & & 1047 & 0.84 & 1.960 & 0.20 & 0.000877 & 10.302 & 0049 \\
\hline 0.0219 & & 1047 & 0.84 & 1.960 & 0.20 & 0.000897 & 10.302 & 0050 \\
\hline 0.0195 & & 1241 & 0.84 & 1.960 & 0.20 & 0.000534 & 10.303 & 0051 \\
\hline 0.0193 & & 1242 & 0.84 & 1.960 & 0.20 & 0.000528 & 10.303 & 0052 \\
\hline 0.0196 & & 1241 & 0.84 & 1.960 & 0.20 & 0.000537 & 10.303 & 0053 \\
\hline 0.0195 & & 1242 & $0.84 i$ & 1.960 & 0.20 & 0.000534 & 10.303 & 0054 \\
\hline 0.0193 & & 1242 & 0.84 & 1.960 & 0.20 & 0.000528 & 10.303 & 0055 \\
\hline 0.0202 & & 1431. & 0.84 & 1.960 & 0.20 & 0.000485 & 10.304 & 0056 \\
\hline 0.0199 & & 1432 & 0.84 & 1.960 & 0.20 & 0.000477 & 10.304 & 0057 \\
\hline 0.0198 & & 1434 & 0.84 & 1.960 & 0.20 & 0.000475 & 10.304 & 0058 \\
\hline 0.0199 & $\therefore$ & 1433 & 0.84 & 1.960 & 0.20 & 0.000477 & 10.304 & 0059 \\
\hline 0.0199 & & $1433^{\circ}$ & 0.84 & 1.960 & 0.20 & 0.000477 & 10.304 & 0060 \\
\hline 0.0197 & & 1599 & 0.84 & 1.960 & 0.20 & 0.001719 & 10.305 & 0061 \\
\hline 0.0196 & & 1596 & 0.84 & 1.960 & 0.20 & 0.001710 & 10.305 & 0062 \\
\hline 0.0223 & & 1590 & 0.84 & 1.960 & 0.20 & 0.001945 & 10.305 & 0063 \\
\hline 0.0239 & & 1586 & 0.84 & 1.960 & 0.20 & 0.002085 & 10.305 & 0064 \\
\hline 0.0211 & $\cdot \cdot$ & 1605 & 0.84 & 1.960 & 0.20 & 0.001841 & 10.305 & 0065 \\
\hline 0.0209 & & 1793 & 0.84 & 1.960 & 0.20 & 0.000397 & 10.306 & 0066 \\
\hline 0.0207 & & 1792 & 0.84 & 1.960 & 0.20 & 0.000394 & 10.306 & 0067 \\
\hline 0.0208 & & 1791 & 0.84 & 1.960 & 0.20 & 0.000395 & 10.306 & 0068 \\
\hline 0.0207 & & 1793 & 0.84 & 1.960 & 0.20 & 0.000394 & 10.306 & 0069 \\
\hline 0.0209 & & 1793 & 0.84 & 1.960 & 0.20 & 0.000397 & 10.306 & 0070 \\
\hline 0.0237 & & 2005 & 0.84 & 1.960 & 0.20 & 0.000470 & 10.307 & 0071 \\
\hline 0.0229 & & 2006 & 0.84 & 1.960 & 0.20 & 0.000454 & 10.307 & 0072 \\
\hline 0.0237 & & 2005 & 0.84 & 1.960 & 0.20 & 0.000470 & 10.307 & 0073 \\
\hline 0.0237 & . & 2005 & 0.84 & 1.960 & 0.20 & 0.000470 & 10.307 & 0074 \\
\hline 0.0235 & . & 2005 & 0.84 & 1.960 & 0.20 & 0.000466 & 10.307 & 0075 \\
\hline 0.0248 & & $2199^{\circ}$ & 0.84 & 1.960 & 0.20 & 0.000725 & 10.308 & 0076 \\
\hline 0.0233 & & 2203 & 0.84 & 1.960 & 0.20 & 0.000681 & 10.308 & 0077 \\
\hline 0.0233 & & 2203. & 0.84 & 1.960 & 0.20 & 0.000681 & 10.308 & 0078 \\
\hline 0.0233 & & 2203 & 0.84 & 1.960 & 0.20 & 0.000681 & 10.308 & 0079 \\
\hline 0.0233 & & 2203 & 0.84 & 1.960 & 0.20 & 0.000681 & 10.308 & 0080 \\
\hline
\end{tabular}


Table A-7

TEST 11 DATA

\begin{tabular}{|c|c|c|c|c|c|c|c|}
\hline K & $\begin{array}{c}\text { Temperature } \\
\left({ }^{\circ} \mathrm{C}\right)\end{array}$ & Density & $\mathrm{O} / \mathrm{M}$ & Pu & Weight & $\begin{array}{c}\text { Test } \\
\text { Number }\end{array}$ & Number \\
\hline 0.0265 & 813 & 0.855 & 1.965 & 0.20 & 0.002152 & 11.201 & 0001. \\
\hline 0.0251 & 820 & 0.855 & 1.965 & 0.20 & 0.002038 & 11.201 & 0002 \\
\hline 0.0256 & 819 & 0.855 & 1.965 & 0.20 & 0.002079 & 11.201 & 0003 \\
\hline 0.0251 & 820 & 0.855 & 1.965 & 0.20 & 0.002038 & 11.201 & 0004 \\
\hline 0.0261 & 817 & 0.855 & 1.965 & 0.20 & 0.002119 & 11.201 & 0005 \\
\hline 0.0224 & 1085 & 0.855 & 1.965 & 0.20 & 0.000797 & 11.202 & 0006 \\
\hline 0.0229 & 1085 & 0.855 & 1.965 & 0.20 & 0.000815 & 11.202 & 0007 \\
\hline 0.0231 & 1084 & 0.855 & 1.965 & 0.20 & 0.000822 & 11.202 & 0008 \\
\hline 0.0233 & 1084 & 0.855 & 1.965 & 0.20 & 0.000830 & 11.202 & 0009 \\
\hline 0.0229 & 1086 & 0.855 & 1.965 & 0.20 & 0.000815 & 11.202 & 0010 \\
\hline 0.0233 & 1296 & 0.855 & 1.965 & 0.20 & 0.000784 & 11.203 & 0011 \\
\hline 0.0227 & 1294 & 0.855 & 1.965 & 0.20 & 0.000764 & 11.203 & 0012 \\
\hline 0.0217 & 1297 & 0.855 & 1.965 & 0.20 & 0.000730 & 11.203 & 0013 \\
\hline 0.0217 & 1296 & 0.855 & 1.965 & 0.20 & 0.000730 & 11.203 & 0014 \\
\hline 0.0217 & 1296 & 0.855 & 1.965 & 0.20 & 0.000730 & 11.203 & 0015 \\
\hline 0.0212 & 1448 & 0.855 & 1.965 & 0.20 & 0.000468 & 11.204 & 0016 \\
\hline 0.0210 & 1451 & 0.855 & 1.965 & 0.20 & 0.000464 & 11.204 & 0017 \\
\hline 0.0210 & 1450 & 0.855 & 1.965 & 0.20 & 0.000464 & 11.204 & 0018 \\
\hline 0.0210 & 1451 & 0.855 & 1.965 & 0.20 & 0.000464 & 11.204 & 0019 \\
\hline 0.0214 & 1450 & 0.855 & 1.965 & 0.20 & 0.000472 & 11.204 & 0020 \\
\hline 0.0206 & 1655 & 0.855 & 1.965 & 0.20 & 0.000495 & 11.205 & 0021 \\
\hline 0.0213 & 1654 & 0.855 & 1.965 & 0.20 & 0.000511 & 11.205 & 0022 \\
\hline 0.0215 & 1655 & 0.855 & 1.965 & 0.20 & 0.000516 & 11.205 & 0023 \\
\hline 0.0208 & 1654 & 0.855 & 1.965 & 0.20 & 0.000499 & 11.205 & 0024 \\
\hline 0.0207 & 1656 & 0.855 & 1.965 & 0.20 & 0.000497 & 11.205 & 0025 \\
\hline 0.0205 & 1825 & 0.855 & 1.965 & 0.20 & 0.000362 & 11.206 & 0026 \\
\hline 0.0205 & 1825 & 0.855 & 1.965 & 0.20 & 0.000362 & 11.206 & 0027 \\
\hline 0.0202 & 1827 & 0.855 & 1.965 & 0.20 & 0.000357 & 11.206 & 0028 \\
\hline 0.0205 & 1825 & 0.855 & 1.965 & 0.20 & 0.000362 & 11.206 & 0029 \\
\hline 0.0205 & 1825 & 0.855 & 1.965 & 0.20 & 0.000362 & 11.206 & 0030 \\
\hline 0.0232 & 2000 & 0.055 & 1.965 & 0.20 & 0.000523 & 11.307 & 0031 \\
\hline 0.0232 & 2060 & 0.855 & 1.965 & 0.20 & 0.000523 & 11.207 & 0032 \\
\hline 0.0236 & 2061 & 0.855 & 1.965 & 0.20 & 0.000532 & 11.207 & 0033 \\
\hline 0.0234 & 2060 & 0.855 & 1.965 & 0.20 & 0.000528 & 11.207 & 0034 \\
\hline 0.0234 & 2058 & 0.855 & 1.965 & 0.20 & 0.000528 & 11.207 & 0035 \\
\hline 0.0247 & 2228 & 0.855 & 1.965 & 0.20 & 0.000490 & 11.208 & 0036 \\
\hline 0.0255 & 2230 & 0.855 & 1.965 & 0.20 & 0.000506 & 11.208 & 0037 \\
\hline 0.0255 & 2230 & 0.855 & 1.965 & 0.20 & 0.000506 & 11.208 & 0038 \\
\hline 0.0252 & 2229 & 0.855 & 1.965 & 0.20 & 0.000500 & 11.208 & 0039 \\
\hline 0.0252 & 2229 & 0.855 & 1.965 & 0.20 & n.000500 & 11.208 & 0040 \\
\hline
\end{tabular}


Table A-8

TEST 11 DATA

\begin{tabular}{|c|c|c|c|c|c|c|c|}
\hline K & $\begin{array}{c}\text { Temperature } \\
\left({ }^{\circ} \mathrm{C}\right)\end{array}$ & Density & $\mathrm{O} / \mathrm{M}$ & $\mathrm{Pu}$ & Weight & $\begin{array}{c}\text { Test } \\
\text { Number }\end{array}$ & Number \\
\hline 0.0256 & 810 & 0.869 & 1.965 & 0.20 & 0.001719 & 11.301 & 0001 \\
\hline 0.0254 & 813 & 0.869 & 1.965 & 0.20 & 0.001706 & 11.301 & 0002 \\
\hline 0.0253 & 813 & 0.869 & 1.965 & 0.20 & 0.001699 & 11.301 & 0003 \\
\hline 0.0262 & 813 & 0.869 & 1.965 & 0.20 & 0.001759 & 11.301 & 0004 \\
\hline 0.0244 & 814 & 0.869 & 1.965 & 0.20 & 0.001639 & 11.301 & 0005 \\
\hline 0.0212 & 1089 & 0.869 & 1.965 & 0.20 & 0.0007 .16 & 11.302 & 0006 \\
\hline 0.0214 & 1090 & 0.869 & 1.965 & 0.20 & 0.000723 & 11.302 & 0007 \\
\hline 0.0211 & 1088 & 0.869 & 1.965 & 0.20 & 0.000713 & 11.302 & 0008 \\
\hline 0.0214 & 1090 & 0.869 & 1.965 & 0.20 & 0.000723 & 11.302 & 0009 \\
\hline 0.0212 & 1089 & 0.869 & 1.965 & 0.20 & 0.000716 & 11.302 & 0010 \\
\hline 0.0200 & 1312 & 0.869 & 1.965 & 0.20 & 0.000503 & 11.303 & 0011 \\
\hline 0.0198 & 1311 & 0.869 & 1.965 & 0.20 & 0.000498 & 11.303 & 0012 \\
\hline 0.0202 & 1313 & 0.869 & 1.965 & 0.20 & 0.000509 & 11.303 & 0013 \\
\hline 0.0202 & 1313 & 0.869 & 1.965 & 0.20 & 0.000509 & 11.303 & 0014 \\
\hline 0.0201 & 1313 & 0.869 & 1.965 & 0.20 & 0.000506 & 11.303 & 0015 \\
\hline 0.0195 & 1462 & 0.869 & 1.965 & 0.20 & 0.000386 & 11.304 & 0016 \\
\hline 0.0194 & 1461 & 0.869 & 1.965 & 0.20 & 0.000384 & 11.304 & 0017 \\
\hline 0.0197 & 1462 & 0.869 & 1.965 & 0.20 & 0.000390 & 11.304 & 0018 \\
\hline 0.0195 & 1462 & 0.869 & 1.965 & 0.20 & 0.000386 & 11.304 & 0019 \\
\hline 0.0195 & 1461 & 0.869 & 1.965 & 0.20 & 0.000386 & 11.304 & 0020 \\
\hline 0.0197 & 1669 & 0.869 & 1.965 & 0.20 & 0.000405 & 11.305 & 0021 \\
\hline 0.0201 & 1669 & 0.869 & 1.965 & 0.20 & 0.000414 & 11.305 & 0022 \\
\hline 0.0196 & 1671 & 0.869 & 1.965 & 0.20 & 0.000403 & 11.305 & 0023 \\
\hline 0.0198 & 1672 & 0.869 & 1.965 & 0.20 & 0.000407 & 11.305 & 0024 \\
\hline 0.0200 & 1671 & 0.869 & 1.965 & 0.20 & 0.000411 & 11.305 & 0025 \\
\hline 0.0199 & 1848 & $0: 869$ & 1.965 & 0.20 & 0.000342 & 11.306 & 0026 \\
\hline 0.0200 & 1849 & 0.869 & 1.965 & 0.20 & 0.000344 & 11.306 & 0027 \\
\hline 0.0197 & 1848 & 0.869 & 1.965 & 0.20 & 0.000339 & 11.306 & 0028 \\
\hline 0.0200 & 1849 & 0.869 & 1.965 & 0.20 & 0.000344 & 11.306 & 0029 \\
\hline 0.0201 & 1850 & 0.869 & 1.965 & 0.20 & 0.000346 & 11.306 & 0030 \\
\hline 0.0222 & 2078 & 0.869 & 1.965 & 0.20 & 0.000300 & 11.307 & 0031 \\
\hline 0.0222 & 2078 & 0.869 & 1.965 & 0.20 & 0.000300 & 11.307 & 0032 \\
\hline 0.0222 & 2078 & 0.869 & 1.965 & 0.20 & 0.000300 & 11.307 & 0033 \\
\hline 0.0221 & 2078 & 0.869 & 1.965 & 0.20 & 0.000299 & 11.307 & 0034 \\
\hline 0.0223 & 2079 & 0.869 & 1.965 & 0.20 & 0.000301 & 11.307 & 0035 \\
\hline 0.0221. & 2244 & 0.869 & 1.965 & 0.20 & 0.000564 & 11.308 & 0036 \\
\hline 0.0210 & 2250 & 0.869 & 1.965 & 0.20 & 0.000536 & 11.308 & 0037 \\
\hline 0.0207 & 2247 & 0.869 & 1.965 & 0.20 & 0.000528 & 11.308 & 0038 \\
\hline 0.0212 & 2250 & 0.869 & 1.965 & 0.20 & 0.000541 & 11.308 & 0039 \\
\hline 0.0217 & 2249 & 0.869 & 1.965 & 0.20 & 0.000554 & 11.308 & 0040 \\
\hline
\end{tabular}


Table A-9

TEST 13 DATA

\begin{tabular}{|c|c|c|c|c|c|c|}
\hline K & $\begin{array}{c}\text { Temperature } \\
\left({ }^{\circ} \mathrm{C}\right)\end{array}$ & Density & $\mathrm{O} / \mathrm{M}$ & $\mathrm{Pu}$ & $\begin{array}{c}\text { Test } \\
\text { Number }\end{array}$ & Number \\
\hline 0.0272 & 959 & 0.91 & 1.986 & 0.10 & 13.301 & 0001 \\
\hline 0.0248 & 974 & 0.91 & 1.986 & 0.10 & 13.301 & 0002 \\
\hline 0.0235 & 982 & 0.91 & 1.986 & 0.10 & 13.301 & 0003 \\
\hline 0.0234 & 985 & 0.91 & 1.986 & 0.10 & 13.301 & 0004 \\
\hline 0.0236 & 984 & 0.91 & 1.986 & 0.10 & 13.301 & 0005 \\
\hline 0.0210 & 1163 & 0.91 & 1.986 & 0.10 & 13.302 & 0006 \\
\hline 0.0212 & 1161 & 0.91 & 1.986 & 0.10 & 13.302 & 0007 \\
\hline 0.0209 & 1163 & 0.91 & 1.986 & 0.10 & 13.302 & 0008 \\
\hline 0.0213 & 11.62 & 0.91 & 1.986 & 0.10 & 13.302 & 0009 \\
\hline 0.0212 & 1161 & 0.91 & 1.986 & 0.10 & 13.302 & 0010 \\
\hline 0.0224 & 1324 & 0.91 & 1.986 & 0.10 & 13.303 & 0011 \\
\hline 0.0217 & 1327 & 0.91 & 1.986 & 0.10 & 13.303 & 0012 \\
\hline 0.0215 & 1329 & 0.91 & 1.986 & 0.10 & 13.303 & 0013 \\
\hline 0.0217 & 1328 & 0.91 & 1.986 & 0.10 & 13.303 & 0014 \\
\hline 0.0216 & 1328 & 0.91 & 1.986 & 0.10 & 13.303 & 0015 \\
\hline 0.0224 & 1493 & 0.91 & 1.986 & 0.10 & 13.304 & 0016 \\
\hline 0.0223 & 1493 & 0.91 & 1.986 & 0.10 & 13.304 & 0017 \\
\hline 0.0226 & 1487 & 0.91 & 1.986 & 0.10 & 13.304 & 0018 \\
\hline 0.0231 & 1487 & 0.91 & 1.986 & 0.10 & 13.304 & 0019 \\
\hline 0.0222 & 1487 & 0.91 & 1.986 & 0.10 & 13.304 & 0020 \\
\hline 0.0233 & $1667^{\circ}$ & 0.91 & 1.986 & 0.10 & 13.305 & 0021 \\
\hline 0.0233 & 1670 & 0.91 & 1.986 & 0.10 & 13.305 & 0022 \\
\hline 0.0232 & 1668 & 0.91 & 1.986 & 0.10 & 13.305 & 0023 \\
\hline 0.0214 & 1663 & 0.91 & 1.986 & 0.10 & 13.305 & 0024 \\
\hline 0.0214 & 1663 & 0.91 & 1.986 & 0.10 & 13.305 & 0025 \\
\hline 0.0251 & 1898 & 0.91 & 1.986 & 0.10 & 13.306 & 0026 \\
\hline 0.0255 & 1898 & 0.91 & 1.986 & 0.10 & 13.306 & 0027 \\
\hline 0.0256 & 1895 & 0.91 & 1.986 & 0.10 & 13.306 & 0028 \\
\hline 0.0248 & 1897 & 0.91 & 1.986 & 0.10 & 13.306 & 0029 \\
\hline 0.0253 & 1898 & 0.91 & 1.986 & 0.10 & 13.306 & 0030 \\
\hline 0.0235 & 2064 & 0.91 & 1.986 & 0.10 & 13.307 & 0031 \\
\hline 0.0235 & 2067 & 0.91 & 1.986 & 0.10 & 13.307 & 0032 \\
\hline 0.0236 & 2065 & 0.91 & 1.986 & 0.10 & 13.307 & 0033 \\
\hline 0.0236 & 2065 & 0.91 & 1.986 & 0.10 & 13.307 & 0034 \\
\hline 0.0238 & 2066 & 0.91 & 1.986 & 0.10 & 13.307 & 0035 \\
\hline 0.0236 & 2266 & 0.91 & 1.986 & 0.10 & 13.308 & 0036 \\
\hline 0.0250 & 2268 & 0.91 & 1.986 & 0.10 & 13.308 & 0037 \\
\hline 0.0255 & 2264 & 0.91 & 1.986 & 0.10 & 13.308 & 0038 \\
\hline 0.0251 & 2267 & 0.91 & 1.986 & 0.10 & 13.308 & 0039 \\
\hline 0.0248 & 2266 & 0.91 & 1.986 & 0.10 & 13.308 & 0040 \\
\hline
\end{tabular}


Table A-10

TEST 3 DATA :

$\begin{array}{ccccccc}K & \begin{array}{c}\text { Temperature } \\ \left({ }^{\circ} \mathrm{C}\right)\end{array} & \text { Density } & \text { O/M } & \text { Pu } & \begin{array}{c}\text { Test } \\ \text { Number }\end{array} & \text { Number } \\ 0.0240 & & & & & & \\ 0.0235 & 901 & 0.93 & 1.950 & 0.30 & 3.101 & 0001 \\ 0.0237 & 1106 & 0.93 & 1.950 & 0.30 & 3.102 & 0002 \\ 0.0217 & 1077 & 0.93 & 1.950 & 0.30 & 3.102 & 0003 \\ 0.0251 & 1302 & 0.93 & 1.950 & 0.30 & 3.103 & 0004 \\ 0.0201 & 1267 & 0.93 & 1.950 & 0.30 & 3.103 & 0005 \\ 0.0207 & 1584 & 0.93 & 1.950 & 0.30 & 3.108 & 0006 \\ 0.0209 & 1758 & 0.93 & 1.950 & 0.30 & 3.109 & 0007 \\ 0.0242 & 1940 & 0.93 & 1.950 & 0.30 & 3.110 & 0008 \\ 0.0237 & 2125 & 0.93 & 1.950 & 0.30 & 3.111 & 0009 \\ 0.0240 & 2279 & 0.93 & 1.950 & 0.30 & 3.112 & 0010 \\ 0.0213 & 919 & 0.93 & 1.950 & 0.30 & 3.201 & 0011 \\ 0.0209 & 1123 & 0.93 & 1.950 & 0.30 & 3.202 & 0012 \\ 0.0205 & 1330 & 0.93 & 1.950 & 0.30 & 3.203 & 0013 \\ 0.0205 & 1573 & 0.93 & 1.950 & 0.30 & 3.204 & 0014 \\ 0.0205 & 1619 & 0.93 & 1.950 & 0.30 & 3.205 & 0015 \\ 0.0205 & 1763 & 0.93 & 1.950 & 0.30 & 3.206 & 0016 \\ 0.0203 & 1389 & 0.93 & 1.950 & 0.30 & 3.207 & 0017 \\ 0.0207 & 1617 & 0.93 & 1.950 & 0.30 & 3.208 & 0018 \\ 0.0212 & 1793 & 0.93 & 1.950 & 0.30 & 3.209 & 0019 \\ 0.0231 & 1796 & 0.93 & 1.950 & 0.30 & 3.210 & 0020 \\ & 2167 & 0.93 & 1.950 & 0.30 & 3.211 & 0021\end{array}$


Table A-11

TEST 12 DATA

\begin{tabular}{|c|c|c|c|c|c|c|}
\hline \multirow{2}{*}{ K } & \multirow{2}{*}{$\begin{array}{c}\text { Temperature } \\
\left.\text { ( }{ }^{\circ} \mathrm{C}\right)\end{array}$} & \multirow[b]{2}{*}{ Density } & \multirow[b]{2}{*}{$\mathrm{O} / \mathrm{M}$} & \multicolumn{3}{|c|}{ Test } \\
\hline & & & & $\mathbf{P u}$ & Number & Number \\
\hline 0.0225 & 880 & 0.976 & 1.860 & 1.00 & 12.201 & $0001^{\circ}$ \\
\hline 0.0205 & 875 & 0.976 & 1.860 . & 1.00 & 1.2 .201 & 0002 \\
\hline 0.0201 & 870 & 0.976 & 1.860 & 1.00 & 12.201 & 0003 \\
\hline 0.0206 & 873 & 0.976 & 1.860 & 1.00 & 12.201 & 0004 \\
\hline 0.0208 & 876 & 0.976 & 1.860 & 1.00 & 12.201 & 0005 \\
\hline 0.0207 & 1121 & 0.976 & 1.860 & 1.00 & 12.202 & 0006 \\
\hline 0.0204 & 1121 & 0.976 & 1.860 & 1.00 & 12.202 & 0007 \\
\hline 0.0208 & 1121 & 0.976 & 1.860 & 1.00 & 12.202 & 0008 \\
\hline 0.0199 & 1121 & 0.976 & 1.860 & 1.00 & 12.202 & 0009 \\
\hline 0.0203 & 1122 & 0.976 & 1.860 & 1.00 & 12.202 & 0010 \\
\hline 0.0205 & 1261 & 0.976 & 1.860 & 1.00 & 12.203 & 0011 \\
\hline 0.0210 & 1259 & 0.976 & 1.860 & 1.00 & 12.203 & 0012 \\
\hline 0.0208 & 1258 & 0.976 & 1.860 & 1.00 & 12.203 & 0013 \\
\hline 0.0207 & 1259 & 0.976 & 1.860 & 1.00 & 12.203 & 0014 \\
\hline 0.0210 & 1260 & 0.976 & 1.860 & 1.00 & 12.203 & 0015 \\
\hline 0.0206 & 1437 & 0.976 & 1.860 & 1.00 & 12.204 & 0016 \\
\hline 0.0211 & 1433 & 0.976 & 1.860 & 1.00 & 12.204 & 0017 \\
\hline 0.0207 & 1434 & 0.976 & 1.860 & 1.00 & 12.204 & 0018 \\
\hline 0.0209 & 1433 & 0.976 & 1.860 & 1.00 & 12.204 & 0019 \\
\hline 0.0208 & 1434 & 0.976 & 1.860 & 1.00 & 12.204 & 0020 \\
\hline 0.0236 & 1604 & 0.976 & 1.860 & 1.00 & 12.205 & 0021 \\
\hline 0.0229 & 1615 & 0.976 & 1.860 & 1.00 & 12.205 & 0022 \\
\hline 0.0231. & 1597 & 0.976 & 1.860 & 1.00 & 12.205 & 0023 \\
\hline 0.0225 & 1614 & 0.976 & 1.860 & 1.00 & 12.205 & 0024 \\
\hline 0.0214 & 1612 & 0.976 & 1.860 & 1.00 & 12.205 & 0025 \\
\hline 0.0191 & 1797 & 0.976 & 1.860 & 1.00 & 12.206 & 0026 \\
\hline 0.0225 & 1789 & 0.976 & 1.860 & 1.00 & 12.206 & 0027 \\
\hline 0.0244 & 1773 & 0.976 & 1.860 & 1.00 & 12.206 & 0028 \\
\hline 0.0224 & 1776 & 0.976 & 1.860 & 1.00 & 12.206 & 0029 \\
\hline 0.0219 & 1775 & 0.976 & 1.860 & 1.00 & 12.206 & 0030 \\
\hline 0.019/ & 940 & 0.976 & 1.860 & 1.00 & 12.301 & 0031 \\
\hline 0.0191 & 934 & 0.976 & 1.860 & 1.00 & 12.301 & 0032 \\
\hline 0.0190 & 935 & 0.976 & 1.860 & 1.00 & 12.301 & 0033 \\
\hline 0.0191 & 936 & 0.976 & 1.860 & 1.00 & 12.301 & 0034 \\
\hline 0.0185 & 935 & 0.976 & 1.860 & 1.00 & 12.301 & 0035 \\
\hline 0.0197 & 1211 & 0.976 & 1.860 & 1.00 & 12.302 & 0036 \\
\hline 0.0197 & 1209 & 0.976 & 1.860 & 1.00 & 12.302 & 0037 \\
\hline 0.0196 & 1210 & 0.976 & 1.860 & 1.00 & 12.302 & 0038 \\
\hline 0.0195 & 1206 & 0.976 & 1.860 & 1.00 & 12.302 & 0039 \\
\hline 0.0201 & 1208 & 0.976 & 1.860 & 1.00 & 12.302 & 0040 \\
\hline 0.0200 & 1357 & 0.976 & 1.860 & 1.00 & 12.303 & 0041 \\
\hline 0.0199 & 1354 & 0.976 & 1.860 & 1.00 & 12.303 & 0042 \\
\hline 0.0201 & 1353 & 0.976 & 1.860 & 1.00 & 12.303 & 0043 \\
\hline 0.0197 & 1354 & 0.976 & 1.860 & 1.00 & 12.303 & 0044 \\
\hline 0.0200 & 1356 & 0.976 & 1.860 & 1.00 & 12.303 & 0045 \\
\hline 0.0220 & 1528 & 0.976 & 1.860 & 1.00 & 12.304 & 0046 \\
\hline 0.0217 & 1526 & 0.976 & 1.860 & 1.00 & 12.304 & 0047 \\
\hline
\end{tabular}


Table A-11 (Continued)

\begin{tabular}{|c|c|c|c|c|c|c|}
\hline K & $\begin{array}{c}\text { Temperature } \\
\left.\text { ( }{ }^{\circ} \mathrm{C}\right)\end{array}$ & Density & O/M & $\mathrm{Pu}$ & $\begin{array}{c}\text { Test } \\
\text { Number }\end{array}$ & Number \\
\hline 0.0221 & 1527 & 0.976 & 1.860 & 1.00 & 12.304 & 0048 \\
\hline 0.0219 & 1527. & 0.976 & 1.860 & 1.00 & 12.304 & 0049 \\
\hline 0.0221 & 1528 & 0.976 & 1.860 & 1.00 & 12.304 & 0050 \\
\hline 0.0239 & 1720 & 0.976 & $1: 860$ & 1.00 & 12.305 & 0051 \\
\hline 0.0233 & 1719 & 0.976 & 1.860 & 1.00 & 12.305 & 0052 \\
\hline 0.0231 & 1719 & 0.976 & 1.860 & $1: 00$ & 12.305 & 0053 \\
\hline 0.0234 & 1720 & 0.976 & 1.860 & 1.00 & 12.305 & 0054 \\
\hline 0.0233 & 1718 & .0 .976 & 1.860 & 1.00 & 12.305 & 0055 \\
\hline 0.0250 & 1914 & 0.976 & 1.860 & 1.00 & 12.306 & 0056 \\
\hline 0.0292 & 1918 & 0.976 & 1.860 & 1.00 & 12.306 & 0057. \\
\hline 0.0221 & 1892 & 0.976 & 1.860 & 1.00 & 12.306 & 0058 \\
\hline 0.0236 & 1887 & 0.976 & 1.860 & 1.00 & 12.306 & 0059 . \\
\hline 0.0232 & 1886 & 0.976 & 1.860 & 1.00 & 12.306 & 0060 \\
\hline
\end{tabular}


Table A-12

TEST 7 AND TEST 13 DATA

\begin{tabular}{|c|c|c|c|c|c|c|}
\hline K & $\begin{array}{c}\text { Temperature } \\
\left.\text { ( }{ }^{\circ} \mathrm{C}\right)\end{array}$ & Density & $\mathrm{O} / \mathrm{M}$ & $\mathbf{P u}$ & $\begin{array}{c}\text { Test } \\
\text { Number }\end{array}$ & Number \\
\hline 0.0260 & 891 & 0.976 & 2.000 & 0 & 7.101 & 0001 \\
\hline 0.0264 & 887 & 0.976 & 2.000 & 0 & 7.101 & 0002 \\
\hline 0.0288 & 885 & 0.976 & 2.000 & 0 & 7.101 & 0003 \\
\hline 0.0285 & 987 & 0.976 & 2.000 & 0 & 7.102 & 0004 \\
\hline 0.0256 & 991 & 0.976 & 2.000 & 0 & 7.102 & 0005 \\
\hline 0.0257 & 992 & 0.976 & 2.000 & 0 & 7.102 & 0006 \\
\hline 0.0254 & 992 & 0.976 & 2.000 & 0 & 7.102 & 0007 \\
\hline 0.0253 & 992 & 0.976 & 2.000 & 0 & 7.102 & 0008 \\
\hline 0.0250 & 1196 & 0.976 & 2.000 & 0 & 7.103 & 0009 \\
\hline 0.0234 & 1193 & 0.976 & 2.000 & 0 & 7.103 & 0010 \\
\hline 0.0242 & 1191 & 0.976 & 2.000 & 0 & 7.103 & 0011 \\
\hline 0.0232 & 1191 & 0.976 & 2.000 & 0 & 7.103 & 0012 \\
\hline 0.0232 & 1191 & 0.976 & 2.000 & 0 & 7.103 & 0013 \\
\hline 0.0243 & 1397 & 0.976 & 2.000 & 0 & 7.104 & 0014 \\
\hline 0.0250 & 1394 & 0.976 & 2.000 & 0 & 7.104 & 0015 \\
\hline 0.0243 & 1392 & 0.976 & 2.000 & 0 & 7.104 & 0016 \\
\hline 0.0246 & 1392 & 0.976 & 2.000 & 0 & 7.104 & 0017 \\
\hline 0.0246 & 1392 & 0.976 & 2.000 & 0 & 7.104 & 0018 \\
\hline 0.0229 & 1567 & 0.976 & 2.000 & 0 & 7.105 & 0019 \\
\hline 0.0226 & 1568 & 0.976 & 2.000 & 0 & 7.105 & 0020 \\
\hline 0.0227 & 1568 & 0.976 & 2.000 & 0 & 7.105 & 0021 \\
\hline 0.0243 & 1568 & 0.976 & 2.000 & 0 & 7.105 & 0022 \\
\hline 0.0234 & 1565 & 0.976 & 2.000 & 0 & 7.105 & 0023 \\
\hline 0.0209 & 1732 & 0.976 & 2.000 & 0 & 7.106 & 0024 \\
\hline 0.0216 & 1730 & 0.976 & 2.000 & 0 & 7.106 & 0025 \\
\hline 0.0211 & 1731 & 0.976 & 2.000 & 0 & 7.106 & 0026 \\
\hline 0.0217 & 1729 & 0.976 & 2.000 & 0 & 7.106 & 0027 \\
\hline 0.0217 & 1730 & 0.976 & 2.000 & 0 & 7.106 & 0028 \\
\hline 0.0291 & 879 & 0.976 & 2.000 & 0 & 7.201 & 0029 \\
\hline 0.0305 & 878 & 0.976 & 2.000 & 0 & 7.201 & 0030 \\
\hline 0.0354 & 878 & 0.976 & 2.000 & 0 & 7.201 & 0031 \\
\hline 0.0331 & 980 & 0.976 & 2.000 & 0 & 7.202 & 0032 \\
\hline 0.0279 & 979 & 0.976 & 2.000 & 0 & 7.202 & 0033 \\
\hline 0.0303 & 979 & 0.976 & 2.000 & 0 & 7.202 & 0034 \\
\hline 0.0297 & 978 & 0.976 & 2.000 & 0 & 7.202 & 0035 \\
\hline 0.0279 & 979 & 0.976 & 2.000 & 0 & 7.202 & 0036 \\
\hline 0.0246 & 1178 & 0.976 & 2.000 & 0 & 7.203 & 0037 \\
\hline U.Ü278 & 1179 & 0.376 & 2.000 & 0 & 7.203 & 0038 \\
\hline 0.0268 & 1178 & 0.976 & 2.000 & 0 & 7.203 & 0039 \\
\hline 0.0253 & 1172 & 0.976 & 2.000 & 0 & 7.203 & 0040 \\
\hline 0.0261 & 1174 & 0.976 & 2.000 & 0 & 7.203 & 0041 \\
\hline 0.0244 & 1395 & 0.976 & 2.000 & 0 & 7.204 & 0042 \\
\hline 0.0223 & 1395 & 0.976 & 2.000 & 0 & 7.204 & 0043 \\
\hline 0.0233 & 1394 & 0.976 & 2.000 & 0 & 7.204 & 0044 \\
\hline 0.0227 & 1392 & 0.976 & 2.000 & 0 & 7.204 & 0045 \\
\hline 0.0224 & 1392 & 0.976 & 2.000 & 0 & 7.204 & 0046 \\
\hline 0.0221 & 1567 & 0.976 & 2.000 & 0 & 7.205 & 0047 \\
\hline
\end{tabular}


Table A-12 (Continued)

\begin{tabular}{|c|c|c|c|c|c|c|}
\hline K & $\begin{array}{c}\text { Temperature } \\
\left.\text { ( }{ }^{\circ} \mathrm{C}\right)\end{array}$ & Density & $O / M$ & $\mathrm{Pu}$ & $\begin{array}{c}\text { Test } \\
\text { Number }\end{array}$ & Number \\
\hline 0.0214 & 1567 & 0.976 & 2.000 & 0 & 7.205 & 0048 \\
\hline 0.0214 & 1568 & 0.976 & 2.000 & 0 & 7.205 & 0049 \\
\hline 0.0214 & 1567 & 0.976 & 2.000 & 0 . & $7.205:$ & 0050 \\
\hline 0.0212 & 1569 & 0.976 & 2.000 & 0 & 7.205 & 0051. \\
\hline 0.0172 & 1739 & 0.976 & 2.000 & 0 & 7.206 & 0052 \\
\hline 0.017 .7 & 1737 & 0.976 & $2: 000$ & 0 . & 7.206 & 0053 \\
\hline 0.0175 & 1738 & 0.976 & 2.000 & 0 & 7.206 & 0054 \\
\hline 0.0177 & 1736 & 0.976 & 2.000 & 0 & 7.206 & 0055 \\
\hline 0.0175 & 1738 & 0.976 & 2.000 & 0 & 7.206 & 0056 \\
\hline 0.0336 & 892 & 0.976 & 2.000 & 0 & 7.301 & 0057 \\
\hline 0.0349 & 888 & 0.976 & 2.000 & 0 & 7.301 & 0058 \\
\hline 0.0388 & 888 & 0.976 & 2.000 & 0 & 7.301 & 0059 \\
\hline 0.0340 & 994 & 0.976 & 2.000 & 0 & 7.302 & 0060 \\
\hline 0.0344 & 994 & 0.976 & 2.000 & 0 & 7.302 & 0061 \\
\hline 0.0343 & 994 & 0.976 & 2.000 & 0 & 7.302 & 0062 \\
\hline 0.0345 & 994 & 0.976 & 2.000 & 0 & 7.302 & 0063 \\
\hline 0.0339 & 994 & 0.976 & 2.000 & 0 & 7.302 & 0064. \\
\hline 0.0281 & 1204 & 0.976 & 2.000 & 0 & 7.303 & 0065 \\
\hline 0.0289 & 1202 & 0.976 & 2.000 & 0 & 7.303 & 0066 \\
\hline 0.0285 & 1202 & 0.976 & 2.000 & 0 & 7.303 & 0067 \\
\hline 0.0289 & 1189 & 0.976 & 2.000 & 0 & 7.303 & 0068 \\
\hline 0.0286 & 1200 & 0.976 & 2.000 & 0 & 7.303 & 0069 \\
\hline 0.0251 & 1419 & 0.976 & 2.000 & 0 & 7.304 & 0070 \\
\hline 0.0246 & 1420 & 0.976 & 2.000 & 0 & 7.304 & 0071 \\
\hline 0.0246 & 14.19 & 0.976 & 2.000 & 0 & 7.304 & 0072 \\
\hline 0.0251 & 1417 & 0.976 & 2.000 & 0 & 7.304 & 0073 \\
\hline 0.0248 & 1416 & 0.976 & 2.000 & 0 & 7.304 & 0074 \\
\hline 0.0234 & 1593 & 0.976 & 2.000 & 0 & 7.305 & 0075 \\
\hline 0.0239 & 1595 & 0.976 & 2.000 & 0 & 7.305 & 0076 \\
\hline 0.0236 & 1595 & 0.976 & 2.000 & 0 & 7.305 & 0077 \\
\hline 0.0241 & 1593 & 0.976 & 2.000 & 0 & 7.305 & 0078 \\
\hline 0.0236 & 1595 & 0.976 & 2.000 & 0 & 7.305 & 0079 \\
\hline 0.0222 & 1759 & 0.976 & 2.000 & 0 & 7.306 & 0080 \\
\hline 0.0221 & 1759 & 0.976 & $2: 000$ & 0 & 7.306 & 0081 \\
\hline 0.0222 & 1758 & 0.976 & 2.000 & 0 & 7.306 & 0082 \\
\hline 0.0220 & 1758 & 0.976 & 2.000 & 0 & 7.306 & 0083 \\
\hline 0.0221 & 1759 & 0.976 & 2.000 & 0 & 7.306 & 0084 \\
\hline 0.0289 & 1124 & 0.976 & 2.000 & 0 & 13.202 & 0085 \\
\hline 0.0277 & 1124 & 0.976 & 2.000 & 0 & 13.202 & 0086 \\
\hline 0.0288 & 1.124 & 0.976 & 2.000 & 0 & 13.202 & 0087 \\
\hline 0.0279 & 1125 & 0.976 & 2.000 & 0 & 13.202 & 0088 \\
\hline 0.0281 & 1125 & 0.976 & 2.000 & 0 & 13.202 & 0089 \\
\hline 0.0259 & 1281 & 0.976 & 2.000 & 0 & 13.203 & 0090 \\
\hline 0.0267 & 1288 & 0.976 & 2.000 & 0 & 13.203 & 0091 \\
\hline 0.0268 & 1290 & 0.976 & 2.000 & 0 & 13.203 & 0092 \\
\hline 0.0283 & 1288 & 0.976 & $2: 000$ & 0 & 13.203 & 0093 \\
\hline 0.0278 & 1289 & 0.976 & 2.000 & 0 & 13.203 & 0094 \\
\hline 0.0248 & 1450 & 0.976 & 2.000 & 0 & 13.204 & 0095 \\
\hline
\end{tabular}


GEAP-13733

Table A-12 (Continued)

$\begin{array}{ccccccc}K & \begin{array}{c}\text { Temperature } \\ \left.{ }^{\circ} \mathrm{C}\right)\end{array} & \text { Density } & \text { O/M } & \text { Pu } & \begin{array}{c}\text { Test } \\ \text { Number }\end{array} & \text { Number } \\ 0.0259 & 1449 & 0.976 & 2.000 & 0 & 13.204 & 0096 \\ 0.0266 & 1442 & 0.976 & 2.000 & 0 & 13.204 & 0097 \\ 0.0269 & 1443 & 0.976 & 2.000 & 0 & 13.204 & 0098 \\ 0.0264 & 1444 & 0.976 & 2.000 & 0 & 13.204 & 0099 \\ 0.0269 & 1626 & 0.976 & 2.000 & 0 & 13.205 & 0100 \\ 0.0265 & 1627 & 0.976 & 2.000 & 0 & 13.205 & 0101 \\ 0.0252 & 1624 & 0.976 & 2.000 & 0 & 13.205 & 0102 \\ 0.0238 & 1630 & 0.976 & 2.000 & 0 & 13.205 & 0103 \\ 0.0238 & 1629 & 0.976 & 2.000 & 0 & 13.205 & 0104 \\ 0.0258 & 1864 & 0.976 & 2.000 & 0 & 13.206 & 0105 \\ 0.0262 & 1865 & 0.976 & 2.000 & 0 & 13.206 & 0106 \\ 0.0261 & 1863 & 0.976 & 2.000 & 0 & 13.206 & 0107 \\ 0.0260 & 1864 & 0.976 & 2.000 & 0 & 13.206 & 0108 \\ 0.0261 & 1863 & 0.976 & 2.000 & 0 & 13.206 & 0109 \\ 0.0265 & 2039 & 0.976 & 2.000 & 0 & 13.207 & 0110 \\ 0.0282 & 2038 & 0.976 & 2.000 & 0 & 13.207 & 0111 \\ 0.0273 & 2038 & 0.976 & 2.000 & 0 & 13.207 & 0112 \\ 0.0271 & 2037 & 0.976 & 2.000 & 0 & 13.207 & 0113 \\ 0.0276 & 2037 & 0.976 & 2.000 & 0 & 13.207 & 0114 \\ 0.0276 & 2232 & 0.976 & 2.000 & 0 & 13.208 & 0115 \\ 0.0289 & 2234 & 0.976 & 2.000 & 0 & 13.208 & 0116 \\ 0.0254 & 2241 & 0.976 & 2.000 & 0 & 13.208 & 0117 \\ 0.0263 & 2242 & 0.976 & 2.000 & 0 & 13.208 & 0118 \\ 0.0247 & 2242 & 0.976 & 2.000 & 0 & 13.208 & 0119\end{array}$




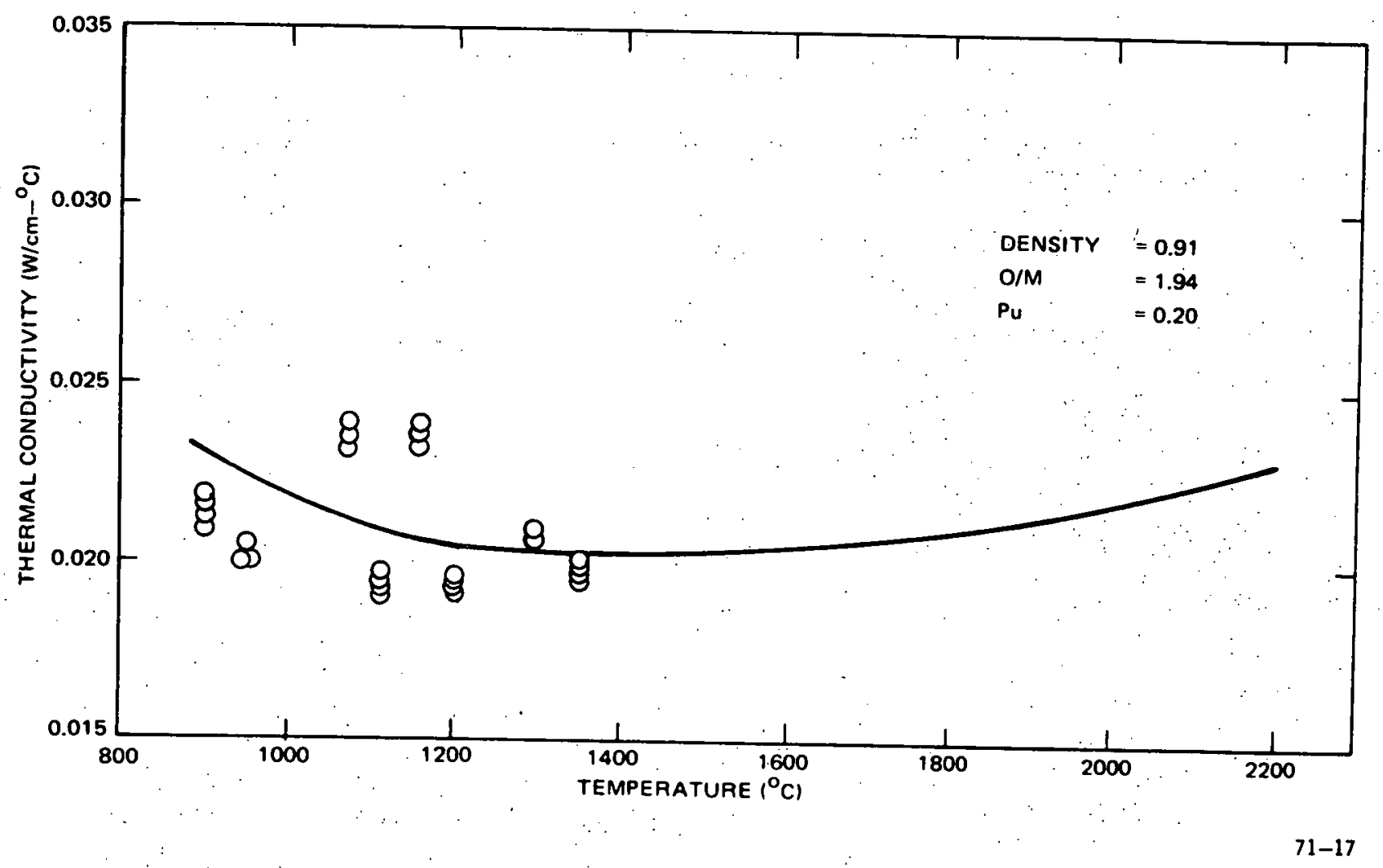

Figure A:1. Test 8 (Part 1)

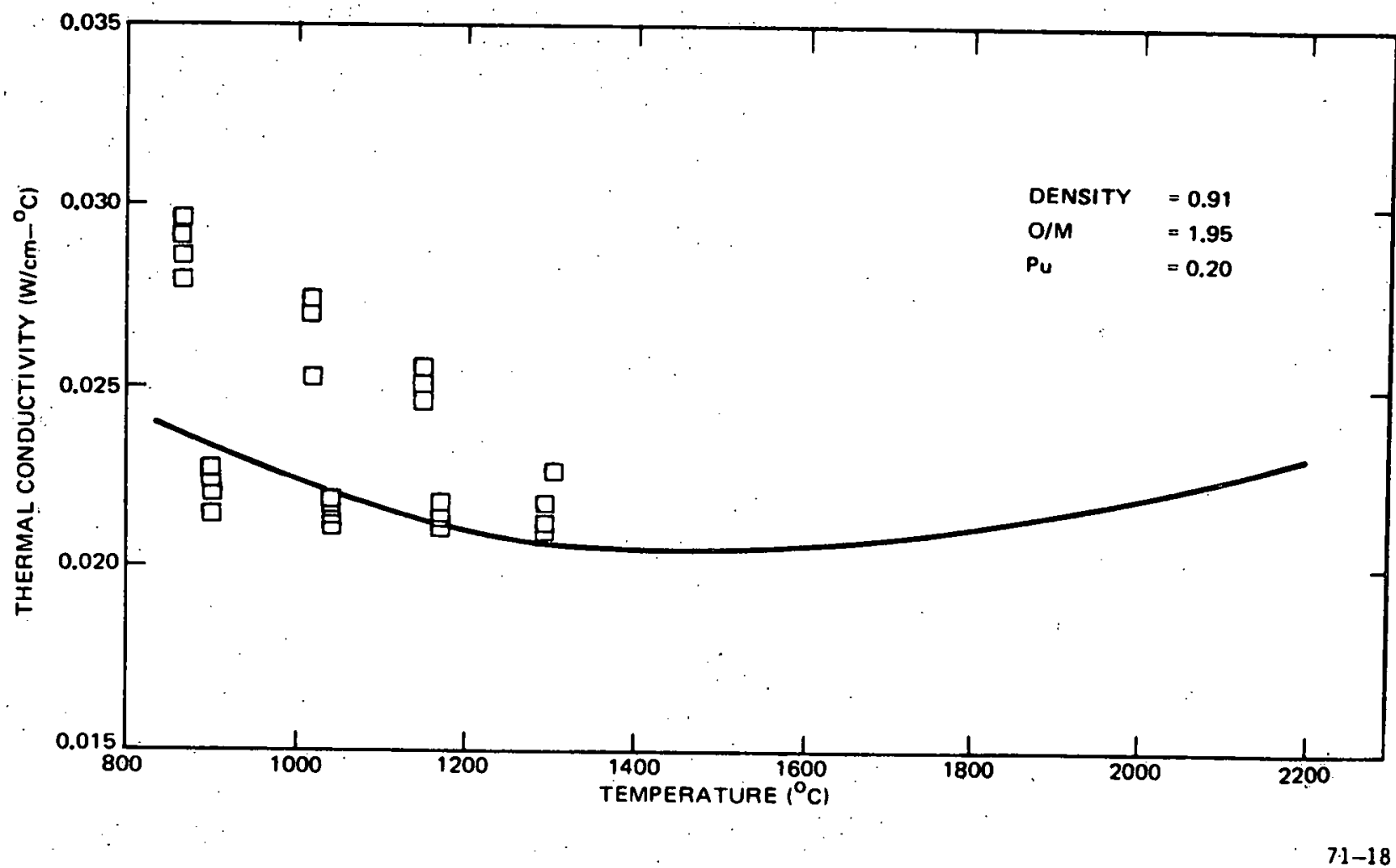

Figure A-2 Test 8 (Part I) 


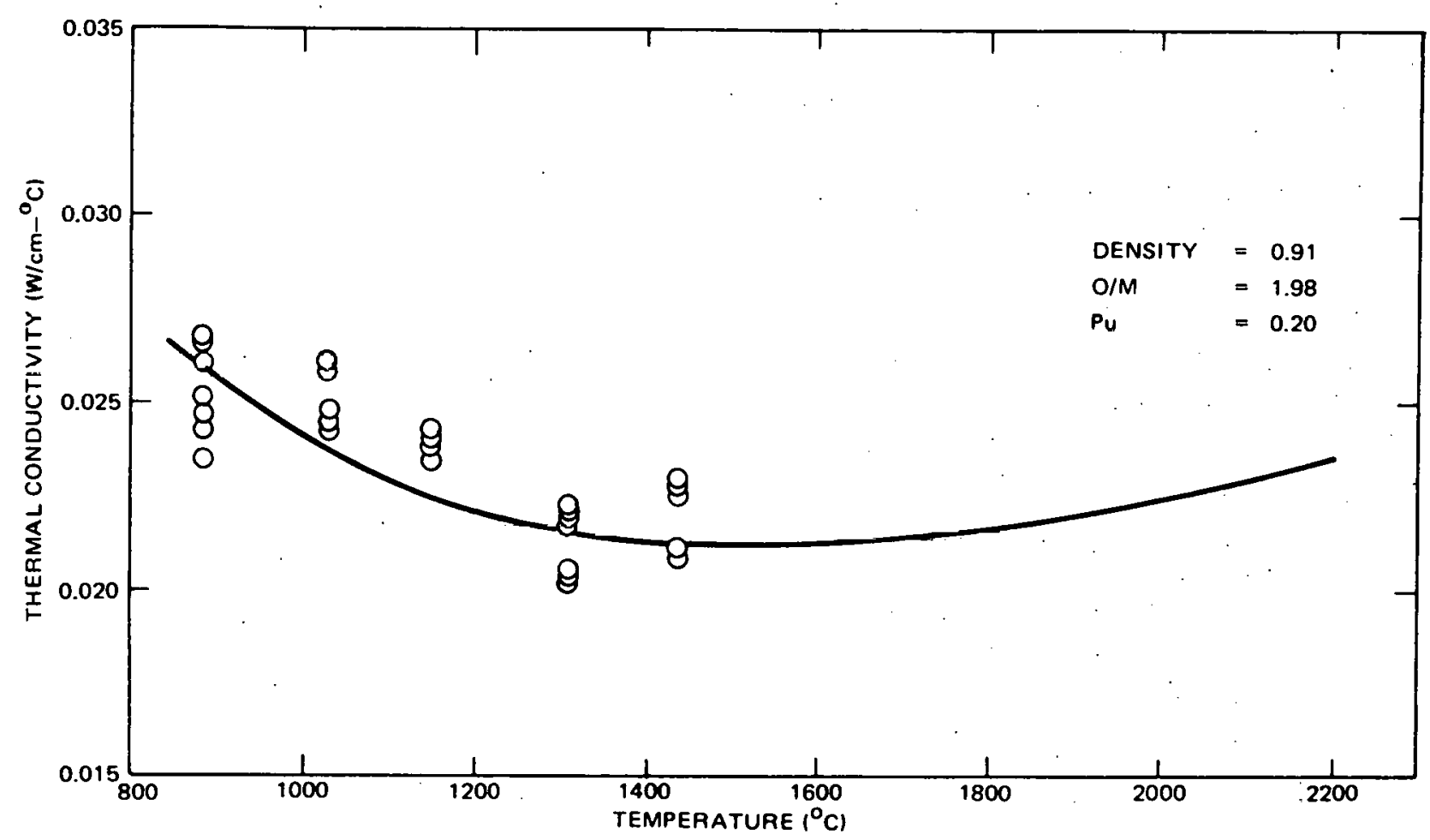

$71-19$

Figure A-3. Test 8 (Part II)

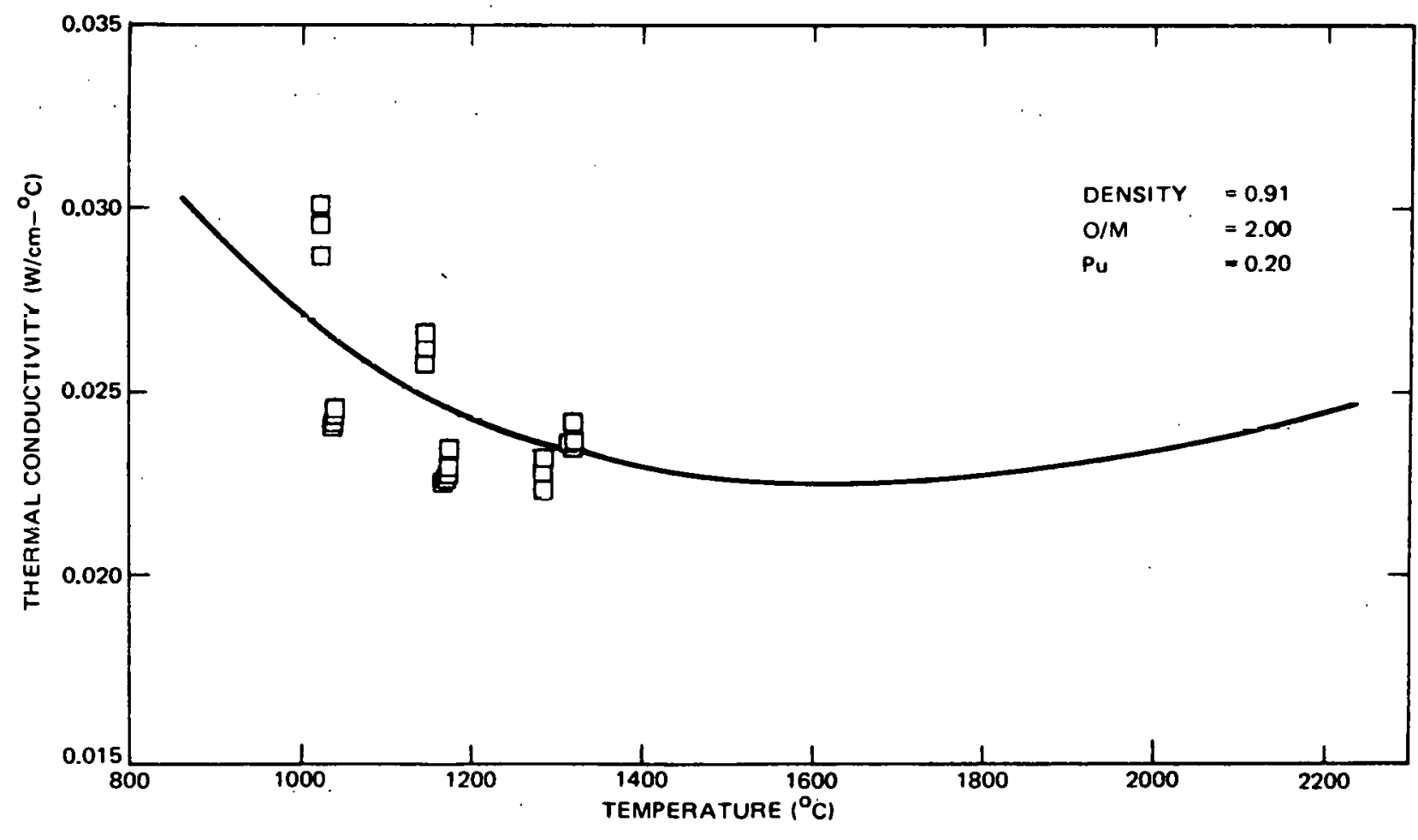

Figure A-4. Test 8 (Part II) 


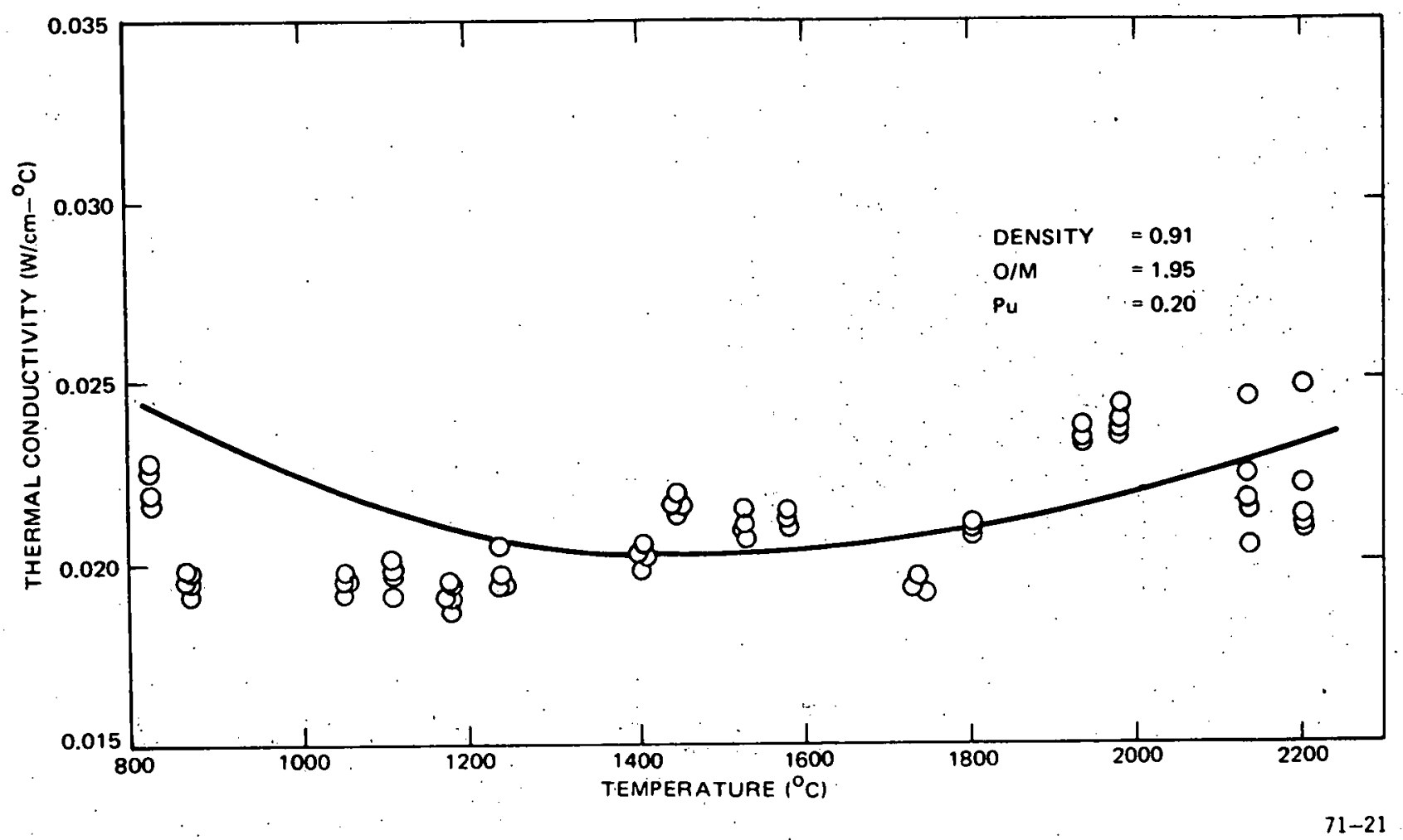

Figure A-5: Test 8 (Part III)

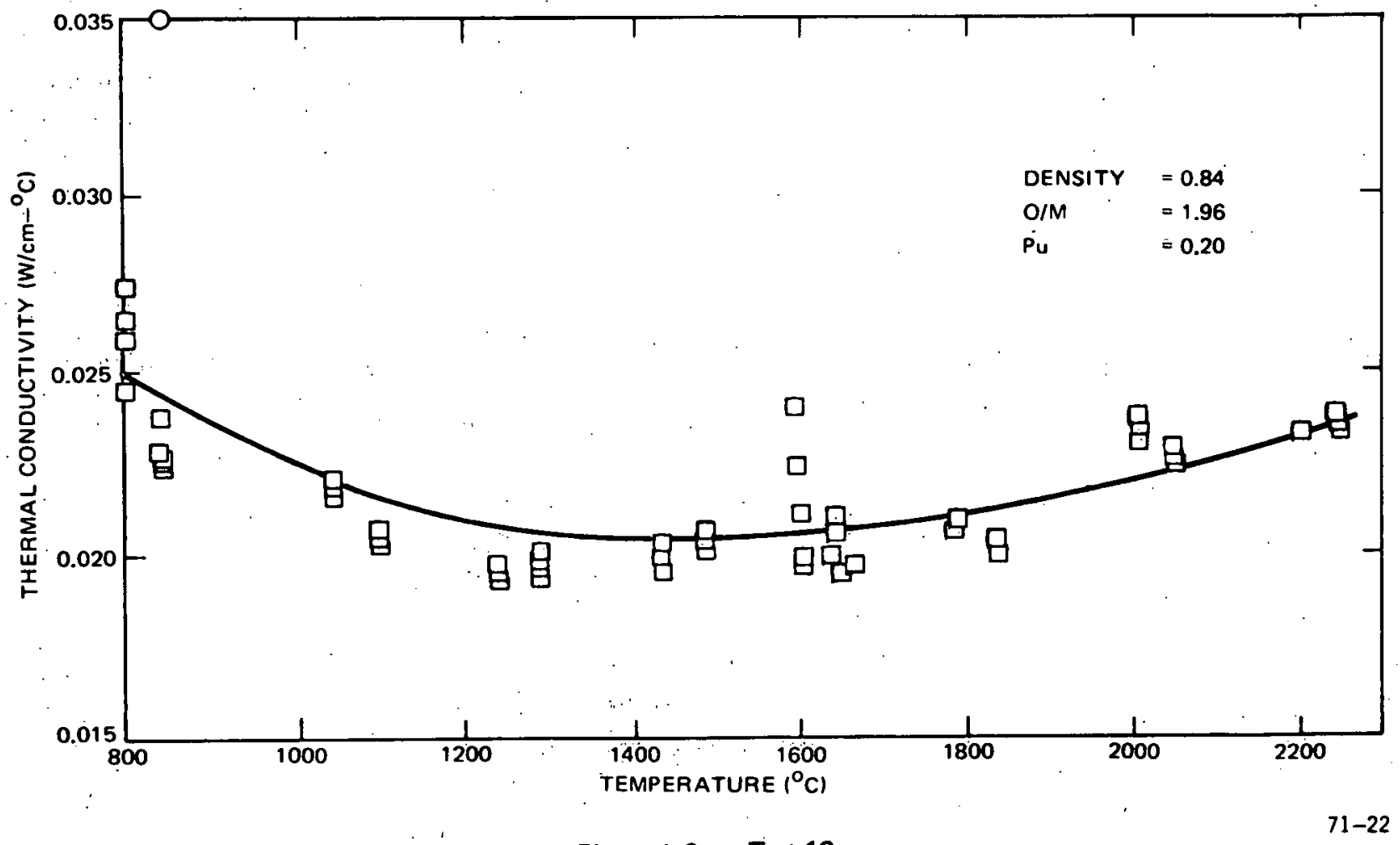

Figure A-6. Test 10 


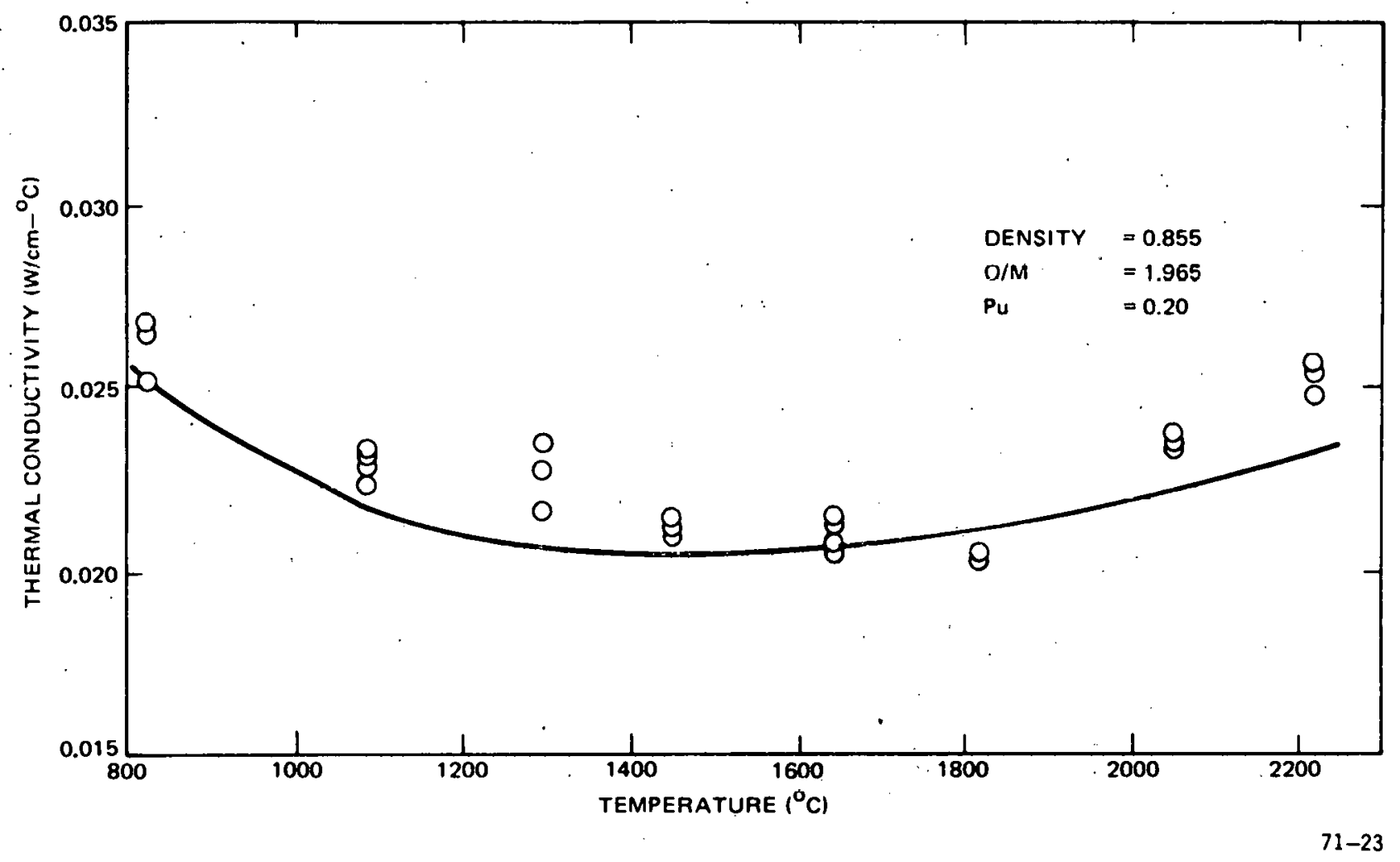

Figure A-7. Test 11

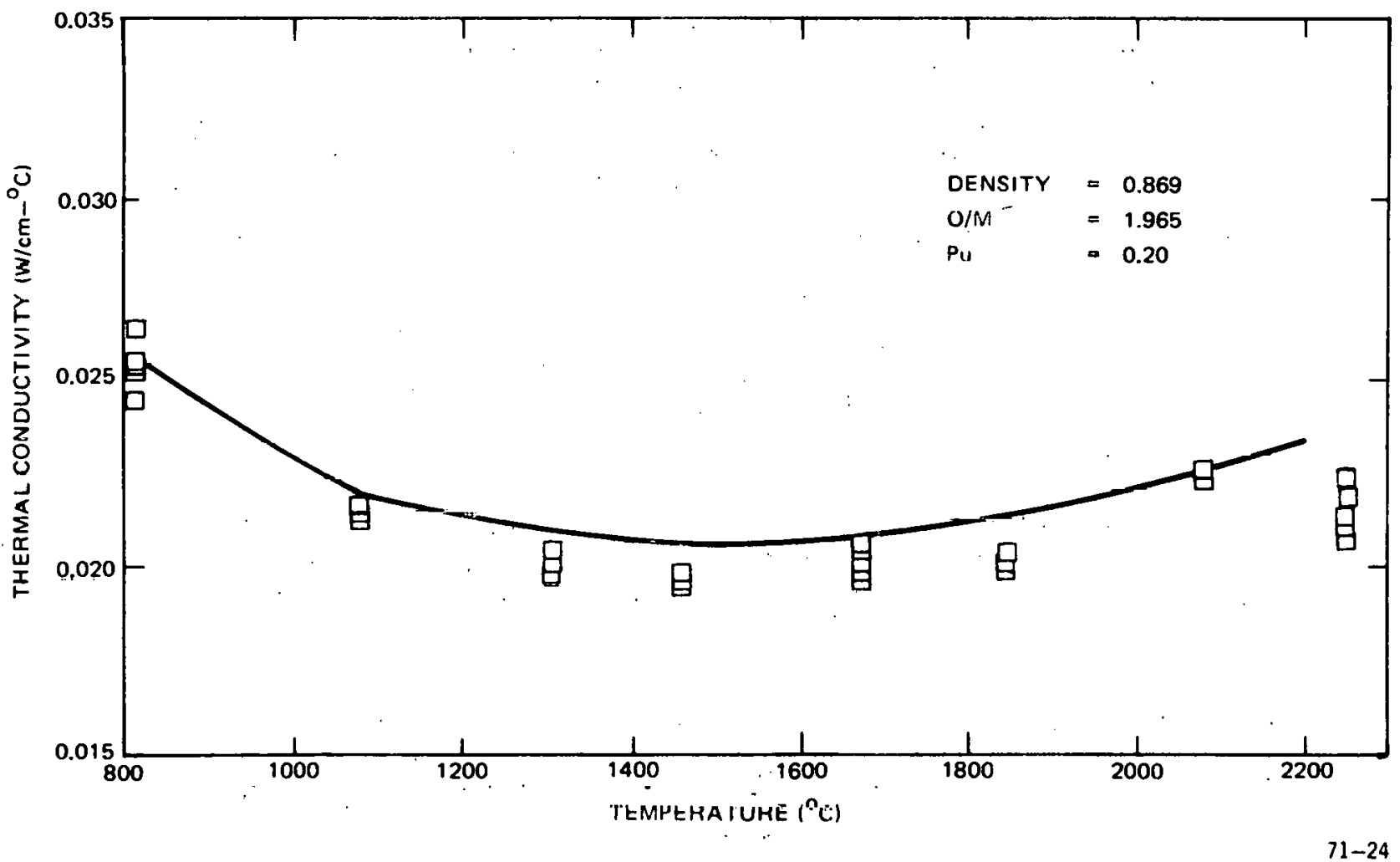

Figure A-8. Test 11 
GEAP-13733

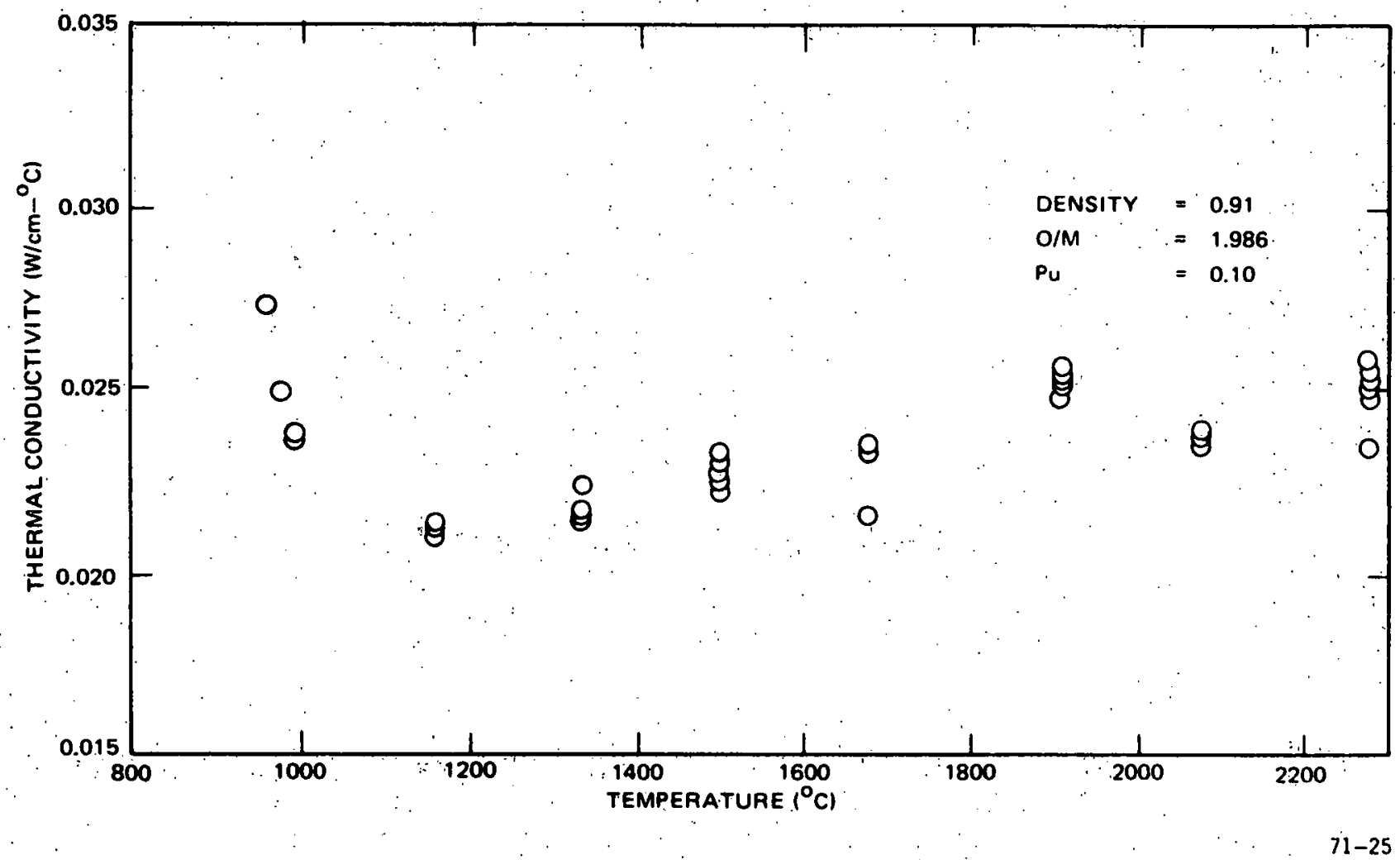

Figure A-9. Test 13

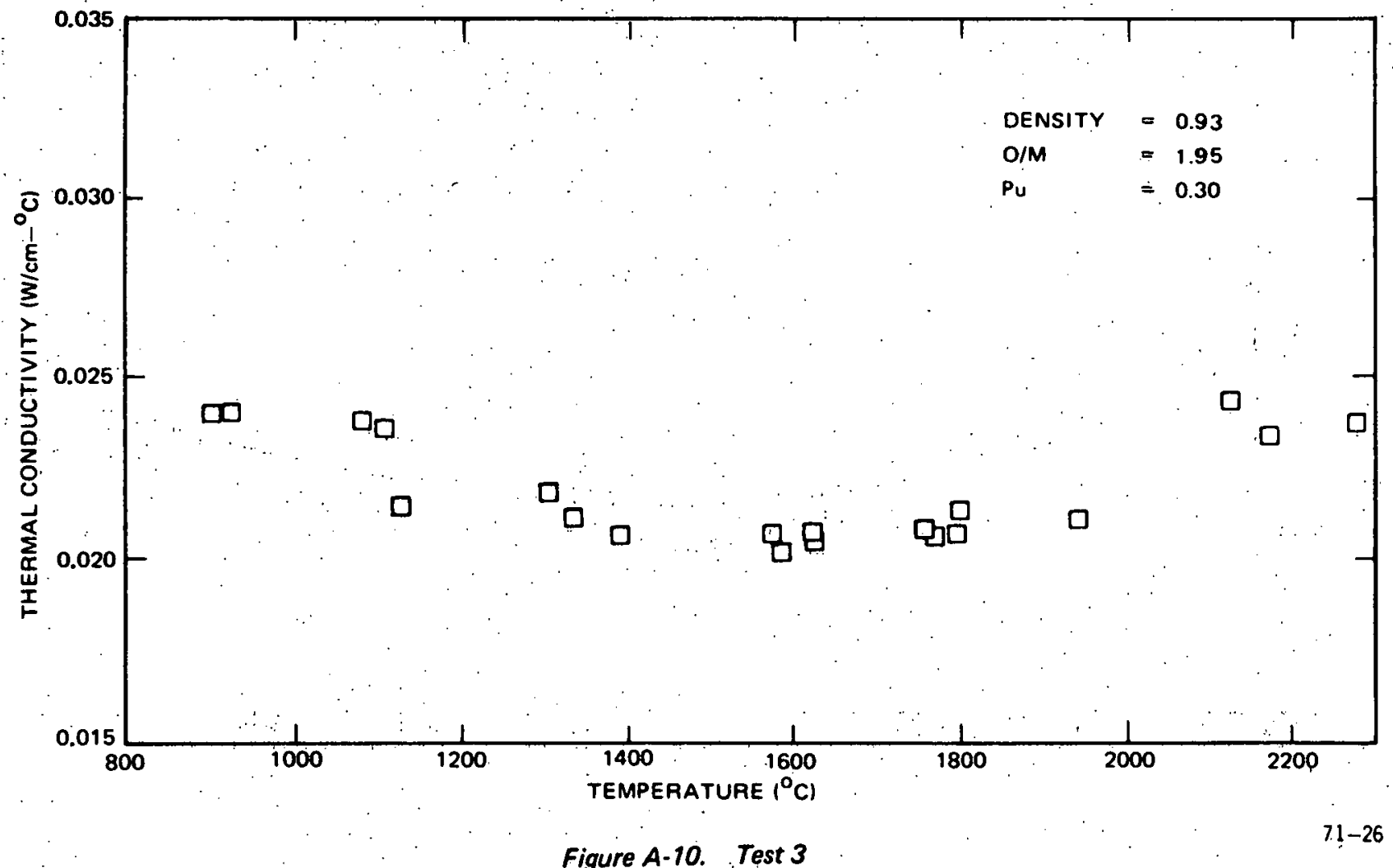

$.50-$ 
GEAP.13733

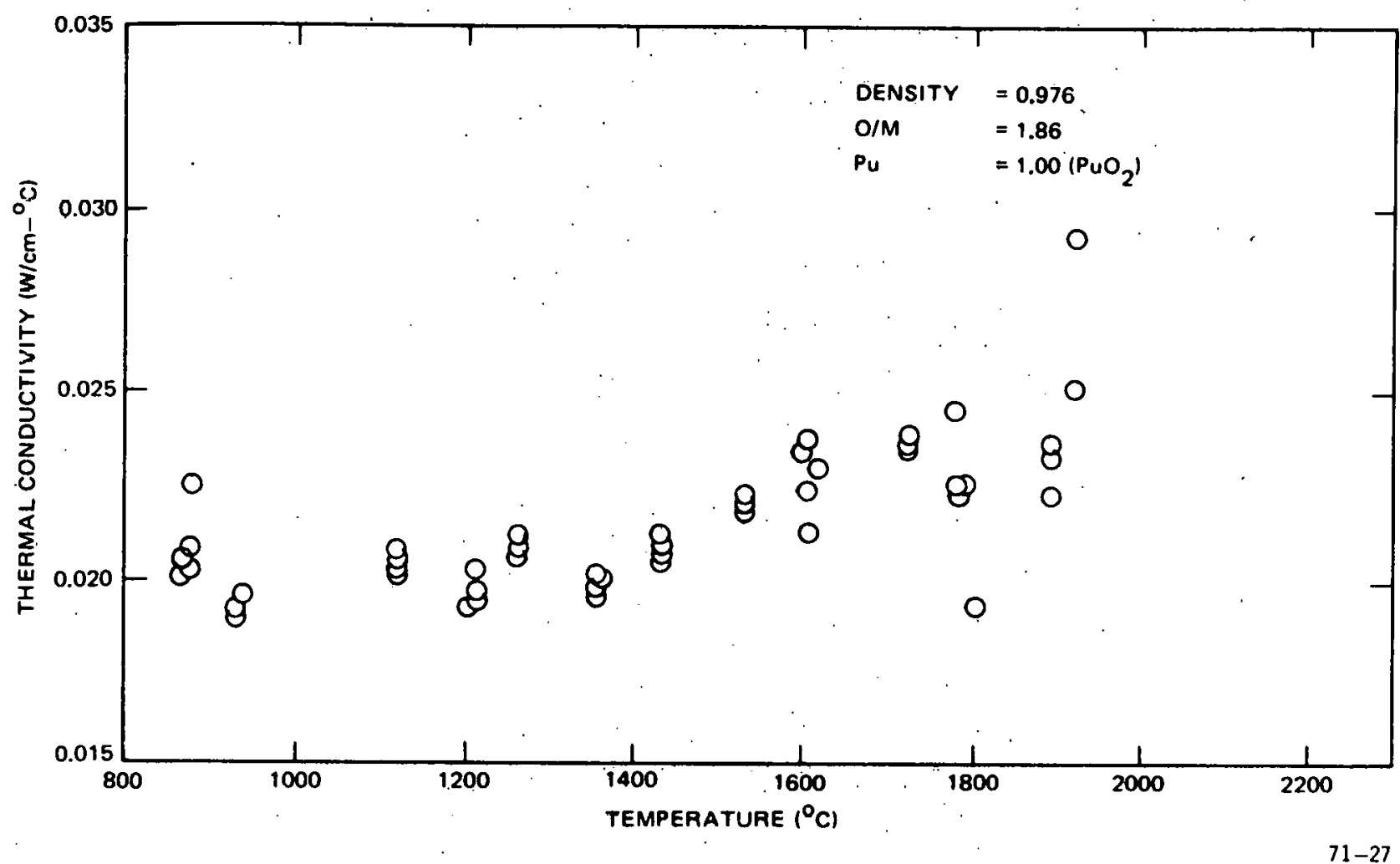

Figure A-11. Test 12

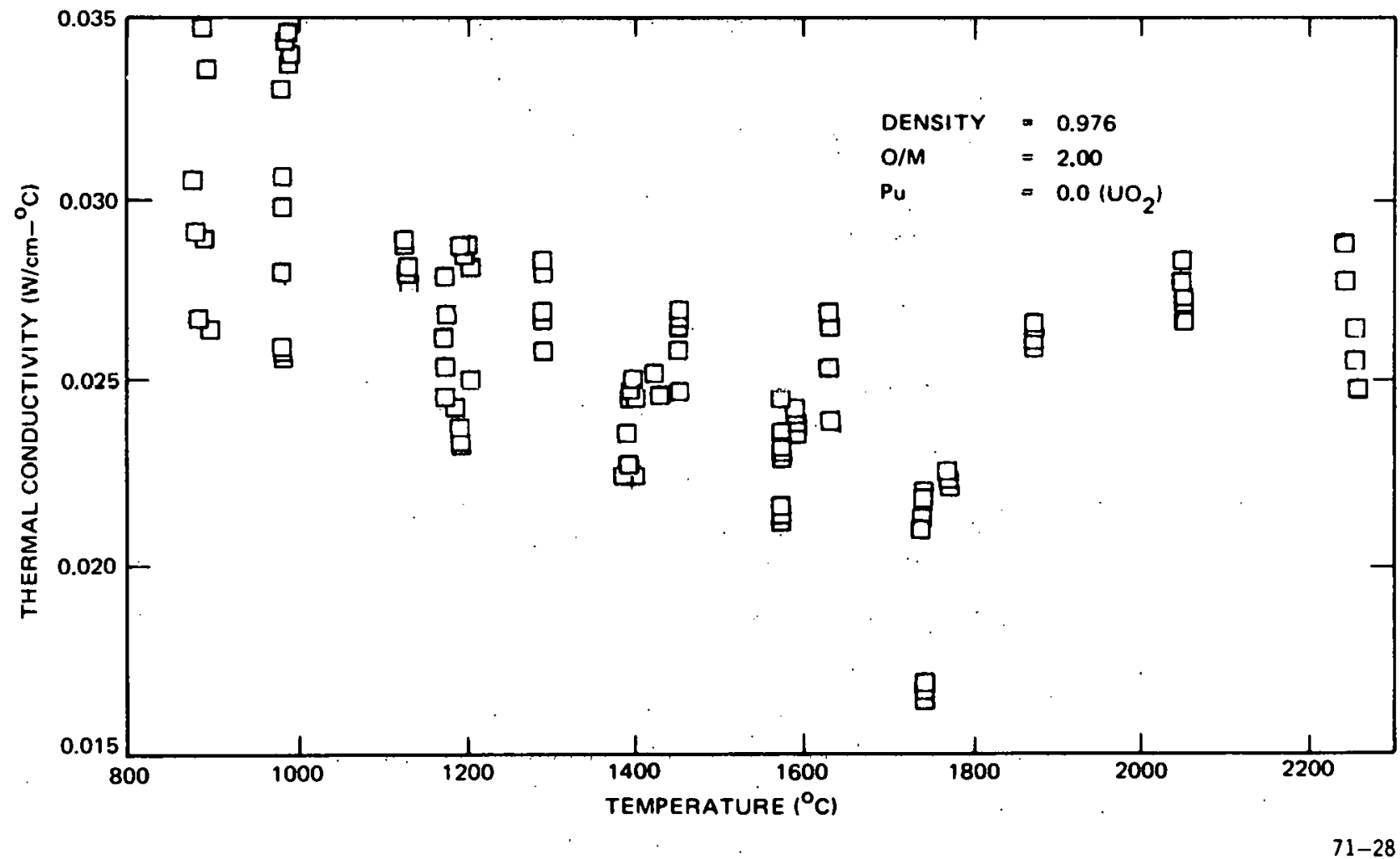

Figure A-12. Test 7 and Test 13 


\section{APPENDIX B. STATISTICAL ANALYSIS RESULTS}

The results of the statistical analysis used to determine the empirical equation for the thermal conductivity of $\left(\mathrm{U}_{0.8} \mathrm{Pu}_{0.2}\right)_{2-x}$ are given in this appendix. As indicated, only the $20 \% \mathrm{Pu} /(\mathrm{Pu}+\mathrm{U})$ data were used to determine the equation. This represented data from Tests $8(1), 8(11), 8(111), 10$ and 11 (see Appendix A) for a total of 396 data points which are indicated by "sample number" here. The "independent variable" is temperature ("C); the "dependent variable" is thermal conductivity $\left(\mathrm{W} / \mathrm{cm}-{ }^{\circ} \mathrm{C}\right)$; the "residual" is the "observed" minus the "predicted" value of the dependent variable; the "percent deviation" is based upon the predicted value of the dependent variable and the " $90 \%$ confidence limits" are based upon the predicted value of the dependent variable.

The term "predicted" is the value determined by the empirical equation. The "observed". value is the measured one. 


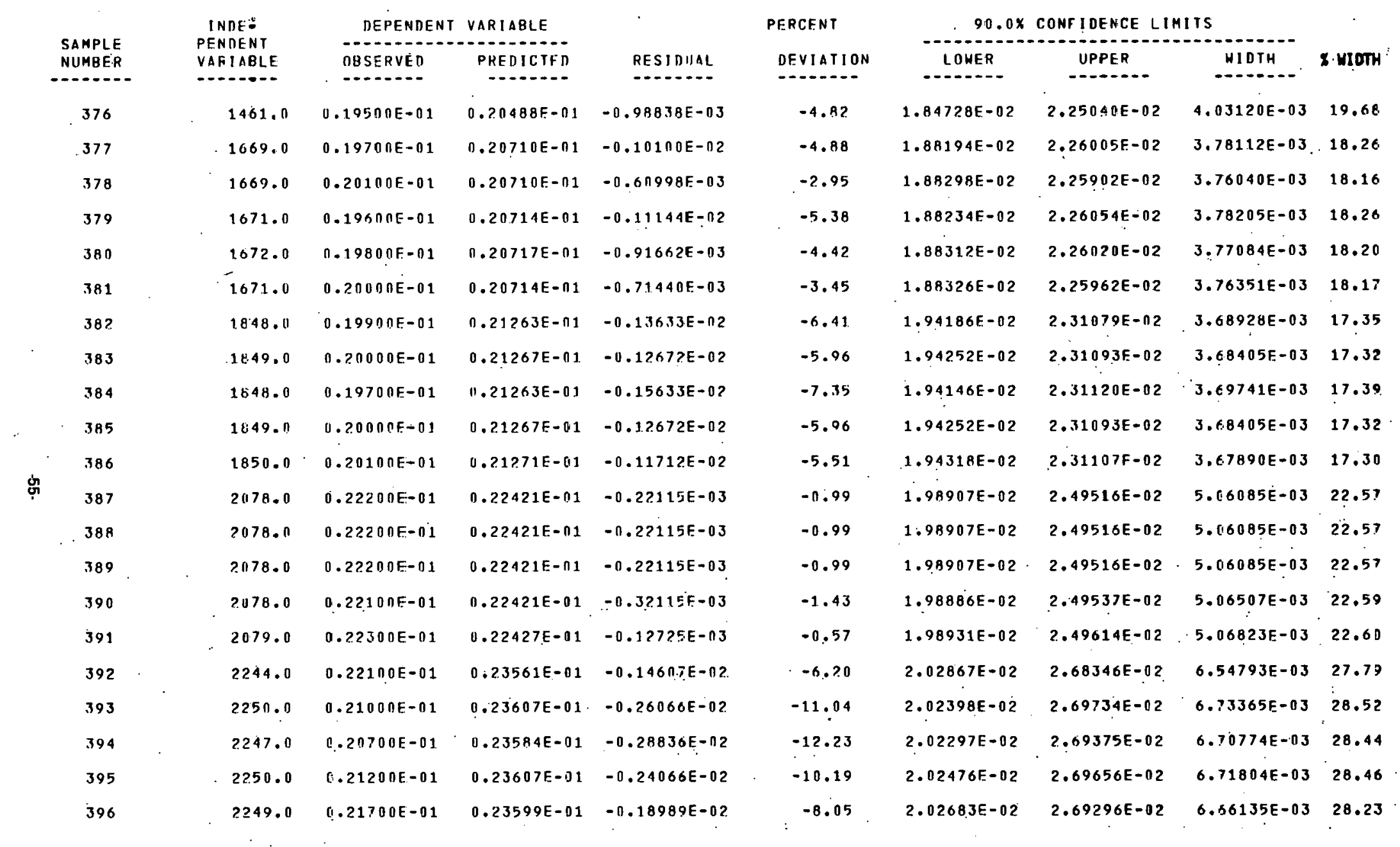




\begin{tabular}{|c|c|c|c|c|c|c|c|c|c|c|}
\hline \multirow{3}{*}{\multicolumn{2}{|c|}{$\begin{array}{l}\text { SAMPLE } \\
\text { NUMBER } \\
\text { SUM }\end{array}$}} & . INDE & DEPENDEN T & VARIABLE & & PERCENT & $\therefore 90.0 x$ & CONFIDENCE LI & ITs & \\
\hline & & $\begin{array}{l}\text { PENDENT } \\
\text { VARIAB̈LEE }\end{array}$ & OBSERVED & PREDICTED & RESIIUUA & DEVIATION & LOHER & UPPER & HIDTH & 8 HIOTH \\
\hline & & $\cdots$ & 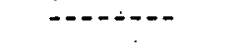 & $\therefore-\ldots$ & $\cdots$ & $\cdots+\cdots$ & $\cdots$ & $\cdots$ & $\cdots+-\cdots$ & \\
\hline & 351 & 2058.0 & $0.23400 E-0.1$ & $0.22292 E-01$ & $0.11078 E-0 ?$ & 4.97 & $2.01862 E-02$ & $2.43981 E-02$ & $4.21195 E-03$ & 18.89 \\
\hline & 352 & 2228.0 & $0.24700 \mathrm{E}-01$ & $0.23432 F-01$ & $0.12685 E-0 ?$ & 5.41 & $2.02185 E-02$ & $2.66445 E-02$ & $6.42603 E-03$ & 27.42 \\
\hline & 353 & $2230: 0$ & $0.25500 E-01$ & $0.23447 E-01$ & $0.20535 E-02$ & 8.76 & $2.02430 E-02$ & $2.66500 E-02$ & $6.40700 E-03$ & 27.33 \\
\hline & 354 & 2.230 .0 & $0.25500 E-01$ & $0.23447 E-01$ & $0.20535 E-02$ & 8.76 & $2.02430 E-02$ & $2.66500 E-02$ & $6.40700 E-03$ & 27.33 \\
\hline & 355 & 2229.0 & $0.25200 E-n 1$ & $0.23439 E-01$ & $0.17610 E-02$ & 7.51 & $2.02341 E-02$ & $2.66440 E-02$ & $6.40 .987 E-03$ & 27.35 \\
\hline & 356 & 2229.0 & $0.25200 E-n 1$ & $0.23439 E-01$ & $0.17610 E-02$ & $7.51^{\circ}$ & $2.02341 E-02$ & $2.66440 E-02$ & $6.40987 E-03$ & 27.35 \\
\hline & 357 & 810.00 & $0.25600 E-01$ & $0.24993 E-01$ & $0.60734 \mathrm{E}-\mathrm{n3}$ & 2.43 & $2.16154 E-02$ & $2.83699 E-02$ & $6.75445 E-03$ & 27.03 \\
\hline & $358^{\circ}$ & 813.00 & $0.2540 \cap E-01$ & $0.24934 E-01$ & $0.46563 E-03$ & 1.87 & $2.15918 E-02$ & $2.82769 E-02$ & $6.68516 \mathrm{E}-03$ & 26.81 \\
\hline & 359 & 813.00 & $0.25300 \mathrm{E}-01$ & $0.24934 E-01$ & $0.36563 E-n 3$ & 1.47 & $2.158 B 3 E-02$ & $2.82804 E-02$ & $6.69204 E-03$ & 26.84 \\
\hline . & 360 & 813.00 & $0.26200 E-01$ & $0.24934 E-\pi .1$ & $0.12656 E-02$ & 5.08 & $2.161 .73 E-02$ & $2.82515 E-02$ & $6.63423 E-03$ & 26.61 \\
\hline & 361 & 814.00 & $0.24400 E-01$ & $0: 24915 E-01$ & $-0.51509 E-03$ & -2.07 & $2.15526 E-02$ & $2.82776 \mathrm{E}-02$ & $6.72505 E-03$ & 26.99 \\
\hline$\square$ & 362 & 1089.11 & $0.212 \cap 0 E-01$ & $0.21623 \mathrm{E}-01$ & $-0.42 .268 E-n 3$ & $-1.95^{\circ}$ & $1.99259 \mathrm{E}-02$ & $2.33194 \mathrm{E}-02$ & $3.39353 E-03$ & 15.69 \\
\hline & 363 & 1090.0 & $0.21400 \mathrm{E}-01$ & $0.21616 E-01$ & $-0.21588 E-\pi 3$ & -1.00 & $1.99257 \mathrm{E}-02$ & $2.33061 E-02$ & $3.38043 E-03$ & $15.64^{\circ}$ \\
\hline & 364 & 1088.1 & $0.21100 \mathrm{E}-01$ & $0.21630 E-01$ & $-0.5 ? 950 \mathrm{E}-03$ & -2.45 & $1.99 .285 E-02$ & $2.33305 E-02$ & $3.40204 E-03$ & 15.7 .3 \\
\hline & 365 & 1090.0 & $0.214011 E-01$ & $0.21616 \mathrm{E}-01$ & $-0.21588 E-0.3$ & $-1 . n 0$ & $1.99257 E-02$ & $2: 33061 E-02$ & $3.38043 E-03$ & 15.64 \\
\hline & 366 & 1089.0 & $0.21200 E-01$ & $0.21623 E-01$ & $-0.42268 E-03$ & -1.95 & $1.99259 \mathrm{E}-02$ & $2.33194 E-02$ & $3.3935 .3 E-.03$ & 15.69 \\
\hline & 367 & 1312.0 & $0.20000 E-01$ & $0.20660 \mathrm{E}-01$ & $-0.65960 E-03$ & -3.19 & $1.88506 E-02$ & $2.24686 E-02$ & $3.61 .800 \mathrm{~F}-03$ & 17.51 \\
\hline & 368 & $1311 \cdot 0$ & $0.19800 E-01$ & $0.20662 E-01$ & $-0.86184 E-n 3$ & -4.17 & $1.88491 E-02$ & $2.24746 E-02$ & $3.62547 E-03$ & 17.55 \\
\hline & 369 & 1313.0 & $0.20200 E-01$ & $0.20657 E-01$ & $-0.45737 E-03$ & -2.21 & $1.88529 F-02$ & $2.24618 F-02$ & $3.60886 E-n 3$ & 17.47 \\
\hline & 370 & 1313.0 & $0.20200 E-01$ & $0.20657 E-01$ & $-0.45737 E-B 3$ & -2.21 & $1.88529 E-02$ & $2.24618 E-02$ & $3: 60886 E-03$ & 17.47 \\
\hline & 371 & 1313.0 & $0.20100 E-01$ & $0.20657 E-01$ & $-0.55737 F=03$ & -2.70 & $1.88503 E-n 2$ & $2.24645 F-.02$ & $3.61420 \mathrm{E}-03$ & 17.50 \\
\hline & 372 & 1462.0 & $0.19500 E-01$ & $0.20488 E-71$ & $-0.99824 E-03$ & -4.82 & $1.84725 E-02$ & $2.25040 E-02$ & $4.03147 E-03$ & 19.68 \\
\hline & 373 & 1461.0 & $0.19400 \mathrm{E}-01$ & $0.204 B 8 E-01$ & $-0.1 .0 B 84 E-12$ & -5.31 & $1.84702 E-02$ & $2.25066 E-02$ & $4.03644 E=03$ & 19.70 \\
\hline & 374 & 1462.0 & $0.1 .970 \cap E-n 1$ & $0.20488 E-01$ & $-0.78824 E-\cap 3$ & -3.85 & $1.84777 E-02$ & $2.24988 \mathrm{EF}-02$ & $4.02109 E-03$ & 19.63 \\
\hline & 375 & $1462 . n$ & $0.1950 \cap E-01$ & $0.20488 F-01$ & $-0.98824 E-n 3$ & -4.82 & $1.8472 .5 E-02$ & $2.25040 E-02$ & $4.03147 E-03$ & 19.68 \\
\hline
\end{tabular}




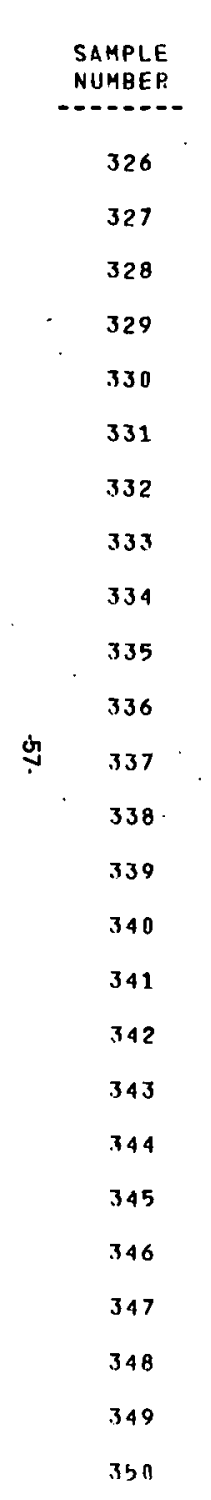

DEPENIENT VARIABLE OBSERVED PREDICTED

RESI DUAL

1086.0

1296.0

$0.229 \cap \cap E-01$

$0.23300 \mathrm{E}-\mathrm{n} 1$

$0.21626 \mathrm{E}-0$

$0.20683 \mathrm{E}-01$

0.2068 BE-01

$0.20681 E-01$

$0.20683 F-01$

$0.20683 E-01$

$0.20479 E-01$

$0.20478 E-01$

$0.20478 E-01$

ก.20478E-01

$1450.0 \quad 0.21000 E-0$

$1451.0 \quad 0.210$ OEE -01

$1450.0 \quad 0.214011 \mathrm{E}-01$

$1055.0 \quad 0.206 n \cap E-01$

$2654.0 \quad 0.213$ AOE-DI

1655.0 0.215nOE-0.1

16.54.0 I.2กBחDF-ก1

2656.0 O.2त7nกE-0.

1625.0 0.205nחF-nI

1125.0 0.205חกE-n1

$1827.70 .202 n 0 F-01$

$1825.0 \quad 0.205010$ E-01

$1825.0 \quad 0.2 \pi 50 \cap E-01$

$2060.0 \quad 0.23200 \mathrm{~F}-01$

$206 n .0 \quad 0.232 n 0 F-111$

21161.0 $11.23600 E-191$

$2060.0 \quad 0.2340115-01$
PFRCENT

DEVIATION

5.89

12.65

9.72

4.93

4.92

4.92

3.52

2.55

2.55

2.55

4.50

$-0.33$

3.06

4.02

0.64

$\pi \cdot 14$

$-3.14$

$-3.14$

$-4.59$

$-3.14$

$-3.14$

4.12

4.02

5.78

4.91

\begin{tabular}{|c|c|c|c|}
\hline LOHER & UPPER & HIDTH & $x$ wiont \\
\hline $1.99466 \mathrm{E}-02$ & $2.33062 E-02$ & $3.35959 E-03$. & 15.53 \\
\hline $1.89608 \mathrm{E}-02$ & $2.24059 E-02$ & $3.44511 E-03$ & 16.66 \\
\hline $89564 E-02$ & $2.24203 E-02$ & $3.46391 E-03$ & 16.74 \\
\hline $1.89264 E-02$ & $2.24353 E-02$ & $3.50890 E-03$ & 16.97 \\
\hline $099298 E-02$ & $2.24369 E-02$ & $3.50713 E-03$ & 16.96 \\
\hline $89298 \mathrm{E}-02$ & $2.24369 E-02$ & $3.50713 E-03$ & 16.96 \\
\hline $84160 E-02$ & $2.25415 E-02$ & $4.12553 E-03$ & 20.15 \\
\hline $1.84100 \mathrm{E}-\mathrm{n2}$ & $2.25457 E-122$ & $4.13569 E-03$ & 20.20 \\
\hline $.84105 E-02$ & $2.25458 E-02$ & $4.13527 E-03$ & 20.19 \\
\hline $84100 E-02$ & $2.25457 E-02$ & $4.13569 \mathrm{E}-03$ & 20.20 \\
\hline $.84193 E-02$ & $2.25370 E-02$ & $4.11764 \mathrm{E}-03$. & 20.11 \\
\hline . $87267 E-02$ & $2.261 .17 E-02$ & $3.88493 E-03$ & $18.8 \mathrm{n}$ \\
\hline $.87391 E-02$ & $2.25952 E-02$ & $3.85609 E-03$ & 18.66 \\
\hline$-87468 E-02$ & $2.25916 E-02$ & $3.84478 E-03$ & 18.60 \\
\hline $.87276 E-02$ & $2.26067 E-0 ?$ & $3.87906 E-03$ & 18.77 \\
\hline $1.87317 E-02$ & $2.26108 E-02$ & $3.87906 E-03$ & 18.77 \\
\hline $1.92374 E-02$ & $2.30920 E-02$ & $3.85464 E-03$ & 18.21 \\
\hline $1.9 ? 374 E-02$ & $2.30920 E-02$ & $3.85464 E-03$ & 18.21 \\
\hline $1.92393 \mathrm{E}-02$ & $2.31051 \mathrm{E}-02$ & $3.86579 F-03$ & 18.20 \\
\hline $1.92 .374 E-02$ & $2.30920 E-02$ & $3.85464 E-03$ & 18.21 \\
\hline $1.92374 \mathrm{E}-02$ & $2.30920 E-02$ & $3.85464 E-03$ & 18.21 \\
\hline $2.01846 E-02$ & $2.44234 E-02$ & $4.23882 E-03$ & 19.00 \\
\hline $2.01846 F-02$ & $2.44234 \mathrm{E}-02$ & $4.23882 E-03$ & 19.00 \\
\hline $.01953 F-02$ & $2.44246 E-0 ?$ & $4.22923 E-03$ & 18.96 \\
\hline BE- & $2.44184 E-02$ & $4.22 .875 E-03$ & \\
\hline
\end{tabular}




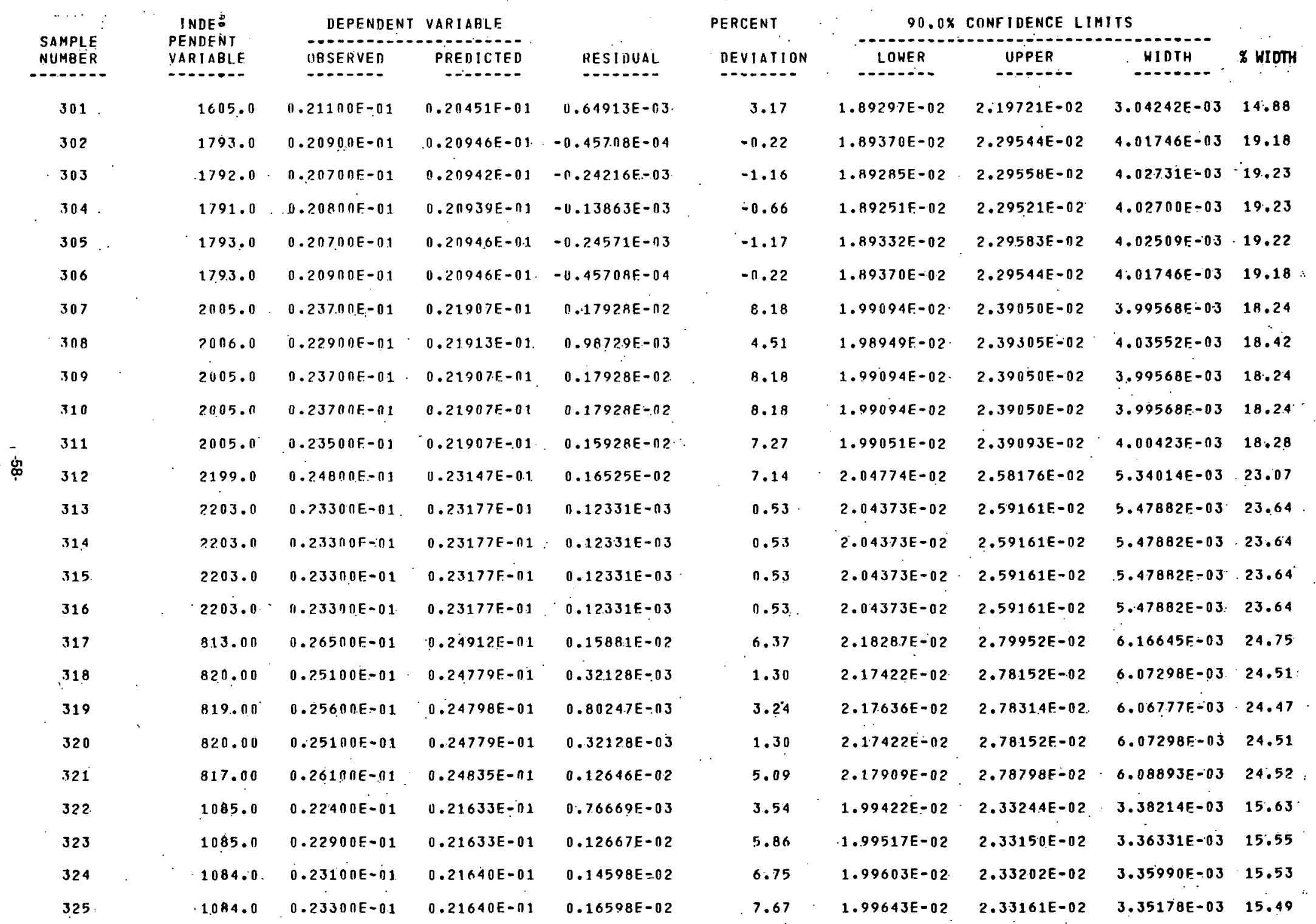




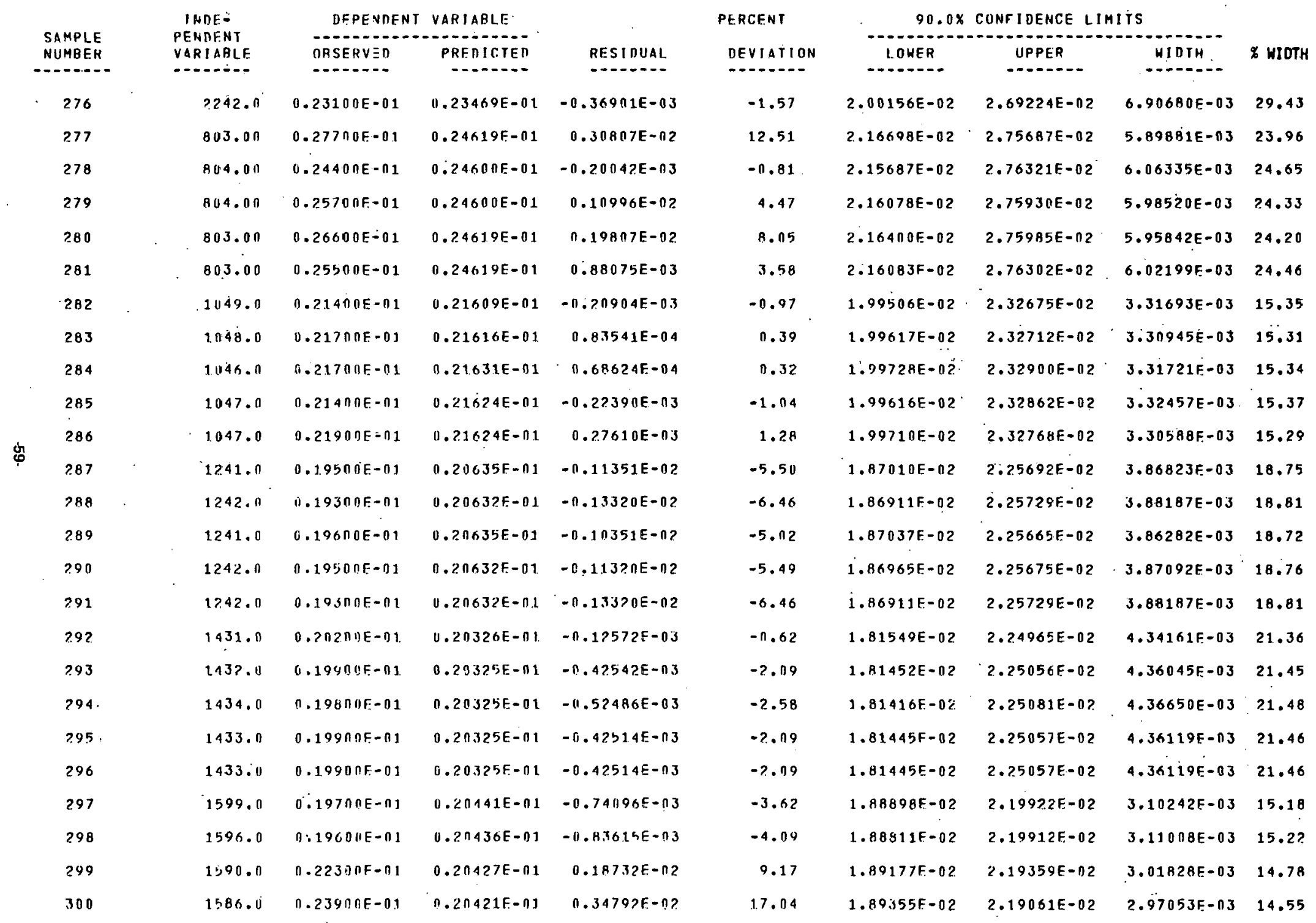




\begin{tabular}{|c|c|c|c|c|c|c|c|c|c|c|}
\hline & & $\begin{array}{l}\text { INDE: } \\
\text { PENDENT }\end{array}$ & DEPENIEN & VARIABLE & & PERCENT & $\begin{array}{r}90.0 x \\
\end{array}$ & CONF I DENQCE L I & ITS . & \\
\hline & NUMBER. & VARIAB̈LE & OBSERVED. & PREDICTED & RESIDUAL & DEVIATION & LOHER & UPPER & HIDTH. & s virion \\
\hline & ........ & - & - & $\cdots$ & -........ & - & - - - & $\cdots$ & - - - & \\
\hline & 251 & 1288.0 & $0.19800 E-01$ & $0.20508 \mathrm{E}-01$ & $-0.70790 E-03$ & -3.45 & $1.85329 E-02$ & $2.24829 E-02$ & $3.95007 E-03$ & 19.26 \\
\hline & 252 & 1484.0 & $0.20200 E-01$ & $0.20327 E-01$ & $-0.12684 E-03$ & -0.62 & $1.80828 E-02$ & $2.25708 E-02$ & $4.48801 E-03$ & 22.08 \\
\hline & 253 & 1483.0 & $0.2040 \cap E-01$ & $0.20327 E-01$ & $0.73495 E-04$ & 0.36 & $1.80889 E-02$ & $2.25641 E-02$ & $4.47517 E-03$ & 22.02 \\
\hline & 254 & 1485.0 & $0.20100 E-01$ & $0.20327 E-01$ & $-0.22719 E-03$ & -1.12 & $1.80806 E-02$ & $2.25738 E-02$ & $4.49314 E-03$ & 22.10 \\
\hline & 255 & 1484.0 & $0.20200 E-01$ & $0.20327 \mathrm{E}-01$ & $-0.22684 E-03$ & -1.12 & $1.80802 E-02$ & $2.25734 E-02$ & $4.49322 E-03$ & 22.10 \\
\hline & 256 & 1485.0 & $0 . ? 0200 E-01$ & $0.20327 E-01$ & $-0.12719 E-133$ & -0.63 & $1.80832 E-02$ & $2.25712 E-02$ & $4.48794 E-03$ & 22.08 \\
\hline & 257 & $1659 . !$ & $0.19700 E-01$ & $0.20557 E-01$ & $-0.85691 E-03$ & -4.17 & $1.87963 E-02$ & $2.23175 E-02$ & $3.52115 E-03$ & 17.13 \\
\hline & 258 & 1653.0 & $0.19000 E-01$ & $0.20541 E-01$ & $-0.94365 E-133$ & -4.59 & $1.87751 E-02$ & $2.23122 E-02$ & $3.53718 E-03$ & 17.22 \\
\hline & 259 & 1641.0 & $0.20000 E-01$ & $0.20518 E-01$ & $-0.51823 E-03$ & -2.53 & $1.87478 E-02$ & $2.22887 E-02$ & $3.54085 E-03$ & 17.26 \\
\hline & 260 & 1638.0 & $0.211 \cap n E-01$ & $0.20512 E-n 1$ & $0.58789 E-03$ & 2.87 & $1.87623 E-02$ & $2.22619 E-02$ & $3.49958 E-03$ & 17.06 \\
\hline & 261 & 1653.0 & $0.20400 E-01$ & $0.2 \pi 544 \mathrm{E}-01$ & $-0.14365 E-03$ & -0.70 & $1.8792 .4 E-02$ & $2.22949 E-02$ & $3.50252 E-03$. & 17.0 .5 \\
\hline & 262 & 1832.0 & $0.107 \cap 0 E-01$ & $0.21091 \mathrm{E}-01$ & $-0.13913 E-02$ & -6.60 & $1.90469 E-02$ & $2.31357 E-02$ & $4.08875 E-03$ & 19.39 \\
\hline & 263 & 183.3 .0 & $0.198 \cap 0 E-01$ & $0.21095 \mathrm{E}-01$ & $-0.12952 E-02$ & -6.1 .4 & $1.90546 E-02$ & $2.31358 \mathrm{E}-02$ & $4.08117 E-03$ & 19.35 \\
\hline & 264 & $1+32.0$ & $0.20300 E-01$ & $0.21091 \mathrm{E}-01$ & $-0.79128 \mathrm{E}-03$ & -3.75 & $1.90615 E-0.2$ & $2.31210 E-02$ & $4.05948 E-03$ & 19.25 \\
\hline & 265 & $1 H 32.0$ & $0.19900 E-01$ & $0.21091 E-01$ & $-0.11913 E-n 2$ & -5.65 & $1.90528 E-02$ & $2.31297 \mathrm{E}-02$ & $4.07692 E-03$. & 19.33 \\
\hline & 2.66 & 1832.0 & $0.198 \cap 0 E-01$ & $0.21091 \mathrm{~F}-01$ & $-0.12913 E-02$ & -6.12 & $1.90499 E-02$ & $2.31327 E-02$ & $40.08281 E-03$ & 19.36 \\
\hline & 2.67 & 2044.0 & $0.22800 F-01$ & $0.22129 \mathrm{E}-01$ & $0.67101 E-03$ & 3.03 & $1.9956 / E-02$ & $2.43013 \mathrm{E}-02$ & $4.34458 E-03$ & 19.63 \\
\hline & 268 & 2048.0 & $0.2260 \cap \mathrm{E}-01$ & $0.22153 E-01$ & $0.44748 E-03$ & 2.02 & $1.99602 E-02$ & $2.43448 E-02$ & $4.38453 E-03$ & 19.79 \\
\hline & $259^{\circ}$ & 2047.0 & $0.22500 E-01$ & $0.22147 E-01$ & $0.35338 E=03$ & 1.60 & $1.99568 \mathrm{E}-02$ & $2.43365 F-102$ & $4.37966 E-03$ & 19.78 \\
\hline & $270^{\prime}$ & $? 047.0$ & $0.22500 E-01$ & $0.22147 E-01$ & $0.35338 E-03$ & 1.60 & $1.9956 \mathrm{BE}-02$ & $2.43365 E-02$ & $4.37966 E-03$ & 19.78 \\
\hline & 271 & 2.049 .0 & $0.228 \cap \cap E-\pi 1$ & $0.22 .158 E-01$ & $0.64158 E-n 3$ & 2.90 & $1.99676 E-02$ & $2.43493 E-02$ & $4.38166 E-03$ & 19.77 \\
\hline & 272 & 2238.0 & $0.23400 E-01$ & $0.23438 E-01$ & $=0.38387 E-174$ & -0.16 & $2.00302 E-02$ & $2.68460 E-02$ & $6.81635 E-03$ & 29.08 \\
\hline & 273 & 2.239 .0 & $0.23600 E-01$ & $0.23446 E-\eta 1$ & $0.15397 E-03$ & 0.66 & $2.00377 E-02$ & $2.68544 E-02$ & $6.81672 E-n 3$ & 29.07 \\
\hline & $? 74$ & 2242.1 & $0.23100 \mathrm{E}-01$ & $0.23169 E-01$ & $-0.369 n 1 F-n 3$ & -1.57 & $2.00156 F-02$ & $2.69224 E-02$ & $6.90680 E-03$ & 29.43 \\
\hline & 275 & 239.0 & $0.23600 . E-01$ & $3446 E-01$ & $0.15397 E-n 3$ & 0.66 & $2.00377 E-02$ & $68544 E-02$ & 6.81672 & 07 \\
\hline
\end{tabular}




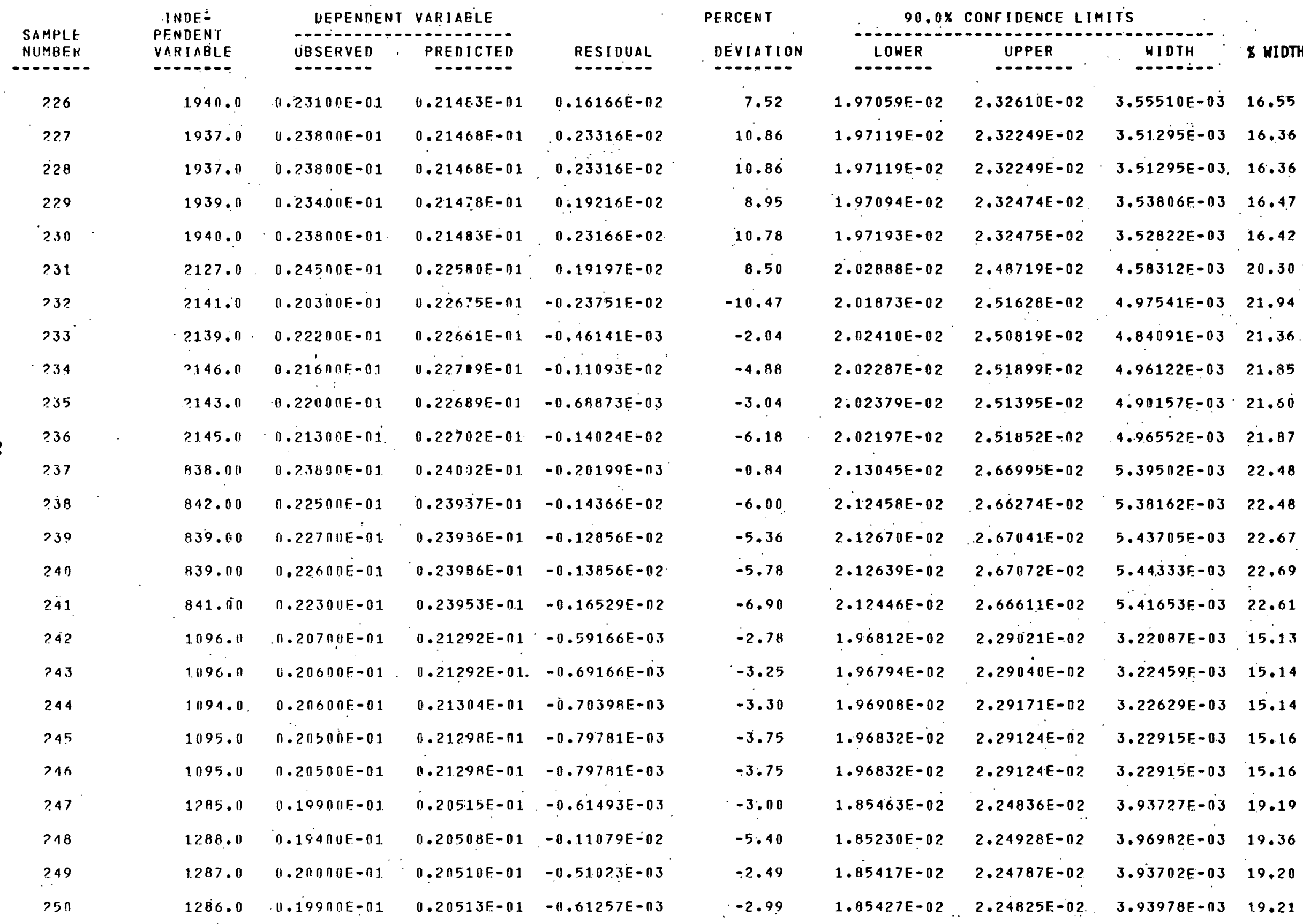


O......-

OBSFHVER PREDICIFD

RESI DUAL

$1065.0 \quad 0.191 \pi 11 \mathrm{E}-01 \quad 0.21141 \mathrm{E}-01 \quad-0.20406 \mathrm{E}-02$

$1.165 .0 .0 .19500 \mathrm{~F}-01 \quad 0.21141 \mathrm{~F}-01 \ldots-0.16406 \mathrm{~F}-02$

$11163.0 \quad 0.1950 \cap E-01$

$1065.0 \quad 0.196 n n E-n 1$

$1065.0 \quad 0.197011 \mathrm{E}-01$.

$0.21153 E-01 \quad-0.16531 E-02$

$0.21141 E-01-0.14406 E-02$

$1187.0 \quad 0.18600 \mathrm{~F}-01$

$118 B .0 \quad 0.190111 \mathrm{~F}-n)$

$1185.0 \quad 0.1930$ OC-01

1183.0. I.1900तE-01

$118 \% .0 \quad 0.19200 \mathrm{E}-01$

$1402.0 \quad 0.2 \pi 100 \mathrm{E}-01$

1397.0 U.?ח20DE-01

$1.599 .0^{\circ} \quad 0.19601 \mathrm{E}-n 1$

$1397.0, \quad 1.202 n \cap E-01$

$1399.0 \quad 0.20690 F-01$

1529.11 0.2150กE-01

$1531.0 \quad 0.20800 \mathrm{~F}-01$

$1532.0 \quad U .20900 E-03$.

1532.0 . $0.2090 \cap E-0.1$

$1.531 .0 \quad 0.21190 \mathrm{E}-n 1$

1743. 11 $11.19100 \mathrm{E}-0.1$

$1 \% 39.0$ ก.1.97DOE-01

$1738.0 \quad 0.192 n 0 E-01$

$1738.0 \quad 0.191 \cap \cap E-n 1$

$1742.0 \quad 0.19390 E-01$

$0.20653 E-n 1 \quad-n .14529 E-n 2$

$0.2 n 653 \mathrm{E}-n 1 \quad-0.15529 \mathrm{E}-02$
$0.21141 E-01$ - $0.15406 E-02$
PFRCENT

AEVIATION

ח-..-..-.

$-9.65$

$-7.76$

$-7.81$

$-7.29$

$-6.81$

$-9.50$

$-7.54$

$-6.13$

$-7.62$

$-6.58$

$-0.26$

0.23

$-1.75$

0.23

2.22

6.43

2.95

3.44

3.44

4.44

$-7.59$

$-4.63$

$-7.03$

$-7.52$

$-6.61$
90.0X CONF IDENCE LIMITS

LONER UPPER NIDTH I WIOTH

$1.86018 E-02$

$2.36794 E-02$

5.07757E-03 24.02

$1.8614 .8 E-02$

$2.36664 E-02$

$5.05162 E-03 \quad 23.9 n$

$1.86174 E-02$

$2.36867 E-02$

$5.0712 .6 F-03 \quad 23.97$

1.86187F-02

2.36625E-02

$5.04377 F-03 \quad 23.86$

1. $86216 \mathrm{E}-02$

$2.36596 E-02$

$5.03793 E-03 \quad 23.83$

$1.8410 .2 F-02$

2.26951E-02

4.2B482E-ก3 20.B5

$1.84205 \mathrm{~F}-02$

$2.26776 E-02$

$4.25705 E-13 \quad 20.7 ?$

1.84330E-02 2.26867E-02.

$4.25366 F-113 \quad 20.69$

1.8426AE-02

$2.27074 E-02$.

$4.28057 F-03$

20.81

$1.84270 E-02$

$2.26783 E-02$

1.82590F-02

2.20447 E-0.2

1.82594F-0?

$2.20483 E-02$

1.8250AF-02

$2.20552 E-02$

1.82594E-02

2. 20483E-02

1. 82694F-02

$2.20366 \mathrm{E}-02$

18.80

1.83655E-02

2:20362E-02

$3.76725 F-03$

18.69

1.83546E-02

2.20515E-02

1.83585F-02

$2.20498 E-02$

$3.69696 E-13$

18.30

1.83585F-02

2. 2ก498E-02

$3.69124 E-03 \quad 18.27$

$1.83612 E-n 2$

$2.20449 F-02$

$3.59124 E-03$

18.27

$1.90263 E-02$

$2.23116 \mathrm{E}-02$

$3.68368 \mathrm{~F}-03 \quad 18.23$

1. $9.0242 \mathrm{E}-02$

$2.22880 \mathrm{~F}-02$

$3.28522 F-0.3$

15.89

1.90099E-02.

2.22.959F-B2

$3.26381 F-03$

15.80

$1.90074 E-02$

2. $22984 E-02$

3.2 B60F- 03

15.91

$1.90267 E-02$

$2.23048 E-102$

$3.29095 E-03 \quad 15.93$

$3.27812 F-03 \quad 15.86$ 


\begin{tabular}{|c|c|c|c|c|c|c|c|c|c|}
\hline SAMPIEE & $\begin{array}{l}\text { INDI: } \\
\text { PENIIENT }\end{array}$ & DEPENDEI & $\begin{array}{l}\text { VARIABLE } \\
-\end{array}$ & & PERCENT & $90.0 x$ & CUNF IDENCE LI & MITS & \\
\hline NUMBFK & VARIABLE & OBSERVEN & PREJICIED & RESIDUAL & DEVIATION & LOWER & UPPER & HIDTH & \& HIOTH \\
\hline$\cdots-\infty$ & $\cdots+\cdots$ & 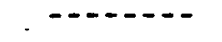 & $\cdots-\cdots$ & 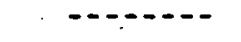 & 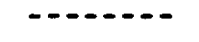 & $\cdots+-\infty$ & 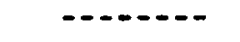 & $----\infty---$ & \\
\hline 176 & 1581.0 & $0.213 \cap 0 E-01$ & $0.2 n \geq 72 E-01$ & $0.10277 E-02$. & 5.07 & $1.84260 F-02$ & $2.21185 E-112$ & $3.69247 E-03$ & $18 \cdot 21$ \\
\hline 1.77 & 1584.0 & $0.21200 \mathrm{E}-01$ & $0.20>77 E-01$ & $0.92277 \mathrm{E}-03$ & 4.55 & $1.84320 E-02$ & $2.21225 E-02$ & $3.69053 E-03$ & $18.2 \pi$ \\
\hline 179 & 1582.0 & $0.21000 E-01$ & $0.2 n \geq 74 E-01$ & $0.72610 E-03$ & 3.58 & $1.84223 E-02$ & $2.21255 E-02$ & $3.70322 F-03$ & $18 \cdot 27$ \\
\hline 179 & $1582 \cdot 0$ & $0.2120 \cap F-0.1$ & $0.2 n \geq 74 E-01$ & $0.92610 E-03$ & 4.57 & $.1 .84266 E-02$ & $2.21212 E-02$ & $3.69465 F-03$ & 18.22 \\
\hline 180 & 1795.11 & $0.20900 E-01$ & $0.20349 \mathrm{E}-01$ & $0.50574 E-04$ & 0.24 & $1.91354 F-02$ & $2.25634 E-02$ & $3.42796 F-03$ & 16.44 \\
\hline 181 & 1797.0 & $0.20900 \mathrm{E}-01$ & $0.20 B 57 E-01$. & $0.13133 E-04$ & 0.21 & $1.91429 E-02$ & $2.25708 E-02$ & $3.427 .90 F-03$ & 16.44 \\
\hline $1.8 ?$ & $1795 . n$ & $.11 .21000 E-01$ & $0.20849 E-01$ & $0.15057 E-03$ & 0.72 & $1.91376 \mathrm{E}-02$ & $2.25613 E-12$ & $3.42372 E-03$ & 16.42 \\
\hline 18.3 & 1795.0 & $0.211 n \cap E-n 1$ & $n \cdot 2 n 849 F-n 1$ & $0.25057 E-03$ & 1.20 & $1.91397 E-02$ & $2.25592 E-112$ & $3.42951 E-03$ & 16.40 \\
\hline 1.84 & 1797.0 & $0.20900 E-01$ & U.20A57E-D1 & $0.43133 E-04$ & 0.21 & $1.91429 E-02$ & $2.25708 E-02$ & $3.42790 F-03$ & 16.44 \\
\hline 145 & $.1984,0$ & $0.73200 \mathrm{~F}-01$. & $0.21713 E-\pi 1$ & $0.14867 E-02$ & 3.85 & $1.97237 E-02$ & $2.370 .30 E-02$. & $3.97922 E-03$ & 18.33 \\
\hline 186 & 1986.0 & $0.23900 F-01$ & $n .21724 E-01$ & $0.2175 B E-02$ & 10.02 & $1.97425 E-02$ & $2.37059 E-02$ & $3.96335 E-03$ & 18.24 \\
\hline 1.87 & 1984.0 & $0.243 n 0 F-01$ & $0.2171 .3 E-01$ & $0.25867 E-02$ & 11.91 & $1.97466 E-02$ & $2.36801 E-0 ?$ & $3.93351 F-0.3$ & 18.12 \\
\hline 188 & 1986.11 & $0.235 \cap 0 E-n 1$. & $0.21724 E-01$ & $0.17758 E-02$ & 8.17 & $1.97338 \mathrm{E}-02$ & $2.37146 E-02$ & $3.98085 F-03$ & $18 \cdot 32$ \\
\hline 149 & 1986.11 & $0.237 n \cap E-01$. & $0.21724 E-01$ & $0.19758 E-02$ & 9.09 & $1.97382 E-02$ & $2.37102 E-02$ & $3.97205 E-03$ & 18.28 \\
\hline 190 & 2.195 .0 & $0.24700 . F-01$. & $0.23057 \mathrm{E}-01$ & $0.16430 E-0 ?$ & 7.13 & $1.99811 \mathrm{~F}-02$ & $2.61330 E-02$ & $6.151 B 7 E-03$ & 26.68 \\
\hline 191 & 2198.0 & $0.22 \cup n O F-n 1$ & $0.23079 E-0.2$ & $-0.19790 E-02$ & -4.68 & $1.988 B 8 E-02$ & $2.62693 E-02$ & $6.38046 E-n 3$ & 27.65 \\
\hline $19 ?$ & $? 196.0$ & $0.209 .00 E-01$ & $0.23 \cap 64 E-01$ & $-0.21644 E-02$ & -9.38 & $1.98496 E-02$ & $2.62792 \mathrm{E}=02$ & $6.42959 E-03$ & 27.88 \\
\hline 193 & 2199.0 & $0.21200 \mathrm{~F}-01$ & $0.23086 E-01$ & $-0.18864 E-02$ & -8.17 & $1.98590 E-02$ & $2.63138 E-02$ & $6.4547 .9 E-03$ & 27.96 \\
\hline 1.94 & ?.19R. 0 & $n \cdot 211 n \cup E-01$ & $0.23079 E-01$ & $-0.19790 E-02$ & -8.58 & $1.98564 \mathrm{~F}-02$ & $2.63017 E-02$ & $6.44524 E-03$ & 27.93 \\
\hline 195 & $219 \mathrm{~g} .0$ & $n .211 n 0 E-01$. & $0.23079 \mathrm{E}-01$ & $-0.1979 \cap E-B ?$ & -8.58 & $1.98564 E-02$ & $2.63017 E-02$ & $6.41524 E-03$ & 27.93 \\
\hline 196 & R2.6.00 & $0.22800 E-01$ & $0.23584 E-01$ & $-0.78366 E-03$ & -3.32 & $1.95601 \mathrm{E}-02$ & $2.76072 E-02$ & $8.04703 E-03$ & $34 \cdot 12$ \\
\hline 1.97 & 827.00 & $0.22600 E-01$ & $0.23568 E-01$ & $-0.96808 E-03$ & -4.11 & $1.95480 E-02$ & $2.75882 E-02$ & $8.040 .25 E-03$ & 34.11 \\
\hline 198 & 829.00 & $0: 21700 E-01$ & $0.23537 \mathrm{E}-01$. & $-0.18371 E-02$ & -7.81 & $1.95001 E=02$ & $2.75742 E-02$ & $8.07411 E-03$ & 34.30 \\
\hline 199 & 42.7 .00 & $0.21900 E-01$ & $0.23568 \mathrm{E}-01$ & $-0.16681 F-0 ?$ & -7.08 & $1.95158 E-02$ & $2.76203 E-02$ & $8.10449 \mathrm{E}$ & .39 \\
\hline 200 & 32.7.0 & $0.21900 \mathrm{E}-01$ & $0.22568 E-01$ & $-0.1668 .1 E-02$ & -7.08 & $1.95158 E-02$ & $2.76203 E-02$ & $8.10449 E-03$ & 34.39 \\
\hline
\end{tabular}




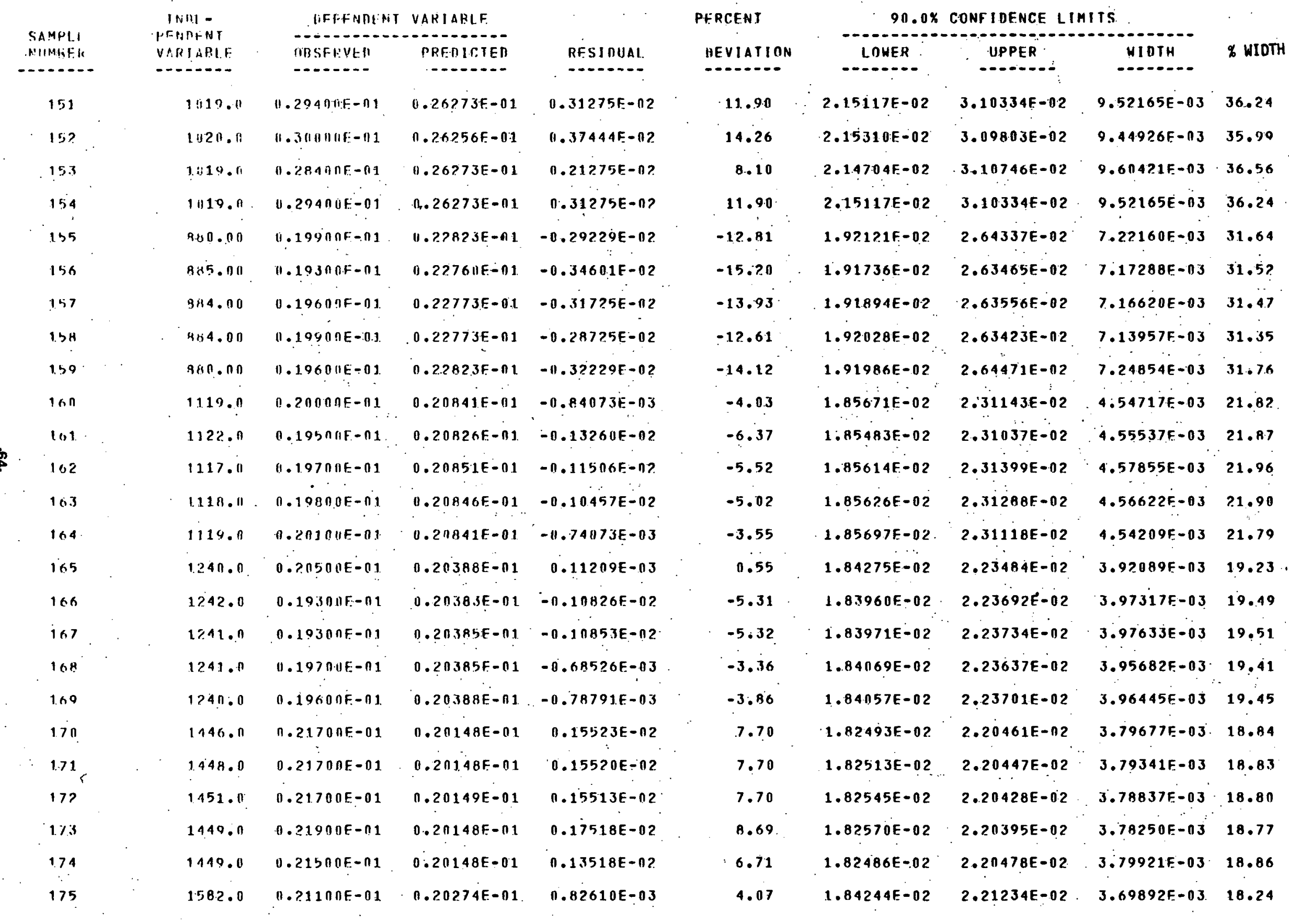




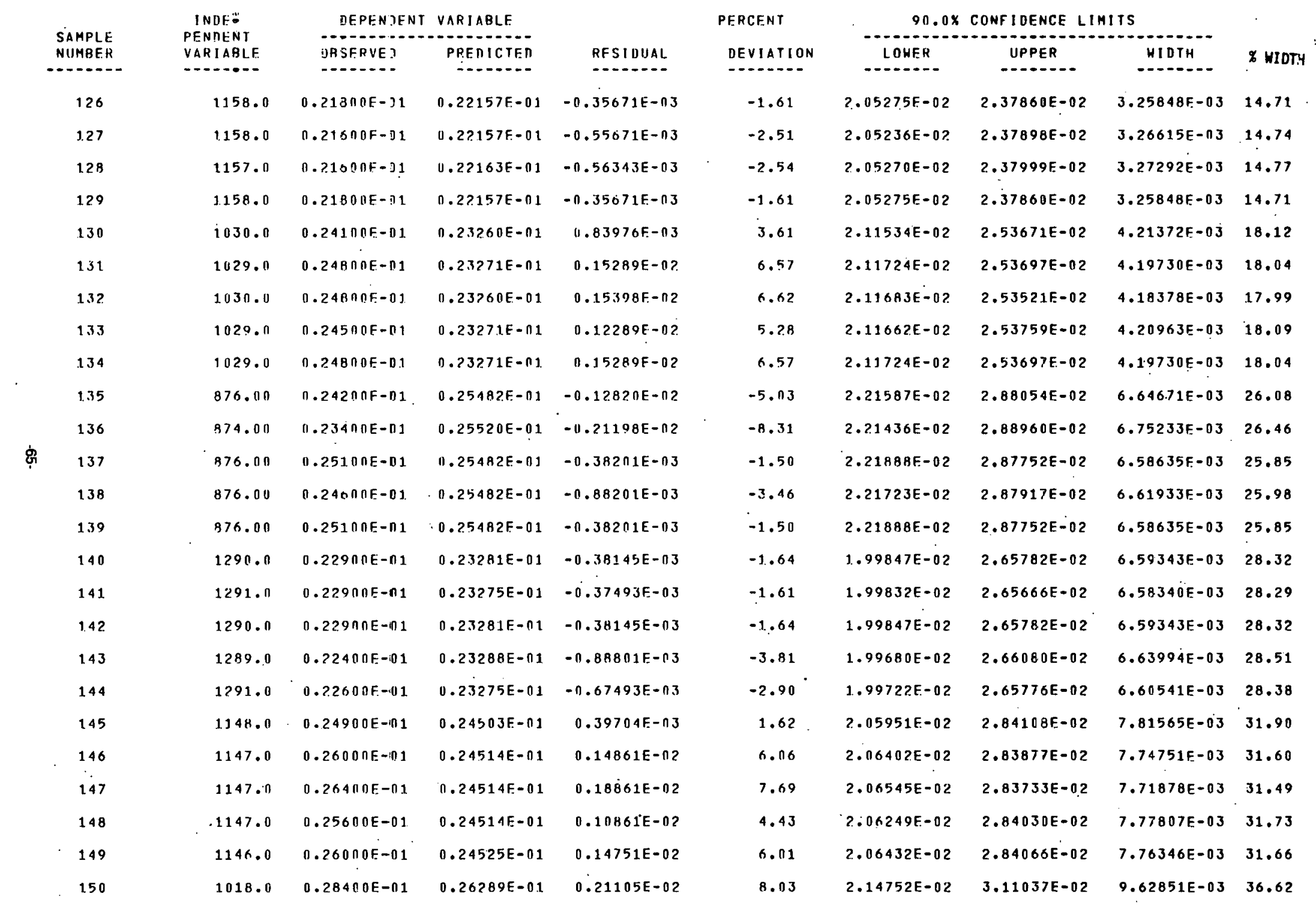




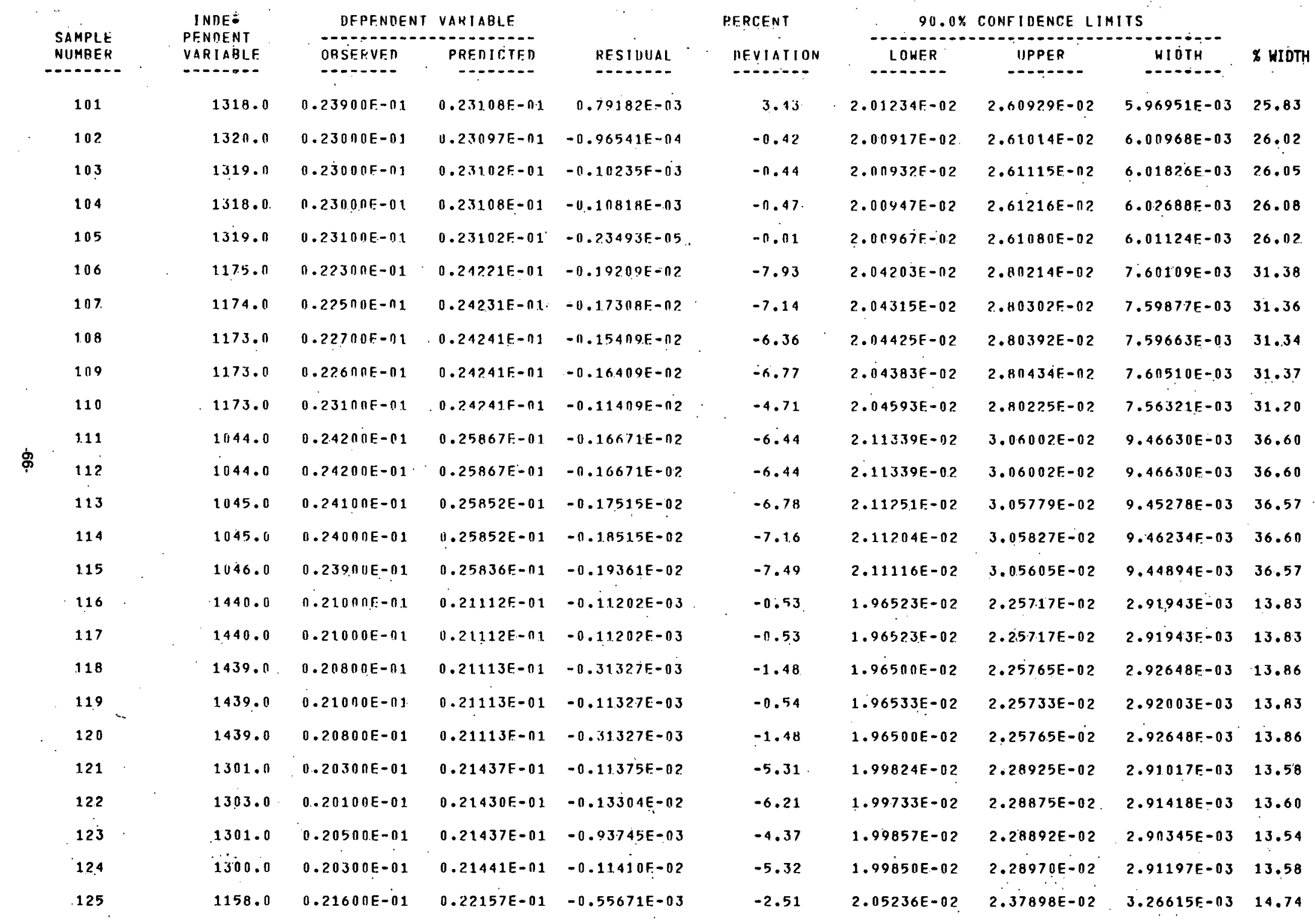




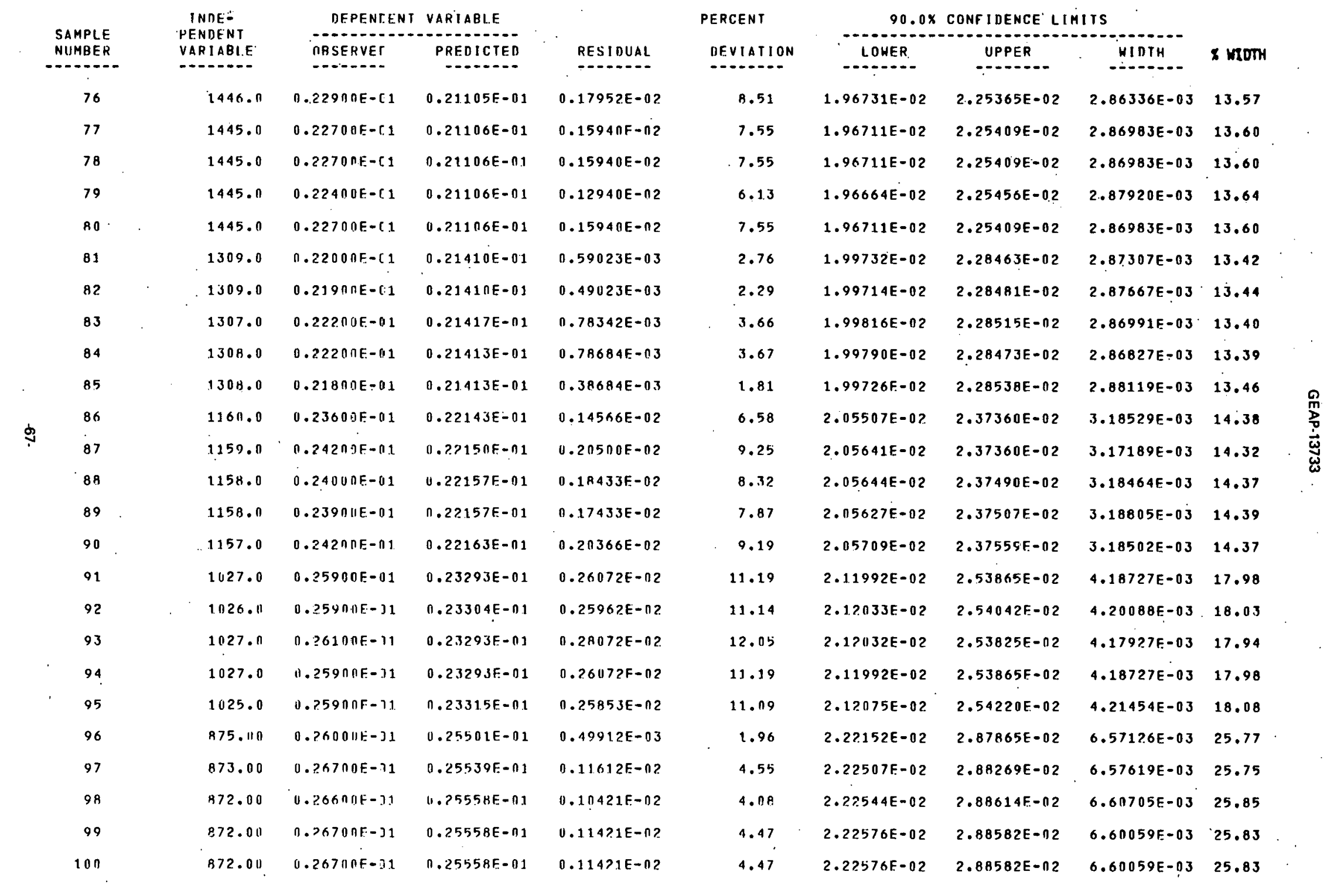




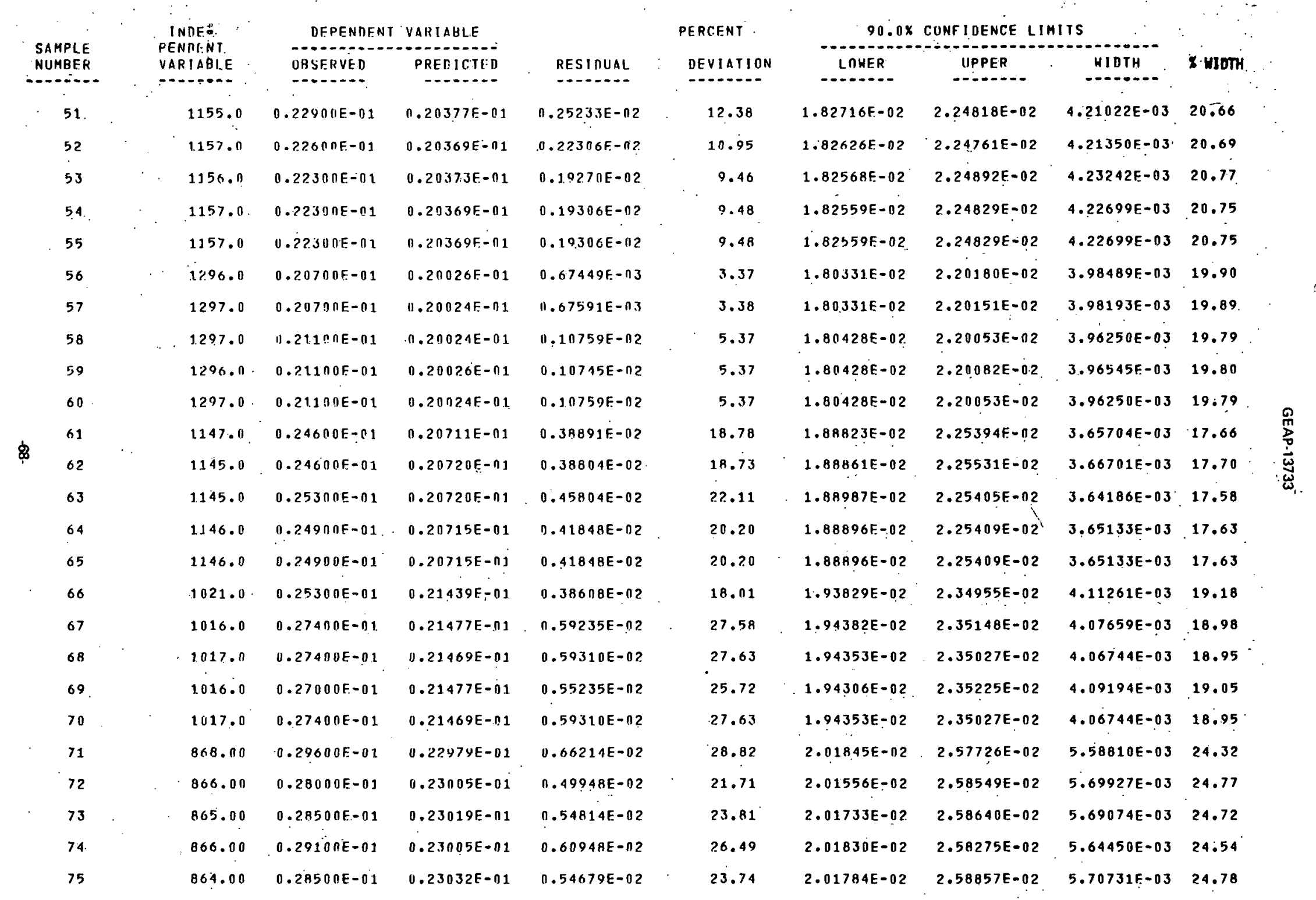




\begin{tabular}{|c|c|c|c|c|c|c|c|c|c|}
\hline \multirow{3}{*}{$\begin{array}{l}\text { SAMPLE } \\
\text { NUMBER }\end{array}$} & & DFPENDEN & VARIARLE & \multirow{2}{*}{\multicolumn{2}{|c|}{ PEPCENT }} & \multicolumn{3}{|c|}{$90.0 \times$ CONFIDERCE LIHITS } & \multirow{3}{*}{5 HIOTH } \\
\hline & PFNIENT & DASFGEA & potanicter & & & 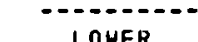 & $x^{2}$ & - & \\
\hline & $\begin{array}{l}\text { VARIABLE } \\
-O-O-\end{array}$ & DHSERVEII & PREDTCIT: & $\begin{array}{l}\text { RES I DUAL } \\
-\end{array}$ & DEVIATIU & LUWT:K & OPFEM & - n & \\
\hline 26 & 1175.0 & $0.217 \cap 0 F-i] 1$ & $0.20597 \mathrm{~F}-01$ & $0.11031 E-\pi 2$ & 5.36 & $1.87562 \mathrm{E}-02$ & $2.24375 E-02$ & $3.68128 E-03$ & 17.87 \\
\hline 27 & 1.172 .0 & $0.21300 E-31$ & $0.20608 \mathrm{~B}-0 \mathrm{~L}$ & $0.69163 E-03$ & 3.36 & $1.87527 \mathrm{E}-02$ & $2.24641 E-02$ & $3.71136 E-03$ & 18.01 \\
\hline 28 & 1171.0 & $0.21400 E-.11$ & $0.20612 E-0.1$ & $0.78776 E-103$ & 3.82 & $1.87564 E-02$ & $2.24681 E-02$ & $3.71168 E-03$ & 18.01 \\
\hline 29 & 1172.0 & $0.214 n \| E-31$ & $0.20608 E-0.1$ & $0.79163 \mathrm{E}-03$ & 3.84 & $1.87547 E-02$ & $2.24620 \mathrm{E}-02$ & $3.70726 E-03$ & 17.99 \\
\hline 30 & 1172.0 & $0.21 .000 E-101$ & $0.20608 E-01$ & $0.3916 .3 E-03$ & 1.90 & $1.87461 E-02$ & $2.24707 E-02$ & $3.72461 E-03$ & 18.07 \\
\hline 31 & 1046.0 & $0.21600 F-01$ & $0.21263 E-01$ & $0.33688 E-03$ & $1.5 \mathrm{H}$ & $1.91 .465 \mathrm{E}-02$ & $2.33797 E-02$ & $4.23319 E-03$ & 19.91 \\
\hline 32 & 1044.0 & $0.210 \cap 0 E-01$ & $0.21277 E-01$ & $-0.27657 E-n 3$ & -1.30 & $1.91362 E-02$ & $2.34169 E-02$ & $4.28075 E-03$ & 20.12 \\
\hline 33 & 1044.8 & $0.21500 \mathrm{E}-01$ & $0.21277 E-01$ & $0.22343 F-n 3$ & 1.05 & $1.91487 E-02$ & $2.34044 E-02$ & $4.25566 E-03$ & 20.00 \\
\hline 34 & 1042.11 & $0.2130 \cap E-01$. & $0.21290 \mathrm{E}-01$ & 0.9A6B3E-05 & 0.05 & $1.91484 E-02$ & $2.34318 E-02$ & $4.28340 E-03$ & 20.12 \\
\hline 35 & $1042 . n$ & $0.21200 E-01$ & $0.21290 \mathrm{E}-01$ & $=0.9 n 132 E-04$ & -0.42 & $1.91459 E-02$ & $2.34343 E-02$ & $4.28843 E-03$ & 20.14 \\
\hline 36 & B91.00 & $0.2200 \mathrm{NE}-01$ & $0.22686 E-01$ & $-0.68628 E-03$ & -3.13 & $1.98219 E-02$ & $2.55507 . E-02$ & $5.72876 E-03$ & 25.25 \\
\hline $37^{\circ}$ & 891.00 & $0.22400 E-01$ & $0.22686 E-01$ & $-0.28628 E-n 3$ & $-1 . ? 0$ & $1.9 R 347 E-n 2$ & $2.55379 \mathrm{~F}-02$ & $5.70325 E-03$ & 25.14 \\
\hline 38 & 990.00 & $0.223 ! 9 F-n .1$ & $0.22698 E-01$ & $-0.39847 E-03$ & -1.76 & $1.98354 E-02$ & $2.55615 E-02$ & $5.72608 E=03$ & 25.23 \\
\hline 39 & 890.00 & $0.22200 E-01$ & $0.22 .698 \mathrm{E}-01$ & $-0.49817 E-03$ & -2.2 .0 & $1.983 .24 E-0 ?$ & $2.55645 E-02$ & $5.73212 E-03$ & 25.25 \\
\hline 40 & 890.00 & $0.215 n \cap E-01$. & $0.22698 \mathrm{~F}-01$ & $-0.1 .1985 E-02$ & -5.28 & $1.98094 E-0 ?$ & $2.55875 E-02$ & $5.77813 E-03$ & 25.46 \\
\hline 41 & 895.01 & U.21001AE-01. & $0.22138 \mathrm{~F}-01$ & $-6.11383 E-n 2$ & -5.14 & $1.9009 n E-02$ & $2.52676 F-02$ & $6.25856 E-03$ & 28.27 \\
\hline 4? & 893.011 & $0.213 n \| E-n 1$ & $0.22160 \mathrm{E}-\mathrm{nt}$ & $-0.86 n 12 F-n 3$ & -3.88 & $1.90262 E-02 ?$ & $2.52941 F-122$ & $6.26787 E-03$ & 28.28 \\
\hline 43 & 893.00 & $0.2070 n F-01$ & $0.22 .160 \mathrm{E}-\mathrm{n1}$ & $-0.14601 E-n 2$ & -6.59 & $1.9 \cap 039 \mathrm{~F}-02$ & $2.53164 E-02$ & $6.31249 E-03$ & 28.49 \\
\hline 44 & 892.011 & $11.2139 \| \mathrm{E}-01$ & $0.22171 \mathrm{E}-01$ & $-\pi .87109 E-03$ & -3.93 & $1.90293 E-0 ?$ & $2.53129 E-02$ & $6.28362 E-03$ & 28.34 \\
\hline 45 & 890.00 & $0.216 n \cap F-01$ & $0.22193 F-01$ & $-0.59314 E-03$ & -2.67 & $1.90464 E-02$ & $2.53398 E-02$ & $6.29340 E-03$ & 28.36 \\
\hline 16 & 1076.0 & $0.236 n \cap F-01$. & $0.20728 \mathrm{~F}-01$ & $0.2871 \mathrm{AE}-02$ & 13.85 & $1.84432 \mathrm{E}-02$ & $2.30131 E-02$ & $4.5699 .1 E-03$ & 05 \\
\hline 47 & 1076.0 & $0.236 n n E-n 1$ & $0.2 \cap 728 E-0.1$ & $0.28718 \mathrm{~F}-\mathrm{n2}$ & 13.85 & $1.84432 E-02$ & $2.30131 E-02$ & $4.56991 E-03$ & 22.05 \\
\hline 48 & 1077.0 & $0.233011 E-01$ & $0.207235-81$ & $0.25771 E-02$ & 12.44 & $1.84344 E-02$ & $2.3 n 114 F-02$ & $4.57693 E-03$ & 22.09 \\
\hline 49 & 11177.0 & $0.236 \cup 0 E-0.2$ & $0 \dot{0} \cdot 2(172.3 E-n 1$ & $0 \cdot ? .8771 \mathrm{E}-\mathrm{n2}$ & $1.3 .8 \mathrm{~A}$ & $1.84418 E-02$ & $2.30040 E-02$ & $4.56213 E-03$ & 22.01 \\
\hline 50 & 1077.0 & $0.239 n 0 E-n 1$. & $0.20723 E-01$ & $0.31771 \mathrm{~F}-\mathrm{n2}$ & 15.33 & $1.84487 E-02$ & $2.29970 E-02$ & $4.54832 E-03$ & 21.95 \\
\hline
\end{tabular}




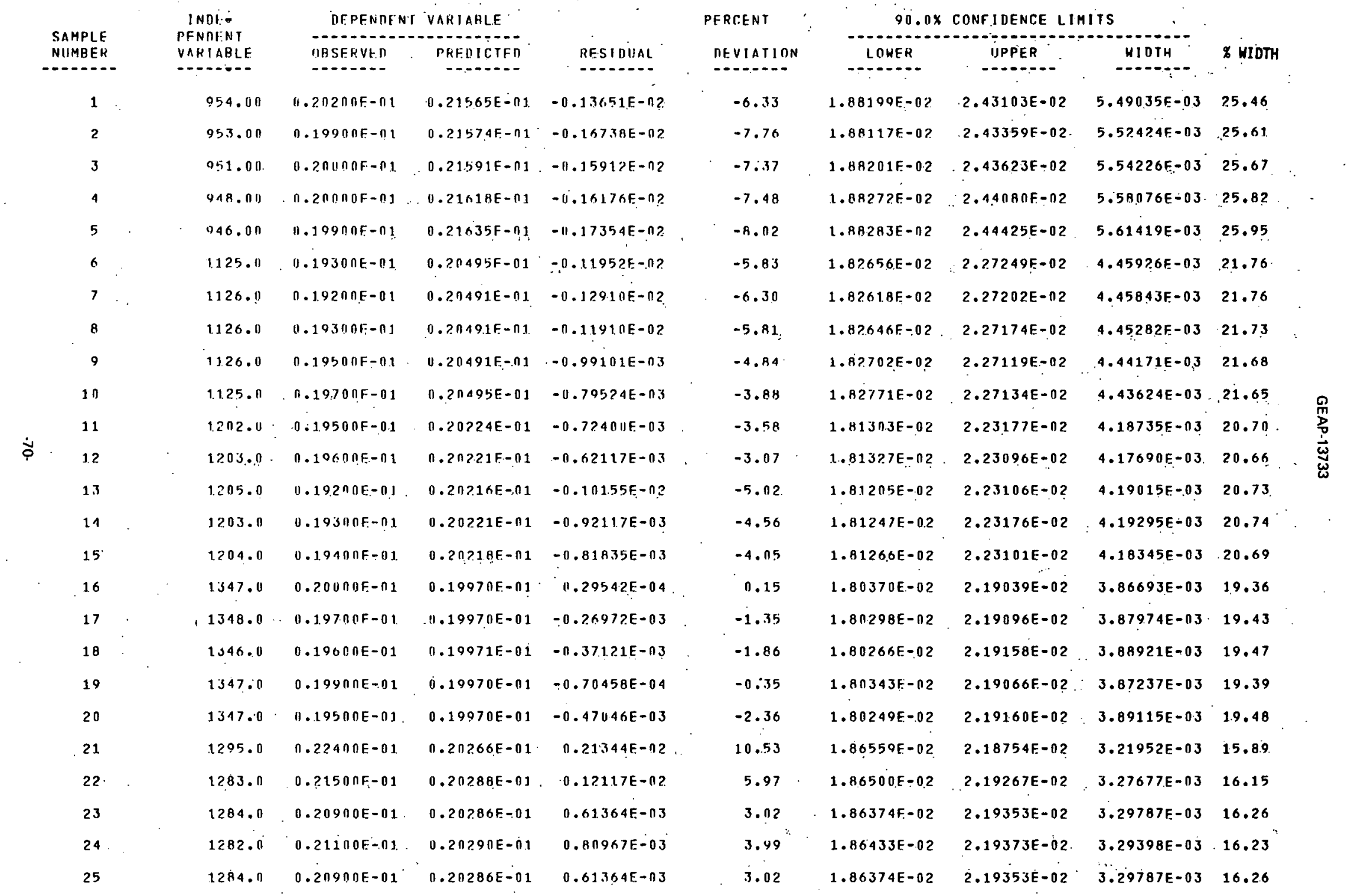


T. A S F NUMEER- 1

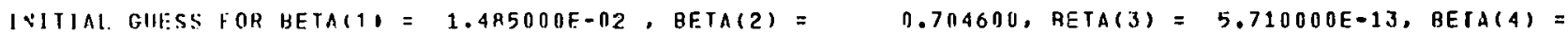

300.000 INITIAI. SUMA OF EPRORS SIJARFD BASFE IN GUESS. FOR BETA VALLIES = 1.02747 IMFROVEN SIIM OF HFPURS SIIIARED HASED OM 21 ITERATIONS $=0.995780$

BFTA(1) $=1.5240 B 2 F-02$. BETA(2) $=0.970194$. BETA(3) $=5.841303 E-13$, BETA(4) $=360.240$

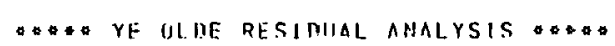

SUA OF THE OFSIDIZALS = 9.014252F-OR?

NAX:MUIH: ANU MINIMUIF HFSETIJAL. VALIIE $=0.621418 \mathrm{E}-0.3-3.460082 \mathrm{E}-0.3$

TIIRPI IN WISTSN STATISTIC =

P!IMS $=191 \quad 198 \quad 9$ )

SKF UNFSS $=1.0220$ EF NOO $1.220290-011$

E!!KTUSIS $=1.73 ? 90 \quad 0.2 .44651$ 


\section{DISTRIBUTION}

Director, Contracts Division

U. S. Atomic Energy Commission

San Francisco Operations Office

2111 Bancroft Way

Berkeley, California 94704

RDT Site Office

U. S. Atomic Energy Commission General Electric Company

310 DeGuigne Drive

-Sunnyvale, California 94086

Chief, California Patent Group

U. S. Atomic Energy Commission

San Francisco Operations Office

P. O. Box 808

Livermore, California 94550

Manager .

Westinghouse Electric Corporation Advanced Reactors Division

P. O. Box 158

Madison, Pennsylvania 15663

Division of Reactor Development and Technology, Headquarters

U. S. Atomic Energy Commission Washington, D. C. 20545

Attn: Assistant Director,

Engineering Standards

Division of Reactor Development and Technology, Headquarters

U. S. Atomic Energy Commission Washington, D. C. 20545

Atrn: Assistant Director, Nuclear Safety

Division of Reactor Development and Technology, Headquarters U. S. Atomic Energy Commission Washington, D. C. 20545

Attn: Assistant Director,

Plant Engineering

Division of Reactor Development and Technology, Headquarters U. S. Atomic Energy Commission Washingron, D. C. 20545

Attn: Assistant Director,

Program Analysis
1 Division of Reactor Development

and Technology, Headquarters

U. S. Atomic Energy Commission

Washington, D. C. 20545

Attn: Assistant Director,

Project Management

1

Division of Reactor Development and Technology, Headquarters

U. S. Atomic Energy Commission Washington, D. C. 20545

Attin: Assistant Director, Reactor Engineering

1

Division of Reactor Development and Technology, Headquarters U. S. Atomic Energy Commission Washington, D. C. 20545

Attn: Assistant Director, Reactor Technology

Division of Reactor Development and Technology, Headquarters

U. S. Atomic Energy Commission Washington, D. C. 20545

1

Attn: Chief, Fuels and Materials Branch

Division of Reactor Development and Technology. Headquarters U. S. Atomic Energy Commission Washington, D. C. 20545

Attn: Chief, Fuel Engineering Branch

Divisiun of Reactor Devolopment and Technology, Headquarters U. S. Atomic Energy Commission Washington, D. C. 20545

Attn: Chief, Reactor Vessels

1 Branch

Assistant Direotor for

Pacific Northwest Programs, RDT

U. S. Atomic Energy Commission

P. O. Box 550

Richland, Washington 99352

1

RDT.Site Office
U. S. Atomic Energy Commission Argonne National Laboratory Building 2,

Argonne, Illinois 60439 
RDT Senior Site Representative

U. S. Atomic Energy Commission P. O. Box 2325

San Diego, California 92112

Division of Naval Reactors

Chief, Nuclear Materials Branch

U. S. Atomic Energy Commission

Washington, D. C. 20545

Director

Division of Reactor Licensing

U. S. Atomic Energy Commission

Washington, D. C. 20545

Director

Mettalurgy Division

Argonne National Laboratory

9700 South Cass Avenue

Argonne, Illinois 60439

Manager, FFTF Project

Pacific Northwest Laboratory

P. O. Box 999

Richland, Washington 99352

\section{Manager}

Chemistry and Metallurgy Division

Pacific Northwest Laboratory

P. O. Box 999

Richland, Washington 99352

RDT Site Office

U. S. Atomic Energy Commission

Oak Ridge National Laboratory

P. O. Box X

Oak Ridge, Tennessee 37830

Director

Division of Reactor Standards

U.S. Atomic Energy Commission

Washington, D. C. 20545

Division of Technical

Information Extension

U. S. Atomic Energy Commission

P. O. Box 62

Oak Ridge, Tennessee 37831

Director

LMFBR Program Office

Argonne National Laboratory

9700 South Cass Avenue

Argonne, Illinois 60439
1 Director

Chemical Engineering Division

Argonne National Laboratory

9700 South Cass Avenue

Argonne, Illinois 60439

1

FFTF Fuels Department

Pacific Northwest Laboratory

P. O. Box 999

Richland, Washington 99352

3

RDT Site Office

U.S. Atomic Energy Commission

Atomics International

$2 \quad$ P. O. Box 1446

Canoga Park, California 91304

RDT Site Office

U.S. Atomic Energy Commission Argonne National Laboratory

$6 \quad$ P. O. Box 2108

Idaho Falls, Idaho 83401

Division Leader (CMB)

Chemistry and Metallurgy Division Los Alamos Scientific Laboratory P. O. Box 1663

Los Alamos, New Mexico 87544

Director

1

1 Metallurgy and Materials

Science Division

Brookhaven National Laboratory

Upton, New York 11973

2

Division Chief, $M$ \& $S$ Division

NASA - Lewis Research Center

21000 Brookpark Road

Cleveland, Ohio 44135

General Manager

1

135

Westinghouse Electric Corporation

Bettis Atomic Power Laboratory

P. O. Box 79

West Mifflin, Pennsyivaniạ 15122

Associate Manager

1

2 Materials Engineering Department

Battelle Memorial Institute

Columbus Laboratories

505 King Avenue

Columbus, Ohio 43201 
lanager, Nuclear Laboratories combustion Engineering Inc.

Nuclear Division

Prospect Hill Road

Windsor, Connecticut 06095

Manager, Plutonium Chemistry and Ceramics Fuels Development

Nuclear Materials and Equipment

Corporation

- Plutonium Laboratory

Leechburg, Pennsylvania 15656

Head, Fuels and Materials

Atomic Power Development Associates

1911 First Street

Detroit, Michigan 48226

Director

Metals and Ceramics Division

Oak Ridge National Laboratory

P. O. Box X

Oak Ridge, Tennessee 37830

Director, Liquid Metal

Engineering Center

Atomics International

P. O. Box 1449

Canoga Park, California 91304

Manager-Advanced Development Activity

General Electric Company

Knolls Atomic Power Laboratory

P. O. Box 1072

Schenectady, New York 12301

Director, LMFBR Technology Program

Atomics International

P. O. Box 309

Canoga Park, California 91304

Director

Nuclear Development Center

The Babcock and Wilcox Company

Atomic Energy Division

Lynchburg, Virginia 24501

Laboratory Assistant Director

Gulf General Atomic Incorporated

P. O. Box 608

San Diego, California 92112
1 Manager, Research

United Nuclear Corporation

Research and Engineering Center

Grasslands Road

Elmsford, New York 10523

1 Director

Nuclear Safety Program

Oak Ridge National Laboratory

P. O. Box Y

Oak Ridge, Tennessee $\mathbf{3 7 8 3 0}$

K-2 Group Leader

1

1 Reactor Division

Los Alamos Scientific' Laboratory

P. O. Box 1663

Los Alamos, New Mexico 87544

2 Westinghouse Electric Corporation

Technical Director

Advanced Reactors Division

P. O. Box 158

Madison, Pennsylvania 15663

1 Manager

1

Liquid Metal Information Center

Atomics International

P. O. Box 1449

Canoga Park, California 91304

1 Irradiation Coordinator

1

EBR-II Project

Argonne National Laboratory

P. O. Box 2528

Idaho Falls, Idaho 83401

Experiment Manager

1

1 EBR-II Pruject

Argonne National Laboratory

9700 South Cass Avenue

Argonne, Illinois 60439

1 Director

9

Reactor Safety \& Analysis Division

Argonne National Laboratory

9700 South Cass Avenue

Argonne, Illinois, 60439

1 Technical Director, FFTF Project

1
P. O. Box 1970

Richland, Washington 99352 
U.S. Atomic Energy Commission

Region II - Division of Compliance Suite 818

230 Peach Tree Street, N. W.

Atlanta, Georgia 30303

Dr. Knox M. Broom, Jr.

Nuclear Specialist

Middle South Services, Inc.

P.O. Box 61000

New Orleans, La.
1 Assistant Director of Pacific Northwest Programs, RDT 1

U.S. Atomic Energy Commission

P.O. Box 550

Richland, Washington 99352

1.

Technical Director, FFTF Project

1

Hannford Engineering Development Laboratory

P.O. Box 1970

Richland, Washington 99352 


\section{BREEDER REACTOR DEPARTMENT}

SUNNYVALE, CALIFORNIA 94086

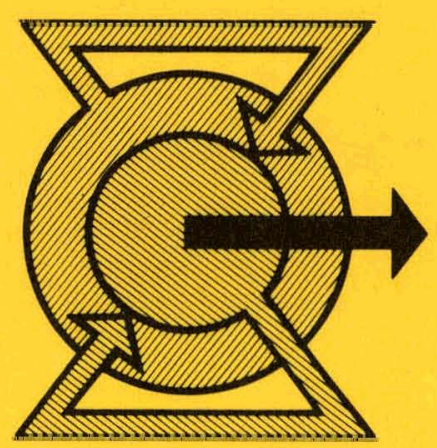

Expanding the World's Energy Reserves

GENERAL ELECTRIC 